\title{
Functions and physical functioning after total knee arthroplasty surgery
}

Citation for published version (APA):

Berghmans, D. D. P. (2019). Functions and physical functioning after total knee arthroplasty surgery. [Doctoral Thesis, Maastricht University]. Drukkerij Walters. https://doi.org/10.26481/dis.20191122db

Document status and date:

Published: 01/01/2019

DOI:

10.26481/dis.20191122db

Document Version:

Publisher's PDF, also known as Version of record

\section{Please check the document version of this publication:}

- A submitted manuscript is the version of the article upon submission and before peer-review. There can be important differences between the submitted version and the official published version of record.

People interested in the research are advised to contact the author for the final version of the publication, or visit the DOI to the publisher's website.

- The final author version and the galley proof are versions of the publication after peer review.

- The final published version features the final layout of the paper including the volume, issue and page numbers.

Link to publication

\footnotetext{
General rights rights.

- You may freely distribute the URL identifying the publication in the public portal. please follow below link for the End User Agreement:

www.umlib.nl/taverne-license

Take down policy

If you believe that this document breaches copyright please contact us at:

repository@maastrichtuniversity.nl

providing details and we will investigate your claim.
}

Copyright and moral rights for the publications made accessible in the public portal are retained by the authors and/or other copyright owners and it is a condition of accessing publications that users recognise and abide by the legal requirements associated with these

- Users may download and print one copy of any publication from the public portal for the purpose of private study or research.

- You may not further distribute the material or use it for any profit-making activity or commercial gain

If the publication is distributed under the terms of Article $25 \mathrm{fa}$ of the Dutch Copyright Act, indicated by the "Taverne" license above, 


\section{FUNCTIONS AND \\ PHYSICAL FUNCTIONING \\ AFTER TOTAL KNEE \\ ARTHROPLASTY SURGERY}


The printing of this thesis was financially supported by Maastricht University, the Department of Physical Therapy of the Maastricht UMC+ and ProCare BV.
4 Maastricht UMC+

Procare

\section{Layout}

François Peeters [ByBEEP]

\section{Cover}

François Peeters [ByBEEP]

\section{Printing}

Drukkerij Walters

\section{Copyright}

(c) Danielle Berghmans, Maastricht 2019

No part of this book may be reproduced or transmitted in any form or by any means, without prior permission in wrtiting by the author, or when appropiate, by the publishers of the publications.

\section{ISBN}

$X X X X X X X X X X X X X$ 


\title{
FUNCTIONS AND \\ PHYSICAL FUNCTIONING \\ AFTER TOTAL KNEE \\ ARTHROPLASTY SURGERY
}

\author{
PROEFSCHRIFT
}

ter verkrijging van de graad van doctor aan de Universiteit Maastricht, op gezag van de Rector Magnificus, Prof. dr. R.M. Letschert, volgens het besluit van het collega van Decanen, in het openbaar te verdedigen op

22 november 2019, 10.00 uur.

door

Danielle Dorothea Petra Berghmans 


\section{Promotores}

Prof. dr. R.A. de Bie

\section{Copromotores}

Prof. dr. A.F. Lenssen

Dr. P.J. Emans

\section{Beoordelingscommissie}

Prof. dr. A.E. Boonen (voorzitter) (Maastricht UMC+, Maastricht)

Dr. T.A.E.J. Boymans (Maastricht UMC+, Maastricht)

Dr. R.P.A. Janssen (Fontys Paramedische Hogeschool, Eindhoven)

Prof. dr. H.H.C.M. Savelberg (Maastricht University, Maastricht)

Prof. dr. P.J. van der Wees (Radboud UMC, Nijmegen) 


\section{CONTENT}

CHAPT ER TWO. Functions, disabilities \& perceived health in the first year after TKA a prospective cohort study

CHAPT ER THREE. Limited predictive value of pre-surgical Not Functional Outcome

Summary

Samenvatting 



\section{CHAPTER ONE.}

GENERAL INTRODUCTION 
Osteoarthritis (OA) of the knee is the most common musculoskeletal joint disorder. It involves structural changes in the joint, such as loss of cartilage and osteophyte formation, while the synovial membrane is irritated, which sometimes leads to joint inflammation. Patients suffer from pain, joint stiffness (especially at the beginning of movement) and crepitations.[1, 2] End-stage OA patients can also have pain at rest and during the night. Besides this, patients can complain of decreased muscle strength and impairment of joint proprioception. Although there is a low correlation between radiographic abnormalities and individual complaints, the risk of complaints increases with increasing radiographic abnormalities.[2]

\section{EPIDEMIOLOGY}

The incidence of knee $\mathrm{OA}$ is higher in women and increases with age. The prevalence in the Netherlands in 2016, was 43.0/1000 for women and 24.0/1000 for men. Between 1990 and 2015, this prevalence increased by $40 \%$ (women) and 55\% (men).[1] Over the next 25 years, OA prevalence is expected to double, due to the ageing of the population.[3]

\section{ETIOLOGY}

Generally speaking, combinations of the following factors can play a part in the development of knee OA; age, sex, body weight, profession, trauma, sports, congenital factors, another joint disease, joint infection/inflammation, prolonged squatting position, knee surgery, joint laxity and reduced muscle strength.[2]

Prognostic factors for an unfavorable course of the disease in terms of pain levels or functional limitations are the amount of pain, reduced muscle strength, major radiographic deformities at the onset of complaints, multiple complaints in daily life, reduced walking speed, age, genetic factors, overweight, poor vitality, and comorbidities.[2]

\section{COMPLAINTS WITHIN THE ICF MODEL}

As a consequence of body function complaints, a quarter of all knee OA patients have problems with daily life activities like rising from a chair, walking, climbing stairs and standing for a longer period of time. This could lead to withdrawal from participation in social events and the inability to perform work or sports activities.[2, 4] This impacts on all levels of the International Classification of Functioning, Disability and Health (ICF) model.[5] The ICF is a classification of health and health-related domains, which comprises functions, activities and participation in daily life. In addition, it includes environmental and personal factors. In the case of OA, environmental and personal factors play a role in the development and progression of the disease. Figure 1 describes the ICF model on the basis of a patient case in one of our studies. 


\section{THERAPEUTIC OPTIONS}

Conservative treatment consists of lifestyle advice, exercise therapy, and medication. If these treatments are not (or no longer) effective, a surgical joint replacement (total knee arthroplasty [TKA]) is the gold standard, and has revolutionized patient care.[5,6] The last decade has seen an annual worldwide increase in TKA surgery. Possible causes of this increase could be a more active life style among older patients, longer life expectancy, increasing body mass index (BMI) and better longterm results of TKA surgery. Other factors that play a role include greater availability of TKA surgery thanks to more orthopedic surgeons, shorter length of stay at the hospital, widening of indication criteria for surgery, and procedural safety and improvement of implant design. $[5,7,8]$

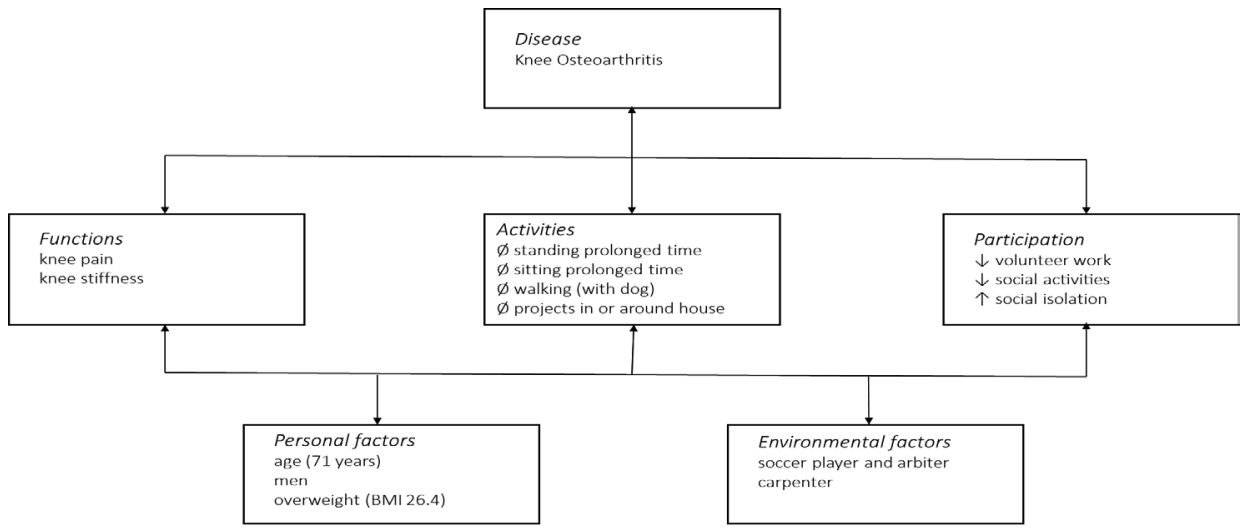

Figure 1 shows the International Classification of Functioning, Disability and Health model (ICF model), as applied to the specific complaints of a patient in our study. $\varnothing$ : not able. BMI: body mass index.

A noteworthy problem in our hospital is the large variance in physical performance among the patient population as determined on the day before surgery. During baseline measurements, we saw patients with relatively minor complaints in daily life, with good strength values and walking patterns, but also patients with such severe limitations due to ROM limitations and pain that accurate strength or gait measurements were impossible.

\section{REHABILITATION IN THE NETHERLANDS}

After TKA surgery, patients in the Netherlands receive in-hospital physical therapy during their hospitalization period, which normally takes 2-5 days. The therapeutic goal is to regain independence in daily function as soon as possible and 
to prepare patients for a safe return to their home. During the sessions, patients get instructions on how to make transfers, how to walk with walking aids and how to climb stairs. Rehabilitation also focuses on the range of motion (ROM) of the operated knee. The duration of hospitalization is decreasing: at our hospital it is currently 3 days. This development entails a change in the role of physical therapists, in which regaining functional independence is the main goal of therapy. Optimizing gait quality is then done by an outpatient physical therapist.

In Dutch hospitals, patients receive in-hospital physical therapy, while most orthopedic surgeons also prescribe physical therapy after discharge. When patients are not able to return home immediately, for example because of social circumstances, they stay at a rehabilitation facility for a predefined period. Afterwards, they go home and receive outpatient physical therapy. In most cases health insurance covers 12 months of therapy after TKA surgery (see figure 2). This may be a unique situation worldwide. [9] Bade et al.[10] described that only $26 \%$ of all patients receive outpatient physical therapy after a TKA. In some countries, the differences in rehabilitation between patients are based on their financial possibilities or health insurance status.[11] In other countries, like Switzerland and the Netherlands, all patients have equal access

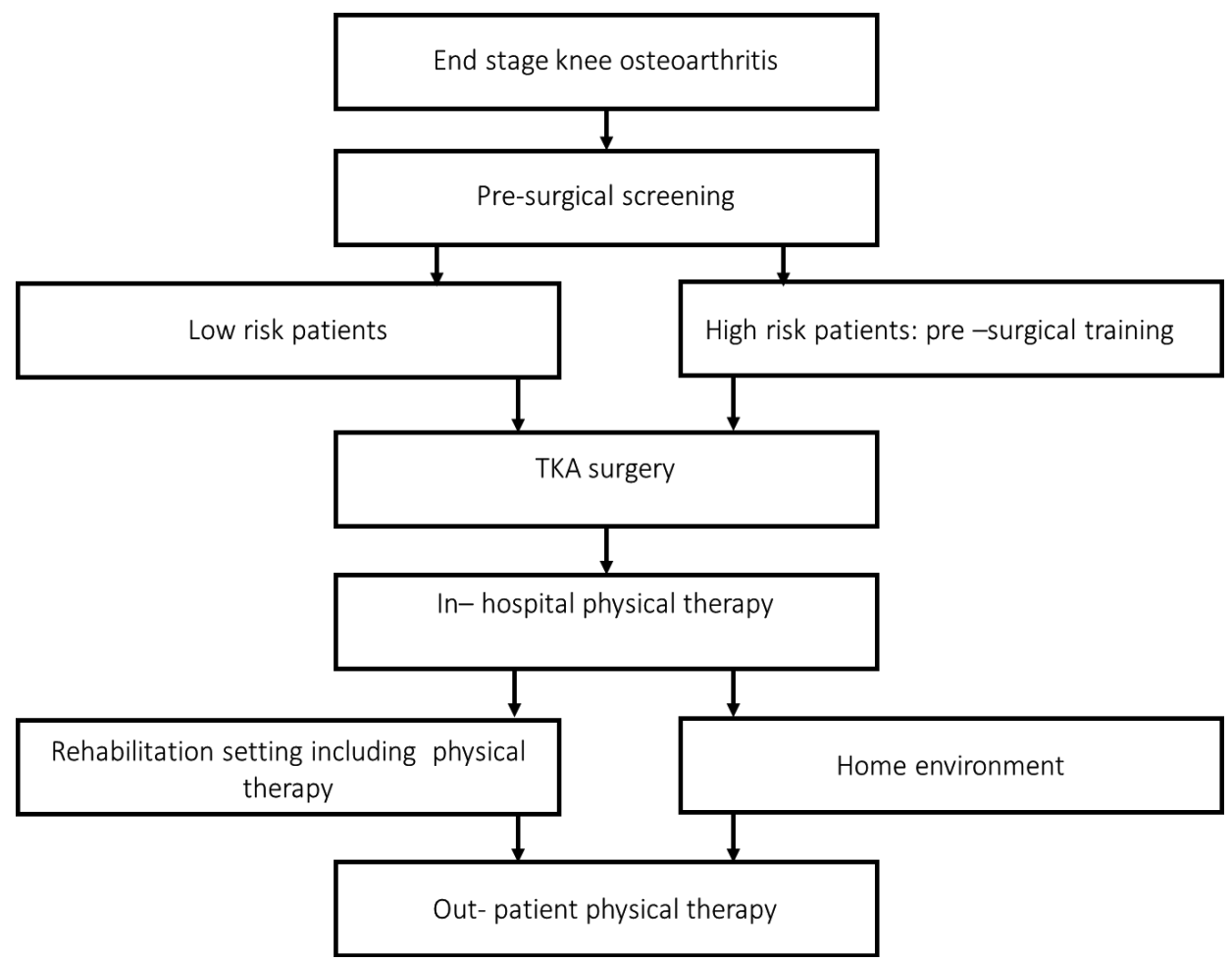

Figure 2 describes the rehabilitation process of a patient after a total knee arthroplasty (TKA) in the Netherlands. 
to the health care system after TKA surgery. However, patients in Switzerland are only prescribed 9 outpatient physical therapy sessions [12], far less than the year-long treatment in the Netherlands. The use of rehabilitation services is one of the least studied aspects of the perioperative management of this population, according to Kennedy et al.[13], based on the National Institutes of Health consensus statement on total knee replacement.[14] Nevertheless, we feel it could to a large extent determine the individual rehabilitation outcomes, since adherence to non-supervised exercise therapy is poor.[15]

\section{MOTIVATION FOR PHD THESIS}

Although we had already performed several studies to identify specific intervention effects in previous years, we did not have an overall picture of the longterm prognosis of TKA patients in the Netherlands. There had not been any studies using extended follow-up (one year) of the course of recovery of functions like muscle strength, ROM, activities, and quality of life. This induced us to start investigating these parameters.

\section{PERSONAL MOTIVATION}

During my work as an inpatient physical therapist I only got to see patients for a short time, which meant I had no clear idea of the level of functioning and satisfaction after several months. This often left me wondering about the progress patients made afterwards. Performing serial measurements in a large cohort was therefore offered a great opportunity to gain more insights and knowledge to share with my patients during their hospitalization.

\section{OUTLINE OF PHD THESIS}

The overall purpose of this dissertation is to give a broad overview of the physical abilities of patients after a TKA in the Netherlands. To this end, we conducted a large cohort study to investigate the functional status of these patients. We combined patient-reported outcome measures (PROMs) with multiple objective performance tests to create a measurement toolkit to investigate all domains of the ICF model in 150 patients with end stage knee OA, before TKA and 3 and 12 months post TKA. This information is helpful in the process of informing and treating patients with a TKA and can be used by both allied health professionals and patients, and could enhance the shared-decision making process (Chapter 2). Next, we were interested in predicting functional outcome 3 and 12 months after TKA, based on a wide range of pre-surgical parameters (including PROMs and objective performance tests, as suggested in previous research [16]) in the same cohort of 150 patients with end stage OA. This information could be suitable for further optimization of indication criteria for TKA surgery (Chapter 3). All outcome measures except for one PROM had already been intensively tested and found to be methodologically suitable for 
this population. The one exception was the patient specific function scale (PSFS). Although this PROM had been recommended for use in the patient population in the Dutch guidelines on knee OA [2], its methodological characteristics had not been comprehensively investigated in this population.[17-23] Hence, the study reported on in Chapter 4 focused on the methodological qualities, reliability, and responsiveness of the PSFS in this population. Chapter 5 reports on a systematic review regarding the isokinetic quadriceps and hamstring strength in the first year after a TKA, in order to compare isokinetic strength values reported worldwide, and with the intention to generate norm values. This review offers an overview of the existing literature and remaining knowledge gaps regarding isokinetic strength in patients in the first year after TKA. This enabled us to see our study results in perspective, and this resulted in a pilot study to determine the impact of a 6-week progressive strength training program on the isokinetic quadriceps and hamstring strength of 12 patients after a TKA (Chapter 6). These results can be used as a first step in the investigation of the effect of progressive strength training and in the design of the right training stimulus to increase (isokinetic) quadriceps and hamstring strength in patients after TKA. The final chapter presents a general discussion of the methodology of our studies, and of the findings presented in this dissertation. In addition, it considers the implications of our findings for clinical practice and briefly discusses aims for future research (Chapter 7). 


\section{REFERENCES}

1. Artrose, Cijfers en Context [https://www.volksgezondheidenzorg.info/ onderwerp/artrose/cijfers-context/huidige-situatie\#node-prevalentie-enaantal-nieuwe-gevallen-van-artrose]

2. KNGF-richtlijn Artrose heup-knie [https://www.fysionet-evidencebased. nl/images/pdfs/richtlijnen/artrose_heup_knie_2018/artrose_heup-knie_ verantwoording_2018.pdf]

3. Welke aandoeningen hebben we in de toekomst? [https://www.vtv2018. $\mathrm{nl} /$ aandoeningen]

4. Priority Medicines for Europe and the World 2013 Update [http://www. who.int/medicines/areas/priority_medicines/Ch6_120steo.pdf]

5. ICF, International Classification of Functioning, Disability and Health [http:// www.who-fic.nl/Familie_van_Internationale_Classificaties/Referentie_ classificaties/ICF_International_Classification_of_Functioning_Disability_ and_Health]

6. Bourne RB, Chesworth BM, Davis AM, Mahomed NN, Charron KD: Patient satisfaction after total knee arthroplasty: who is satisfied and who is not? Clin Orthop Relat Res 2010, 468(1):57-63.

7. Pozzi F, Snyder-Mackler L, Zeni J: Physical exercise after knee arthroplasty: a systematic review of controlled trials. Eur J Phys Rehabil Med 2013, 49(6):877.

8. Ghomrawi HM, Mancuso CA, Westrich GH, Marx RG, Mushlin Al, Group EDS: Discordance in TKA expectations between patients and surgeons. Clin Orthop Relat Res 2013, 471(1):175-180.

9. Jones CA, Voaklander DC, Suarez-Alma ME: Determinants of function after total knee arthroplasty. Phys Ther 2003, 83(8):696-706.

10. Bade MJ, Kohrt WM, Stevens-Lapsley JE: Outcomes before and after total knee arthroplasty compared to healthy adults. J Orthop Sports Phys Ther 2010, 40(9):559-567.

11. Lingard EA, Berven S, Katz JN: Management and care of patients undergoing total knee arthroplasty: variations across different health care settings. Arthritis Care Res 2000, 13(3):129-136.

12. Benz T, Angst F, Oesch P, Hilfiker R, Lehmann S, Mebes CM, Kramer E, Verra $\mathrm{M}$ : Comparison of patients in three different rehabilitation settings after knee or hip arthroplasty: a natural observational, prospective study. BMC Musculoskeletal Disord 2015, 16(1):317.

13. Kennedy DM, Stratford PW, Riddle DL, Hanna SE, Gollish JD: Assessing recovery and establishing prognosis following total knee arthroplasty. Phys Ther 2008, 88(1):22-32.

14. Rankin EA, Alarcòn GS, Chang RW, Cooney Jr LM: NIH Consensus Statement on total knee replacement December 8-10, 2003. JB JS Open Access 2004, 86(6):1328. 
15. Campbell R, Evans M, Tucker M, Quilty B, Dieppe P, Donovan J: Why don't patients do their exercises? Understanding non-compliance with physiotherapy in patients with osteoarthritis of the knee. J Epidemiol Community Health 2001, 55(2):132-138.

16. Bolink S, Grimm B, Heyligers I: Patient-reported outcome measures versus inertial performance-based outcome measures: A prospective study in patients undergoing primary total knee arthroplasty. Knee 2015, 22(6):618623.

17. Chatman AB, Hyams SP, Neel JM, Binkley JM, Stratford PW, Schomberg A, Stabler M: The Patient-Specific Functional Scale: measurement properties in patients with knee dysfunction. Phys Ther 1997, 77(8):820-829.

18. Beurskens AJ, de Vet HC, Koke AJ: Responsiveness of functional status in low back pain: a comparison of different instruments. Pain 1996, 65(1):7176.

19. Beurskens AJ, de Vet HC, Koke AJ, Lindeman E, van der Heijden GJ, Regtop W, Knipschild PG: A patient-specific approach for measuring functional status in low back pain. Journal Manipulative Physiol Ther 1999, 22(3):144148.

20. Hall AM, Maher CG, Latimer J, Ferreira ML, Costa LO: The patient-specific functional scale is more responsive than the Roland Morris disability questionnaire when activity limitation is low. Eur Spine J 2011, 20(1):79-86.

21. Horn KK, Jennings S, Richardson G, Vliet D, Hefford C, AbbottJH: The patientspecific functional scale: psychometrics, clinimetrics, and application as a clinical outcome measure. J Orthop Sports Phys Ther 2012, 42(1):30-42.

22. McMillan CR, Binhammer PA: Which outcome measure is the best? Evaluating responsiveness of the Disabilities of the Arm, Shoulder, and Hand Questionnaire, the Michigan Hand Questionnaire and the PatientSpecific Functional Scale following hand and wrist surgery. Hand (N Y) 2009, 4(3):311-318.

23. Pengel LH, Refshauge KM, Maher CG: Responsiveness of pain, disability, and physical impairment outcomes in patients with low back pain. Spine (Phila Pa 1976) 2004, 29(8):879-883. 



\title{
CHAPTER TWO.
}

\author{
FUNCTIONS, DISABILITIES \& PERCEIVED \\ HEALTH IN THE FIRST YEAR AFTER TKA
}

A PROSPECTIVE COHORT STUDY

Danielle D. P. Berghmans

Antoine F. Lenssen

Pieter J. Emans

Rob A. de Bie

\section{Published}

BERGHMANS, Danielle DP, et al. Functions, disabilities and perceived health in the first year after total knee arthroplasty; a prospective cohort study. BMC Musculoskelet Disord, 2018, 19.1: 250. 


\section{ABSTRACT}

\section{Background}

In end-stage knee osteoarthritis total knee arthroplasty (TKA) is an effective intervention to reduce pain and improve functioning in the majority of patients. However, after TKA some patients still experience pain, loss of function, deficient muscle strength or reduced walking speed. This study systematically assesses patients' functions, disabilities and health before TKA and at short- (3 months) and long-term (12 months) on all International Classification of Functioning, Disability and Health domains.

\section{Methods}

In this prospective cohort study 150 patients underwent the following tests before and at 3 and 12 months after surgery: Western Ontario and McMaster Universities Arthritis Index, Short Form 12, Knee Society Score, Patient Specific Functioning Scale, knee range of motion, quadriceps and hamstring strength, gait parameters, global perceived effect (only after surgery). All data was analyzed with repeated measures ANOVA for all measurement time points.

\section{Results}

Despite increased gait speed, quadriceps strength and scores on questionnaires being above pre surgical levels, patients do not reach levels of healthy persons. Walking speeds approach normal values and are higher in our study compared with the literature. Quadriceps strength stays at around 70 till $80 \%$ of norm values. However, dissatisfaction rates are below $10 \%$, which is low compared to the literature.

\section{Conclusions}

Quality of life, activities, muscle strength and gait parameters improve significantly after TKA. However, some complaints regarding activities and walking speed remain. Most striking outcome is the remaining deficit in quadriceps strength. 


\section{INTRODUCTION}

Osteoarthritis (OA) is one of the ten most disabling diseases in developed countries: $9.6 \%$ of all men and $18.0 \%$ of all women over 60 years of age have symptomatic osteoarthritis.[1] While pain is the most prominent symptom, $80 \%$ of these patients have limitations in movement, and $25 \%$ cannot perform daily activities.[1] An increase in prevalence is expected due to ageing and obesity.[1-5]

In end-stage osteoarthritis, joint replacement is an effective intervention to reduce pain and improve functioning in the majority of patients.[3, 6-9] However, it has been reported that $15-30 \%$ of patients still experience pain and loss of function after total knee arthroplasty (TKA).[7, 9-12]

Several studies have investigated recovery after TKA. Although most describe a $10-20 \%$ improvement in quadriceps strength and gait parameters in comparison to the pre-operative status, values remained lower than in healthy peers or the uninvolved leg.[11-19] A correlation between quadriceps strength and functional performance after TKA $[18,19]$ seems logical, for functional performance can be assumed to improve with quadriceps strength. Several studies found improvements in patient-reported outcome measures (PROMs), functional status and quality of life.[12-14, 20, 21] However, patients often did not regain optimal health.[22] No relation with strength is investigated in these studies.

Although several studies investigated aspects of recovery after TKA, no study yet has incorporated all domains of the International Classification of Functioning, Disability and Health (ICF) in their assessment. Interesting findings in the ICF domains may be missed by the limited follow-up, population size and incompleteness of ICF domains of other studies. We therefore performed a prospective cohort study in which 150 patients scheduled for TKA were followed till one year after surgery, and in which we systematically assessed all domains of the ICF. Our first objective was to provide a more complete overview of current physical recovery rates of patients with TKA in the first year after surgery in the Netherlands. We hypothesize that the patients in our study will improve on all parameters in the first year after surgery. Our second objective is to generate normative quadriceps and hamstrings strength values for patients receiving a TKA in the Netherlands.

\section{METHODS}

\section{Study Design}

This prospective cohort study assessed all patients with the same set of measurement instruments during personal follow-up consultations at three time points before and after surgery. We chose as an endpoint a follow-up time of one year, as no further major improvement can be expected after this time period.[7, 23] 


\section{Patients}

Between March 1, 2011 and March 1, 2013, all consecutive patients with knee osteoarthritis scheduled for a TKA at the osteoarthritis clinic of Maastricht University Medical Centre (MUMC+) were informed about the study in writing and verbally at least one week before the planned surgery. On the day before surgery, when patients arrived at the hospital, they were contacted by the researcher, and written informed consent was obtained.

At the start of the study, we performed a sample size calculation. Based on the number of determinants and the pragmatic rule of thumb to include ten cases for each determinant we would need at least 120 cases to obtain adequate power (10x12 determinants $=120$ ). Since we expected a lost of follow up of $15 \%$ we would need 140 subjects. To be on the safe side we included 10 patients more $(\mathrm{N}=150)$.

Inclusion criteria were: Dutch speaking patients between 18 and 80 years at the time of surgery, diagnosed with knee osteoarthritis for which primary TKA was indicated. Patients were excluded if they underwent a unicondylar knee arthroplasty (UKA), had a neurological problem influencing ambulation or had an immobile hip or ankle arthrodesis. Severe comorbidities were excluded since all patients had to be eligible for surgery.

The local medical ethics committee of the MUMC+ reviewed and approved the study (NL33015.068.10 / METC 10-2-083). The rights of the subjects were protected under the Helsinki Declaration.

\section{Surgery}

All patients received a cemented Scorpio or Scorpio NRG TKA (Stryker, Kalamazoo, Michigan, USA). After performing a medial parapatellar approach a bony referenced, tibia first technique was used. A tourniquet was only used during the cementation period of the prosthesis. A previous study reported no differences in Range of Motion (ROM), function or Quality of Life between these two prosthesis.[24]

\section{Procedure}

After signing informed consent, patients were enrolled in the cohort study. All assessments were performed by the research team the day before surgery and 3 and 12 months after surgery. We chose these time points because of scheduled appointments, enabling us to have personal contact with the patients without involving extra travel time. The patients were not shown the answers or the values obtained in previous sessions.

\section{Measurements}

In addition to the demographic patient characteristics (age, sex, height and weight), the following questionnaires and measurements were performed by a research team using a standardized protocol. 
Health status questionnaires

The Western Ontario and McMaster Universities Osteoarthritis Index (WOMAC) is a self-administered disease-specific health questionnaire designed to measure the functional ability of the osteoarthritic hip and knee.[25] The WOMAC provides aggregate scores for each of three subscales: joint pain, joint stiffness and function. The WOMAC is a responsive instrument that yields reliable and valid measurements in patients with hip and knee osteoarthritis and has been extensively used to evaluate this patient population.[9, 25-27] The 5-point Likert version of this measure was used in our study. The scale was transformed to a range from 0 to 100 points (100 being the best score).

The Patient Specific Functional Scale (PSFS) records patients' perceptions of their disabilities.[28] Patients define their main complaints (i.e. difficulties performing certain activities) and rate the difficulty of performance on an 11-point numerical rating scale (NRS) (10 = no problems; $0=$ impossible) [28] The three main complaints had to be defined as specifically as possible, and had to cause difficulties related to the osteoarthritis of the knee. The PSFS is a reliable and responsive measure in this population, $[29,30]$ and its validity has been confirmed in a population of patients with knee problems.[29]

The Knee Society Score (KSS) is a knee-joint specific questionnaire and consists of two parts: a knee score (0-100, 100 being the best score) and a function score (0-100, 100 being the best score).[31] The KSS is a valid and responsive measure in a population of patients after TKA.[32]

The Short Form 12 (SF12) is a generic multidimensional questionnaire measuring quality of life from a patient's perspective. It is a short version of the SF36 and includes two components (physical and mental health), representing these respective domains (scale 0-100,100 being the best score). It is a valid, reliable and responsive measure in a general population and easy to administer.[33]

The Global Perceived Effect (GPE) is a 2-item scale on which patients can rate their overall recovery since a predefined point (in this study pre-surgical function) in time and their satisfaction with the treatment, on 7-point Likert scales (ranging from 2 [satisfied] to 14 [dissatisfied]). Its reliability and validity are good in patients with musculoskeletal disorders.[34]

\section{Physical performance tests}

Muscle strength was assessed with a Biodex ${ }^{\circledR}$ System 3 Pro dynamometer (Biodex System 3 Pro Dynamometer, Biodex Medical Systems, Inc., Biodex Medical Systems, USA). Isokinetic strength $(60 \%$ s and $180 \%$, in $\mathrm{Nm})$ of the quadriceps and the hamstrings was measured using respectively five and ten repetitions. The peak volitional values were used in the analysis. The Biodex ${ }^{\circledR}$ is a reliable and valid isokinetic dynamometer.[35]

ROM was measured with a long-arm goniometer, (Goniometer, Long Arm, Gymna, Belgium), according to Lenssen et al.[36] Extension and flexion were measured 
in supine position, with hyperextension noted as a positive value. Measuring ROM with a long-arm goniometer has been reported to be valid and reliable at group level.[36]

The gait parameters of step length and walking speed were measured with the GAITRite ${ }^{\circledR}$ system (CIR systems, PA, USA), a highly valid and reliable tool to assess temporospatial gait parameters in patients undergoing a TKA.[37]

\section{Statistical analyses}

Analyses were performed with SPSS for Windows version 23.[38] Means and standard deviations were calculated to describe characteristics. Repeated Measures ANOVA were performed to test for significant differences between baseline till 3 months after surgery and between 3 and 12 months after. A significance level of $\mathrm{p}<.05$ was used. A Bonferroni correction was used to correct for multiple testing.

Patients who dropped out during the test period were not replaced. All available data was analyzed; in case data was missing, the mean value of the parameter at that time point was imputed.

We also compared the strength of the quadriceps and hamstrings measured in our population with that of controls. We built a norm data set, consisting of 245 patients, 166 women (mean age 58.4 years [10.1], weight $69.6 \mathrm{~kg}$ [10.9]) and 129 men (56.2 years [10.7], weight $83.9 \mathrm{~kg}$ [10.6]). We tested their isokinetic quadriceps and hamstrings strength at an angular speeds of $60 \% \mathrm{~s}$ and $180 \% \mathrm{~s}$. We calculated formulas (table 1) for both sexes in both angular speeds for the quadriceps and hamstrings. These formulas were used to calculate the mean norm values for our population. These values and the percentage of the norm values are presented.

\begin{tabular}{|c|c|c|c|}
\hline & & Men & Women \\
\hline \multirow{2}{*}{ Quadriceps } & $60 \% / s$ & $305-2,67 * a g e$ & $172-1,42 *$ age \\
\hline & $180 \% / \mathrm{s}$ & 207-1,96*age & 108-0,94*age \\
\hline \multirow{2}{*}{ Hamstrings } & $60 \% / 5$ & $193-1,66 *$ age & $116-1,01 *$ age \\
\hline & $180 \% / \mathrm{s}$ & 149-1,36*age & 89-0,81*age \\
\hline
\end{tabular}

Table 1 shows the fomula for calculating the isokinetic strength for a healthy population. Age in years.

\section{Results}

Between March 1, 2011 and March 1, 2013, we included 150 patients, 71 men and 79 women, with a mean age of $64.7 \pm 8.0$ years. The majority of patients had surgery of the right knee (right 89, left 61) and mean BMI was $31.2 \mathrm{~kg} / \mathrm{m}^{2}$ for men and $30.7 \mathrm{~kg} / \mathrm{m}^{2}$ for women (table 2). We lost 4 patients at 3-months follow-up and an additional 3 at the 12-month measurement. Not all patients were able to come to the hospital for the follow-up measurements, so data on physical tests (strength, 
temporospatial gait parameters and ROM) were unavailable for 7 patients at 3-months and for 9 patients at the 12-month measurement ( 4 of whom were the same as those at the three-month measurement).

\begin{tabular}{l|cc}
\hline & Men & Women \\
\hline Age $(\mathrm{y})(\mathrm{sd})$ & $64.2(8.8)$ & $65.1(7.4)$ \\
Height $(\mathrm{m})(\mathrm{sd})$ & $1.75(0.06)$ & $1.66(0.06)$ \\
Weight $(\mathrm{Kg})(\mathrm{sd})$ & $95.7(13.6)$ & $84.6(15.5)$ \\
Body Mass Index $\left(\mathrm{Kg} / \mathrm{m}^{2}\right)(\mathrm{sd})$ & $31.2(4.2)$ & $30.7(5.5)$ \\
\hline
\end{tabular}

Table 2 shows age, height, weight and body mass index for men and women. sd; standard deviation.

With the exception of the SF12, patients improved significantly on all questionnaires over 3 and 12 months. The largest improvement occurred within the first three months. The largest and significant improvement of the SF12 Physical component was only between baseline and 3 months (table 3).

\begin{tabular}{l|c|cc|cc}
\hline & Baseline & \multicolumn{2}{|c|}{ 3 months } & \multicolumn{2}{c}{ 12 months } \\
& & & sig. & \multicolumn{2}{c}{ sig. } \\
\hline Short Form - 12; Physical (sd) & $33.5(7.9)$ & $38.8(7.7)$ & 0.000 & $39.3(9.2)$ & 1 \\
Short Form - 12; Mental (sd) & $44.7(10.6)$ & $45.0(9.6)$ & 1 & $46.4(9.2)$ & 0.164 \\
WOMAC Pain (sd) & $10.6(4.1)$ & $16.0(4.1)$ & 0.000 & $17.6(4.4)$ & 0.000 \\
WOMAC Stifness (sd) & $4.1(1.9)$ & $4.9(1.9)$ & 0.000 & $5.8(1.9)$ & 0.000 \\
WOMAC Function (sd) & $39.0(12.3)$ & $54.4(13.0)$ & 0.000 & $58.2(12.9)$ & 0.000 \\
WOMAC Total (sd) & $54.1(16.2)$ & $75.4(17.6)$ & 0.000 & $81.7(18.0)$ & 0.000 \\
PSFS 1 (sd) & $1.9(2.0)$ & $2.8(3.4)$ & 0.000 & $6.6(3.7)$ & 0.000 \\
PSFS 2 (sd) & $2.2(2.1)$ & $4.8(3.6)$ & 0.000 & $6.8(3.4)$ & 0.000 \\
PSFS 3 (sd) & $2.4(2.4)$ & $4.9(3.6)$ & 0.000 & $6.9(3.4)$ & 0.000 \\
Knee Society Score; Knee (sd) & $52.5(16.4)$ & $76.1(17.3)$ & 0.000 & $84.1(17.5)$ & 0.000 \\
Knee Society Score; Function (sd) & $57.2(13.1)$ & $69.4(15.4)$ & 0.000 & $74.8(18.5)$ & 0.000 \\
\hline
\end{tabular}

Table 3 shows the scores on the questionnaires are given at baseline and 3 and 12 months after surgery. Significance of progression from baseline to 3 months and from 3 till 12 months. N; number. sd: standard deviation. WOMAC; Western Ontario and McMaster Universities Osteoarthritis Index. PSFS; Patient Specific Functional Complaint. Sig; p-value.

The GPE is shown in figure 1. After three months, $5.3 \%$ of all patients reported to have fully recovered from surgery, and after one year $25.3 \%$ did so. After 3 months, $2.7 \%$ of all patients were totally dissatisfied with the result and the treatment, against $1.3 \%$ after one year. Overall, the majority of patients were satisfied with the result, but had some residual complaints. 


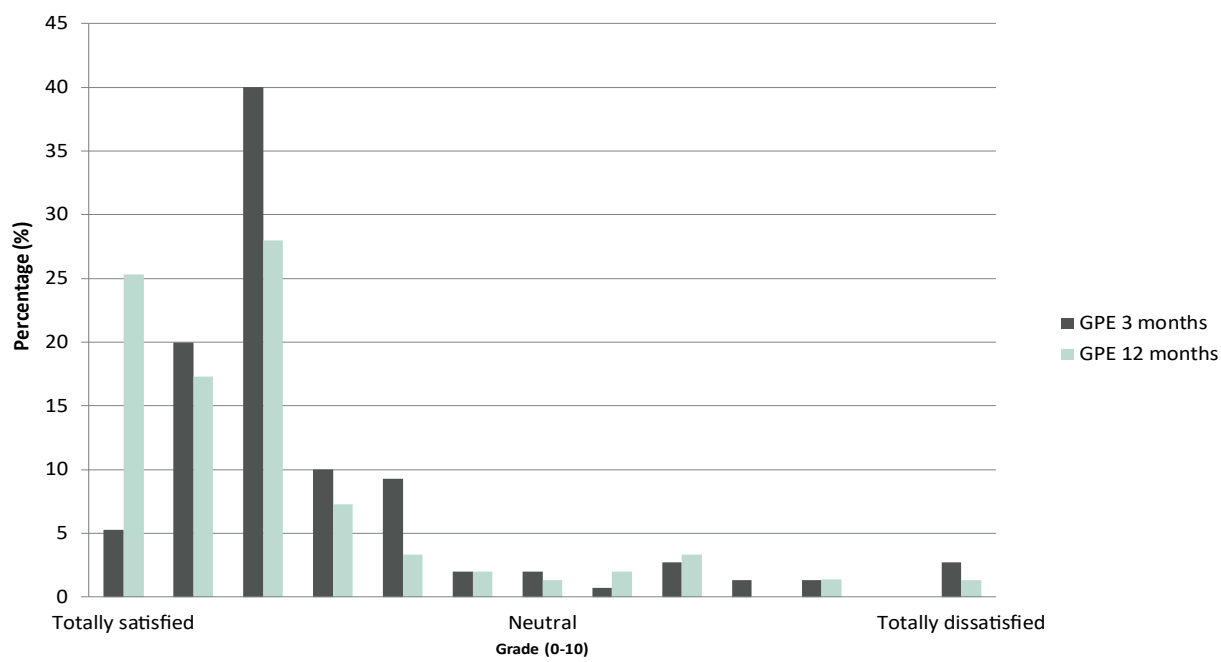

Figure 1 shows the Global Perceived Effect scores 3 and 12 months after TKA, with percentages. GPE; Global Perceived Effect.

Figure 2 and 3 show respectively the $60 \%$ s isokinetic quadriceps and hamstrings muscle strength in the peri-operative phase of men and women. After three months the quadriceps isokinetic strength measured at $60 \% \mathrm{~s}$ speed is back on pre-surgical level for women (baseline $43.4 \mathrm{Nm}$ [27.8]; 3 months 46.1 Nm [17.1]; significance 1.000) and for men (baseline 67.9 Nm [35.5]; 3 months $73.3 \mathrm{Nm}$ [26.2]; significance 0.521). The quadriceps $180 \%$ s only improved significantly in men in 3 three months (baseline $43.3 \mathrm{Nm}$ [23.0]; 3 months $50.5 \mathrm{Nm}$ [17.4]; significance 0.005), women were back on pre-surgical level (baseline $29.2 \mathrm{Nm}$ [16.4]; 3 months $30.0 \mathrm{Nm}$ [11.7]; significance 1.000). Over 12 months a significant improvement was demonstrated, at both angular speeds and for both sexes (women 60\% $64.5 \mathrm{Nm}$ [18.9] 180\% 38.2 [11.8]; men 60\%: $95.2 \mathrm{Nm}$ [30.5] 180\%/s: 61.8 [19.1]). $60 \%$ s Isokinetic Hamstrings strength in men and women improved significantly in the first year after surgery, compared to pre-surgical values (women; baseline 33.3 Nm [18.9]; 3 months $39.8 \mathrm{Nm}$ [16.7]; significance 0.009; 12 months $50.7 \mathrm{Nm}$ [16.2]; significance 0.000; men; baseline $48.0 \mathrm{Nm}$ [23.4]; 3 months $65.6 \mathrm{Nm}$ [22.8]; significance 0.000; 12 months 77.2 Nm [26.1]; significance 0.000 ). $180 \%$ s Isokinetic Hamstrings strength only improved significant in men in both time periods (baseline 37.8 Nm [18.6]; 3 months 47.1 Nm [17.8]; significance 0.000; 12 months 54.4 Nm [20.9]; significance 0.002. and in women only between 3 and 12 months (baseline 24.4 Nm [12.6]; 3 months $27.1 \mathrm{Nm}$ [11.3]; significance 0.263; 12 months $33.3 \mathrm{Nm}$ [11.6]; significance 0.000.) 


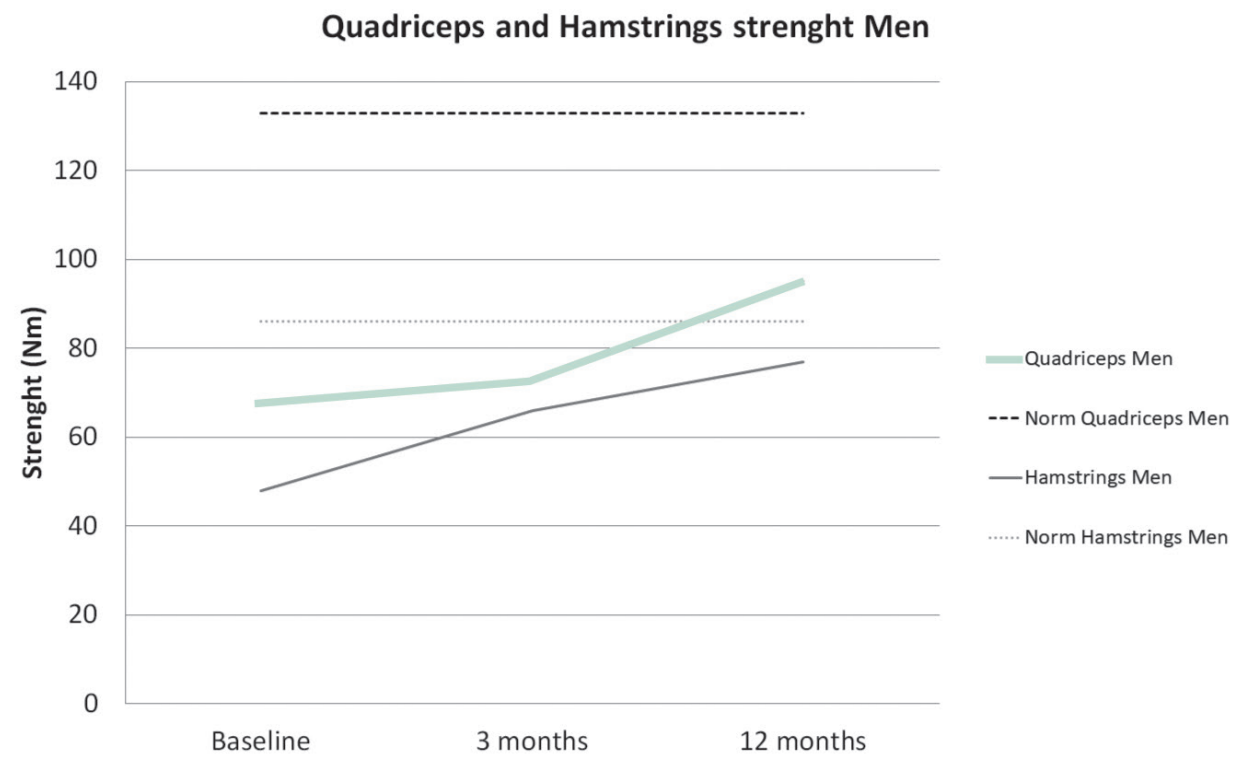

Figure 2 present the development of the Isokinetic Quadriceps and Hamstrings strength in the first year after a TKA in men and the reference values for this population.

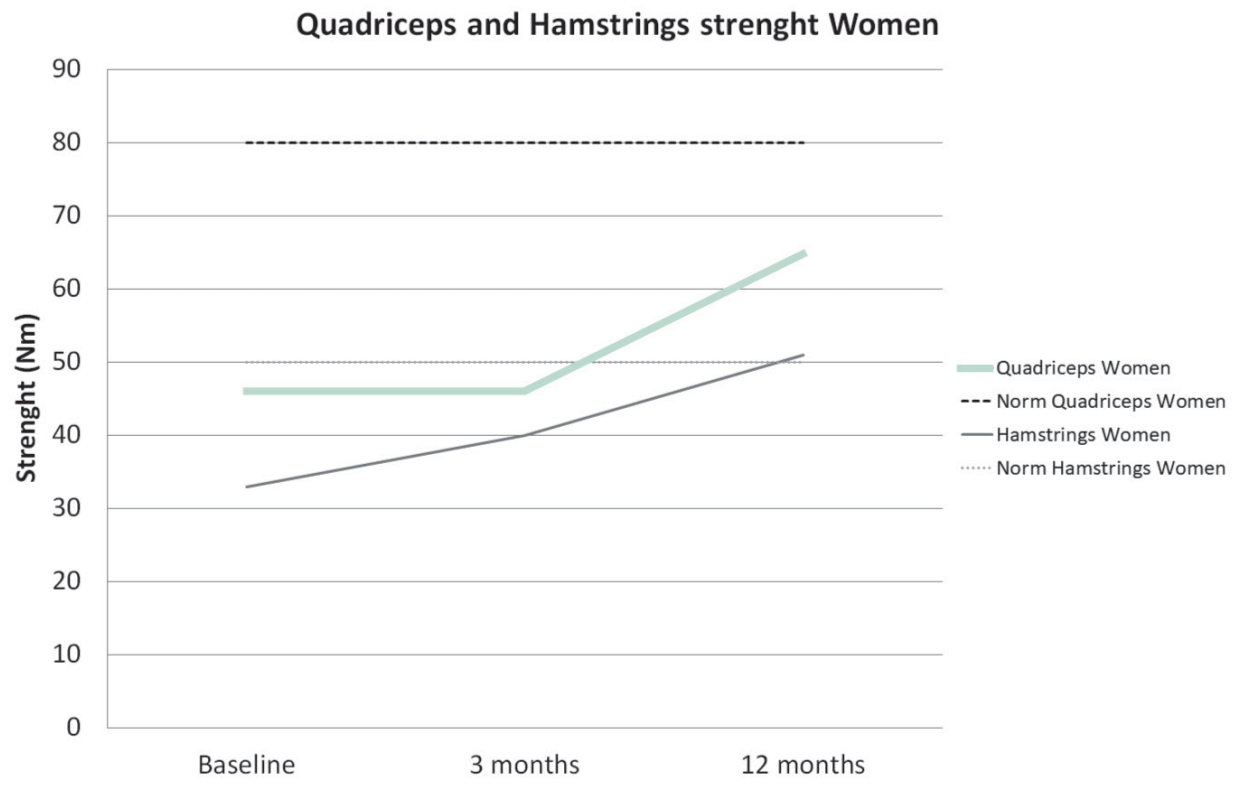

Figure 3 present the development of the Isokinetic Quadriceps and Hamstrings strength in the first year after a TKA in women and the reference values for this population. 
We also compared muscle strength of our patients with that of healthy individuals. At baseline, our patients had $51.6 \%$ to $63.3 \%$ of the quadriceps strength of healthy persons, and $56.8-69.5 \%$ of the hamstrings strength. At 3 months, values were $55.7 \%$ to $64.4 \%$ of the quadriceps and $76.1-79.5 \%$ of the hamstrings, respectively, and at 12 months $72.0 \%$ to $81.7 \%$ and $88.4 \%$ to $100.7 \%$, respectively.

\begin{tabular}{l|c|cc|cc}
\hline & Baseline & \multicolumn{2}{|c|}{ 3 months } & \multicolumn{2}{|c}{ 12 months } \\
& & & sig. & & sig. \\
\hline Flexion $\left(^{\circ}\right)(\mathrm{sd})$ & $120.1(12.6)$ & $114.9(13.7)$ & 0.001 & $120.6(14.7)$ & 0.000 \\
Extension $\left(^{\circ}\right)(\mathrm{sd})$ & $-2.3(5.7)$ & $-2.5(5.3)$ & 1 & $-1.3(5.7)$ & 0.085 \\
\hline
\end{tabular}

Table 4 shows flexion and extension values prior to surgery and 3 and 12 months after surgery, in degrees. Significance of progression from baseline to 3 months and from 3 till 12 months. sig.; $p$-value.

Table 4 lists the ROM values. The mean baseline flexion was $120^{\circ}$. Flexion was limited immediately after surgery, but increased again during the first weeks. After three months, flexion had returned almost to baseline value, although there was still a significant difference. At 12 months, the flexion had returned to baseline level. Overall, extension ROM did not change significantly after a TKA.

\begin{tabular}{|c|c|c|c|c|c|c|}
\hline \multicolumn{2}{|c|}{ 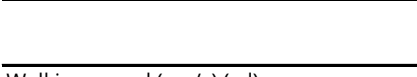 } & \multirow{3}{*}{$\begin{array}{c}\text { Baseline } \\
98.9(23.3) \\
57.6(11.2)\end{array}$} & \multicolumn{2}{|c|}{3 months } & \multicolumn{2}{|c|}{$\begin{array}{r}12 \text { months } \\
\text { sig. }\end{array}$} \\
\hline Walking speed (c & s) (sd) & & $108.4(19.9)$ & 0.000 & $117.0(19.9)$ & 0.000 \\
\hline \multirow{2}{*}{ Step lenght } & Surgical leg $(\mathrm{cm})(\mathrm{sd})$ & & $61.9(8.3)$ & 0.000 & $64.1(8.5)$ & 0.000 \\
\hline & Healthy leg $(\mathrm{cm})(\mathrm{sd})$ & $58.0(9.9)$ & $62.2(8.6)$ & 0.000 & $64.8(8.7)$ & 0.000 \\
\hline
\end{tabular}

Table 5 shows walking speed and step length pre-surgical and 3 and 12 months after TKA with the significance level. sig.; p-value.

Table 5 shows walking speed and step length. The step length of the healthy and surgical leg increased significantly over time. With increasing step length, walking speed also increased significantly over time after TKA $(98.9 \mathrm{~cm} / \mathrm{s}$ at baseline, 108.4 $\mathrm{cm} / \mathrm{s}$ at 3 months and $117.0 \mathrm{~cm} / \mathrm{s}$ at 12 months). Improvement of walking speed between baseline and the 3-month measurement was comparable to that between the 3- and 12-month measurements. The largest improvement in step length was between baseline and 3-month measurements. 


\section{DISCUSSION}

This study reports on the first year of physical recovery of patients undergoing a TKA in the Netherlands and could therefore be useful in informing patients about prognostic consequences of a TKA.

The most remarkable finding in this study is the persistent limited muscle strength. Whilst other outcome measures improved to nearly normal values compared to the healthy population, quadriceps strength lagged behind. Before surgery, strength was half of that of matched healthy persons, a higher deficit than reported in the literature.[12, 15] Three months after surgery, mean strength was comparable to pre-surgical values. Although strength increased from 3 till 12 months after TKA, it never reached 'healthy' values. We do not expect that pain has a role in the muscle strength deficit since a large amount of patient did not experienced pain during strength measurement after the surgery, in contrast with the measurement pre-surgically. One reason could be the changed kinematics of the knee (altered patellofemoral kinematics) and/or muscle loss due to surgery. A change in strength was seen in an in vitro study by Ostermeier et al.[39], who compared hinged and nonhinged TKAs. Further, during therapy focus is on functional training and isokinetic strength measurement is not performed standardly. Our large study population underlined the muscle deficit already reported in other studies with a smaller sample size.[12, 15-19] In these studies even a higher deficit was described three months after surgery.[12, 18] Further, the total gain in muscle strength in the first year was higher in our study compared to the literature.[15] This could be due to the larger improvement in the first months compared with the literature. A reason could be the health care system in the Netherlands. The main part of all patients receive routinely a prescription for physical therapy after the TKA surgery for one year physical therapy. Generally, they have therapy twice a week. This could result in a faster and larger improvement of muscle strength which focuses on activity level, like walking with and without crutches and walking stairs. This is in contrast with the amount of physical therapy patients receive in other countries worldwide. Bade et al.[12] described that only $26 \%$ of all patients receive outpatient physical therapy. This could also possibly explain the smaller deficit of walking speed in our study. Walking speed in our pre-surgical $[12,13]$ and post-surgical patients is higher than reported in the literature in which patients with a TKA walked $20 \%$ more slowly than healthy individuals one year after surgery.[8, 13, 17] Before surgery, the walking speed of patients in our study $(98,9 \mathrm{~cm} / \mathrm{s})$ was $20.0-26.1 \%$ lower than in a healthy population (healthy walking speed for women [60-69 years] $1.24 \mathrm{~m} / \mathrm{s}$ and for men [60-69 years] $1.34 \mathrm{~m} / \mathrm{s})$.[40] After surgery, walking speed $(108.4 \mathrm{~cm} / \mathrm{s})$ increased but remained lower than in healthy persons (between $81.0-87.3 \%$ of the healthy walking speed).[40] After 12 months, walking speed $(117.0 \mathrm{~cm} / \mathrm{s})$ still increased, but did not reach the healthy level (attaining between $87.3 \%$ and $94.2 \%$ of the walking speed of healthy individuals). However, in terms of managing pedestrian street crossings with lights (which are designed for $1.2 \mathrm{~m} / \mathrm{s}$ ), $81 \%$ of our population were unable to cross the street safely 
before their surgery. After three months, this percentage had decreased to $65 \%$, but after 12 months it was still 49\%.

Pua et al.[41] investigated the relationship between walking speed and physical parameters in the first 16 weeks after TKA. They found ipsilateral quadriceps strength as strongest predictor for walking speed. No linear relationship existed till 111 newton, a steep rise in gait speed was observed with every gain in muscle strength. After 111 Newton the speed increased more gradually. However, according to Alnahdi et al.[42], the influence of quadriceps strength on gait patterns is only moderate till six months and in the period till one year it even decreases.

All questionnaires regarding level of functioning, quality of life and patientspecific complaints yielded lower scores compared to healthy controls, both pre- and postsurgical. (For healthy peers, we assumed highest possible score on the WOMAC, KSS and PSFS [related to knee problems] may be expected. For the SF12 we used reference data from the United states of America in which the healthy population had a score on the mental part of 51.6 and 43.9 on the physical part.[43]) However, a large and significant increase was reported on all questionnaires over the 12 months following surgery. This is in agreement with previous studies.[4, 9, 12-15, 18, 20-22] Only, our population seemed to recover faster; they performed on pre-surgical level at three months, while in other studies this took about six months.[12] Again, this could be due to the amount of physical therapy in the Netherlands, focused on activities like walking, walking stairs and making transfers.

Possible due to the faster increase in strength, walking speed and questionnaires, our patients were more satisfied compared to those in other studies, as seen on the GPE (8.7\% dissatisfied at 3 months, $7.9 \%$ dissatisfied at 12 months, whereas in other studies 15-30\% of the patients were dissatisfied).[7, 9-12] However, a relation between satisfaction and improvement in pain, function and handicap is difficult, and therefore, according to Genet et al.[14] satisfaction should be investigated as an independent parameter.

Nonetheless, patients' physical capability can be satisfying, their spare capacity could be less, giving a higher risk for frailty in case of a trauma or hospitalization. Therefore, despite of the importance of their satisfaction as success indicator for surgery, measuring their functional activity level is an important indicator.

\section{Limitations}

We decided to use performance tests to assess functions and questionnaires to measure activities, so the results regarding activities are from the patients' view and could therefore be subjective.

Another limitation is that we do not have information about osteoarthritis in other joints of the patients. Which might have an influence on the functional performance.

Our findings confirm that a TKA improves quality of life for patients with knee osteoarthritis and can be used to inform patients about possible prognostic 
consequences of a TKA, which is imported in patient-centered care. However, patients do not reach the values attained by healthy persons, and complaints persist in the first year after surgery. Quadriceps strength in particular remains limited, which may be a reason for persistent complaints. In our opinion most muscle deficits are not noticed during daily activities. However, in case of illness of (surgical) stress patients have less spare capacity and will have a higher chance to become frail. Physical therapy focuses on ROM and daily activities, but testing and training quadriceps strength until normal values are attained (if possible) is an important part of the therapy. As mentioned earlier, further research should focus on the effect of more progressive resistance training on the remaining muscle strength deficits in the first year after TKA. Besides this, further investigation in pathophysiology of muscle weakness is necessary.

\section{Conclusions}

Quality of life, activities, muscle strength and gait parameters improve significantly after a TKA. However, complaints on activities and walking speed remain. Most striking was the limited quadriceps strength, which we believe may restrict patients in daily life. Therefore, future studies should address the impact of strength training after a TKA on the improvement in muscle strength and daily activities. 


\section{REFERENCES}

1. Chronic rheumatic conditions [http://www.who.int/chp/topics/rheumatic/ en/]

2. KNGF: KNGF-standaard Beweeginterventie Artrose. 2008.

3. Kennedy DM, Stratford PW, Riddle DL, Hanna SE, Gollish JD: Assessing recovery and establishing prognosis following total knee arthroplasty. Phys Ther 2008, 88(1):22-32.

4. Papakostidou I, Dailiana ZH, Papapolychroniou T, Liaropoulos L, Zintzaras E, Karachalios TS, Malizos KN: Factors affecting the quality of life after total knee arthroplasties: a prospective study. BMC Musculoskelet Disord 2012, 13(1):116.

5. Priority Medicines for Europe and the World 2013 Update [http://www. who.int/medicines/areas/priority_medicines/Ch6_120steo.pdf]

6. Beers MH, Berkow R: The Merck Manual, vol. 2: Bohn Stafleu Van Loghum; 2003.

7. Zeni JA, Jr., Snyder-Mackler L: Early postoperative measures predict 1- and 2-year outcomes after unilateral total knee arthroplasty: importance of contralateral limb strength. Phys Ther 2010, 90(1):43-54.

8. Mizner RL, Petterson SC, Stevens JE, Axe MJ, Snyder-Mackler L: Preoperative quadriceps strength predicts functional ability one year after total knee arthroplasty. J Rheumatol 2005, 32(8):1533-1539.

9. Jones CA, Voaklander DC, Suarez-Alma ME: Determinants of function after total knee arthroplasty. Phys Ther 2003, 83(8):696-706.

10. Bourne RB, Chesworth BM, Davis AM, Mahomed NN, Charron KD: Patient satisfaction after total knee arthroplasty: who is satisfied and who is not? Clin Orthop Relat Res 2010, 468(1):57-63.

11. Yoshida Y, Mizner RL, Ramsey DK, Snyder-Mackler L: Examining outcomes from total knee arthroplasty and the relationship between quadriceps strength and knee function over time. Clin Biomech 2008, 23(3):320-328.

12. Bade MJ, Kohrt WM, Stevens-Lapsley JE: Outcomes before and after total knee arthroplasty compared to healthy adults. J Orthop Sports Phys Ther 2010, 40(9):559-567.

13. Bolink S, Grimm B, Heyligers I: Patient-reported outcome measures versus inertial performance-based outcome measures: A prospective study in patients undergoing primary total knee arthroplasty. Knee 2015, 22(6):618623.

14. Genet F, Schnitzler A, Lapeyre E, Roche N, Autret K, Fermanian C, Poiraudeau S: Change of impairment, disability and patient satisfaction after total knee arthroplasty in secondary care practice. Ann Réadapt Med Phys 2008, 51(8):671-676, 676-682.

15. Meier W, Mizner R, Marcus R, Dibble L, Peters C, Lastayo PC: Total knee arthroplasty: muscle impairments, functional limitations, and 
recommended rehabilitation approaches. J Orthop Sports Phys Ther 2008, 38(5):246-256.

16. Rossi MD, Hasson S: Lower-limb force production in individuals after unilateral total knee arthroplasty. Arch Phys Med Rehabil 2004, 85(8):12791284.

17. Walsh M, Woodhouse LJ, Thomas SG, Finch E: Physical impairments and functional limitations: a comparison of individuals 1 year after total knee arthroplasty with control subjects. Phys Ther 1998, 78(3):248-258.

18. Mizner RL, Petterson SC, Snyder-Mackler L: Quadriceps strength and the time course of functional recovery after total knee arthroplasty. J Orthop Sports Phys Ther 2005, 35(7):424-436.

19. Silva M, Shepherd EF, Jackson WO, Pratt JA, McClung CD, Schmalzried TP: Knee strength after total knee arthroplasty. J Arthroplasty 2003, 18(5):605611.

20. Dailiana ZH, Papakostidou I, Varitimidis S, Liaropoulos L, Zintzaras E, Karachalios T, Michelinakis E, Malizos KN: Patient-reported quality of life after primary major joint arthroplasty: a prospective comparison of hip and knee arthroplasty. BMC Musculoskeletal Disord 2015, 16(1):1.

21. Poortinga S, Van den Akker-Scheek I, Bulstra SK, Stewart RE, Stevens M: Preoperative Physical Activity Level Has No Relationship to the Degree of Recovery One Year after Primary Total Hip or Knee Arthroplasty: A Cohort Study. PloS one 2014, 9(12):e115559.

22. Finch $\mathrm{E}$, Walsh $\mathrm{M}$, Thomas SG, Woodhouse LJ: Functional ability perceived by individuals following total knee arthroplasty compared to age-matched individuals without knee disability. J Orthop Sports Phys Ther 1998, 27(4):255-263.

23. Lingard EA, Katz JN, Wright EA, Sledge CB: Predicting the outcome of total knee arthroplasty. J Bone Joint Surg 2004, 86(10):2179-2186.

24. Lützner J, Hartmann A, Lützner C, Kirschner S: Is range of motion after cruciate-retaining total knee arthroplasty influenced by prosthesis design? A prospective randomized trial. J Arthroplasty 2014, 29(5):961-965.

25. Bellamy N, Buchanan WW, Goldsmith $\mathrm{CH}$, Campbell J, Stitt LW: Validation study of WOMAC: a health status instrument for measuring clinically important patient relevant outcomes to antirheumatic drug therapy in patients with osteoarthritis of the hip or knee. J Rheumatol 1988, 15(12):1833-1840.

26. Collins NJ, Misra D, Felson DT, Crossley KM, Roos EM: Measures of knee function: International Knee Documentation Committee (IKDC) Subjective Knee Evaluation Form, Knee Injury and Osteoarthritis Outcome Score (KOOS), Knee Injury and Osteoarthritis Outcome Score Physical Function Short Form (KOOS-PS), Knee Outcome Survey Activities of Daily Living Scale (KOS-ADL), Lysholm Knee Scoring Scale, Oxford Knee Score (OKS), Western 
Ontario and McMaster Universities Osteoarthritis Index (WOMAC), Activity Rating Scale (ARS), and Tegner Activity Score (TAS). Arthritis Care Res 2011, 63(S11):S208-S228.

27. Gill SD, de Morton NA, Mc Burney $\mathrm{H}$ : An investigation of the validity of six measures of physical function in people awaiting joint replacement surgery of the hip or knee. Clin Rehabil 2012, 26(10):945-951.

28. Stratford P: Assessing disability and change on individual patients: a report of a patient specific measure. Physiother Can 1995, 47(4):258-263.

29. Chatman AB, Hyams SP, Neel JM, Binkley JM, Stratford PW, Schomberg A, Stabler M: The Patient-Specific Functional Scale: measurement properties in patients with knee dysfunction. Phys Ther 1997, 77(8):820-829.

30. Berghmans DD, Lenssen AF, van Rhijn LW, de Bie RA: The Patient-Specific Functional Scale: Its Reliability and Responsiveness in Patients Undergoing a Total Knee Arthroplasty. J Orthop Sports Phys Ther 2015, 45(7):550-556.

31. Insall JN, Dorr LD, Scott RD, Scott WN: Rationale of the Knee Society clinical rating system. Clin Orthop Relat Res 1989, 248(248):13-14.

32. Lingard EA, Katz JN, Wright RJ, Wright EA, Sledge CB: Validity and responsiveness of the Knee Society Clinical Rating System in comparison with the SF-36 and WOMAC. J Bone Joint Surg Am 2001, 83-A(12):18561864.

33. Ware Jr JE, Kosinski M, Keller SD: A 12-Item Short-Form Health Survey: construction of scales and preliminary tests of reliability and validity. Med Care 1996, 34(3):220-233.

34. Kamper SJ, Ostelo RW, Knol DL, Maher CG, de Vet HC, Hancock MJ: Global Perceived Effect scales provided reliable assessments of health transition in people with musculoskeletal disorders, but ratings are strongly influenced by current status. J Clin Epidemiol 2010, 63(7):760-766. e761.

35. Drouin JM, Valovich-mcLeod TC, Shultz SJ, Gansneder BM, Perrin DH: Reliability and validity of the Biodex system 3 pro isokinetic dynamometer velocity, torque and position measurements. Eur J Appl Physiol 2004, 91(1):22-29.

36. Lenssen AF, van Dam EM, Crijns YH, Verhey M, Geesink RJ, van den Brandt PA, de Bie RA: Reproducibility of goniometric measurement of the knee in the in-hospital phase following total knee arthroplasty. BMC Musculoskelet Disord 2007, 8:83.

37. Webster KE, Wittwer JE, Feller JA: Validity of the GAITRite walkway system for the measurement of averaged and individual step parameters of gait. Gait Posture 2005, 22(4):317-321.

38. Field AP: Discovering statistics using SPSS: SAGE publications Ltd; 2009.

39. Ostermeier S, Friesecke C, Fricke S, Hurschler C, Stukenborg-Colsman C: Quadriceps force during knee extension after non-hinged and hinged TKA: an in vitro study. Acta orthop 2008, 79(1):34-38. 
40. Bohannon RW, Andrews AW: Normal walking speed: a descriptive metaanalysis. Physiotherapy 2011, 97(3):182-189.

41. Pua Y-H, Seah FJ-T, Clark RA, Poon CL-L, Tan JW-M, Chong H-C: Factors associated with gait speed recovery after total knee arthroplasty: A longitudinal study. In: Semin Arthritis Rheum: 2017: Elsevier; 2017: 544551.

42. Alnahdi AH, Zeni JA, Snyder-Mackler L: Gait after unilateral total knee arthroplasty: frontal plane analysis. J Orthop Res 2011, 29(5):647-652.

43. Interpreting the SF12 [http://health.utah.gov/opha/publications/2001hss/ sf12/SF12_Interpreting.pdf] 



\title{
CHAPTER THREE.
}

\author{
LIMITED PREDICTIVE VALUE OF \\ PRE-SURGICAL LEVEL OF FUNCTIONING FOR \\ FUNCTIONING AT 3 \& 12 MONTHS AFTER TKA
}

Danielle D.P. Berghmans

Antoine F. Lenssen

Pieter J. Emans

Lodewijk W. van Rhijn

Rob A. de Bie

\section{Published}

Berghmans, D. D., Lenssen, A. F., Emans, P. J., van Rhijn, L. W., \& de Bie, R. A. (2019). Limited predictive value of pre-surgical level of functioning for functioning at 3 and 12 months after TKA. Knee Surg Sports Traumatol Arthrosc, 27(5), 1651-1657. 


\section{ABSTRACT}

\section{Purpose}

A total knee arthroplasty (TKA) is a cost-effective option to relieve pain and improve knee function in patients suffering from osteoarthritis. However, results differ among patients. The predictive value of pre-surgically assessed factors on the level of functioning after 3 and 12 months was investigated in this study.

\section{Methods}

This study used an inception cohort design and a follow-up of 12 months. One hundred and fifty patients who were to receive a TKA were assessed presurgically with an International Classification of Functioning, Disability and Health (ICF) core assessment set: Knee Society Score (KSS), Western Ontario and McMaster Universities Osteoarthritis Index (WOMAC), Short-Form 12 (SF12), Patient-Specific Function Scale (PSFS), range of motion (ROM), quadriceps and hamstring strength and gait parameters. The main outcome measure was WOMAC-Function at 3 and 12 months after surgery.

\section{Results}

Pre-surgical physical and mental health on the SF12 and functioning and stiffness on the WOMAC explained $23 \%$ of the variance in the level of functioning 3 months after surgery. Pre-surgical knee function measured with the KSS-Knee, and functioning as assessed by WOMAC-Function explained $16 \%$ of the variance of the level of functioning 12 months after surgery.

\section{Conclusions}

The results of this study show that better functioning before surgery, less knee stiffness and a better physical and mental health to some extent predict better functioning 3 months after surgery. This effect is less evident at 12 months.

This study is clinically relevant since it provides benchmark data for health care providers who want to compare their individual patients. 


\section{INTRODUCTION}

Several studies have investigated the influence of pre-surgical predictors on functional status post surgery. They found that scores on post-surgical health status questionnaires concerning level of functioning or quality of life are influenced by demographic factors [1-4] (age, sex, body composition), psychosocial factors [1-5], medical factors (e.g. previous surgeries, complications, comorbidities)[1, 3, 5, 6], baseline physical functioning [1, 2, 4-8], use of walking devices [6], walking distance [6] and pre-surgical pain.[5, 7, 8]

However, existing evidence remains suboptimal, which is partly due to differences in study designs, specifically differences in prediction time periods $[1,2,4,6,9]$, predictors $[1,3-8]$ and outcome variables $[2,4]$, as well as small study populations [1, 9]. Low quality evidence was also reported in a systematic review by Harmelink and Zeegers et al. (2017)[10] of prognostic factors for pain, functioning and quality of life one year after TKA surgery. As far as we know, no study has combined self-perceived questionnaires with a wide range of physical tests in a large population. Furthermore, no other study has objectively measured gait parameters in an extensive group of patients and used it in a prediction model.[11] This information is clinically relevant to determine the overall status of a patient. Recently there has been a great deal of interest regarding the effect of improving pre-surgical status on the immediate post-surgical recovery.[12] In the present study, the relationship between pre-surgical functional parameters and functional ability in the longer term was examined. Large datasets regarding the pre- and post-surgical functional status of TKA patients are lacking, which makes our study unique. In addition, the large study sample enabled us to investigate the relationship between multiple parameters and the post-surgical functional status. Our hypothesis was that taking account of pre-surgical functional parameters and self-report questionnaires assessing the 'function' and 'disability' domains of the International Classification of Functioning, Disability and Health model (ICF) would make the prediction models more complete. This information could inform clinicians and patients in the pre-surgical process.

A prognostic cohort study was conducted to determine the predictive value of factors measured before surgery for the level of functioning (measured with the Western Ontario and McMaster Universities Osteoarthritis Index function scale [WOMACF]) 3 and 12 months after a TKA.

The hypothesis was that the a combination of pre-surgical functions and demographic variables would predict the post-surgical level.

\section{MATERIALS AND METHODS}

The local medical ethics committee reviewed and approved the study (NL33015.068.10 / METC 10-2-083). The rights of subjects were protected under the Declaration of Helsinki.

An inception cohort design was used to recruit all consecutive patients with 
end-stage osteoarthritis one day before surgery. All patients were assessed as described in the Procedure section, before surgery. The WOMAC was repeated at 3 and 12 months after surgery, during a personal follow-up contact.

\section{Patients}

One hundred fifty consecutive patients with osteoarthritis of the knee scheduled for a TKA at the Maastricht University Medical Centre (MUMC+) were informed about the study in writing and verbally at least one week before the planned surgery The day before their surgery, all patients to be included were contacted by the researcher, and written informed consent was obtained. Four patients were lost to follow-up in the first prediction model (up to 3 months), and two additional patients were lost to follow-up in the second model (up to 12 months).

Inclusion criteria were: Dutch-speaking patients aged between 18 and 80 years at the time of surgery, diagnosed with osteoarthritis of the knee for which primary TKA was indicated. Patients were excluded if they underwent a unicondylar knee arthroplasty, had a neurological problem influencing ambulation or had an immobile hip or ankle arthrodesis. In addition, severe comorbidities (including severe psychological comorbidities) were automatically excluded because all patients had to be eligible for surgery.

The study population consisted of 79 women and 71 men. Mean age was 64.7 years ( \pm 7.9 ). Appendix 1 shows baseline values for all parameters. The number of patients differed somewhat between the measurement instruments, because of inability to test due to unavailability or malfunction of the assessment equipment, or due to patients' inability (only regarding the quadriceps and hamstrings isometric $30^{\circ}$ measurements, in patients whose ROM was limited).

\begin{tabular}{l|ccc|ccc|ccc}
\hline & \multicolumn{3}{|c|}{ Baseline } & \multicolumn{3}{c|}{ 3 months } & \multicolumn{3}{c}{$\mathbf{1 2}$ months } \\
& $\boldsymbol{n}$ & mean & $\mathbf{9 5 \% C l}$ & $\boldsymbol{n}$ & mean & 95\%Cl & $\boldsymbol{n}$ & mean & $\mathbf{9 5 \% C l}$ \\
\hline WOMAC-Pain & 149 & 10.7 & $10.0-11.4$ & 146 & 16.0 & $15.3-16.7$ & 144 & 17.6 & $16.8-18.4$ \\
WOMAC-Stiffness & 149 & 4.1 & $3.8-4.4$ & 146 & 4.9 & $4.6-5.2$ & 144 & 5.8 & $5.5-6.1$ \\
WOMAC-Function & 149 & 39.0 & $36.9-41.1$ & 146 & 54.4 & $52.2-56.6$ & 144 & 58.2 & $56.0-60.4$ \\
WOMAC-Total & 149 & 54.1 & $51.4-56.8$ & 146 & 75.4 & $72.4-78.4$ & 144 & 81.7 & $78.6-84.8$ \\
\hline
\end{tabular}

Table 1 Mean values of the WOMAC subscales at baseline and 3 and 12 months post TKA. n; number. 95\% Cl; 95\% confidence interval.

\section{Surgery}

All operations were performed by two orthopaedic surgeons, both with extensive experience with the procedure and prosthesis. All patients received a cemented Scorpio or Scorpio NRG Knee System (Stryker, Kalamazoo, Michigan, USA). After a medial parapatellar approach, a bony referenced, tibia-first technique was used. A cemented patella component was placed in 21 patients and a tourniquet was 
only used during the cementation period of the prosthesis. A previous study reported no differences in ROM, functioning or quality of life between the two prostheses.[13]

\section{Procedure}

After signing informed consent, patients were enrolled in the study. All assessments were performed by the research team at the hospital on the day before surgery. The WOMAC was reassessed after 3 and 12 months. Patients were not shown the answers they had given at baseline or at 3 months.

All factors of the function and disability level of the ICF Model were included. The WOMACF was chosen as a primary outcome measure, as this scale comprises a variety of activities that are important in daily life.

Health insurance is mandatory in the Netherlands, so there were no financial obstacles. Patients who were unable to return to their own homes after surgery had the option of going to a rehabilitation facility.

After surgery, patients received per protocol physical therapy in the hospital phase, aimed at increasing functional independence. After patients had left the hospital, physical therapy was continued in a private practice setting and patients received therapy according to the Dutch guidelines on TKA.[14]

\section{Measurements}

In addition to assessing the patients' demographic characteristics (age, sex, height and weight), the following measurements were performed by the physical therapy team, using a standardized protocol.

\section{Health status questionnaires}

The WOMAC is a self-administered disease-specific health questionnaire designed to measure functional ability of the osteoarthritic hip and knee. The WOMAC provides aggregate scores for each of 3 subscales: joint pain, joint stiffness and function. Together, they form the total WOMAC score. The WOMAC is a responsive instrument that yields reliable and valid measurements in a population of patients with hip and knee osteoarthritis and has been used extensively to evaluate this patient population.[6] The 5-point Likert version of the WOMAC was used in our study (scale 0 to 100 points, 100 = best score). The baseline sub-scores were used as parameters in this study, while the function sub-score of the WOMAC at 3 and 12 months was used as the outcome measure.

The Patient Specific Function Scale (PSFS) is a questionnaire to record patients' perceptions of their disabilities.[15] Patients define their main complaints regarding activities and rate the difficulty of performance on an 11-point numerical rating scale (NRS).[15] The PSFS is a reliable and responsive measure in this population.[16]

The Knee Society Score (KSS) is a knee-joint specific questionnaire and consists of two parts: a knee score and a function score.[17] The KSS is a valid and responsive measure in a population of patients following TKA.[18] 
The Short Form 12 (SF12) is a generic multidimensional questionnaire measuring quality of life from patients' point of view. It is a short version of the SF36 and includes two components (physical and mental health), representing their respective domains. It is a valid, reliable and responsive measure in a general population.[19]

\section{Physical performance test}

Muscle strength was assessed with a Biodex ${ }^{\circledR}$ System 3 Pro dynamometer, measuring isometric ( $30^{\circ}$ and $60^{\circ}$, in $\mathrm{Nm}, 3$ repetitions each) and isokinetic peak torques (velocities of $60^{\circ}$ and $180 \%$ second, in $\mathrm{Nm}, 5$ and 10 repetitions, respectively) of the quadriceps and hamstrings. The Biodex ${ }^{\circledR}$ is a reliable and valid instrument.[20]

Range of motion (ROM) was measured with a long-arm goniometer according to Lenssen et al.[21] Extension and flexion were measured in supine position, with hyperextension recorded as positive values. Measuring ROM is reliable at group level in patients after a TKA.[21]

The gait parameters were measured with the GAITRite ${ }^{\circledR}$ system, a highly valid and reliable tool for measuring gait parameters in patients undergoing a TKA.[22] An electronic walkway is connected to a computer via six pressure-activated sensor pads inserted in a roll-up carpet.

\section{Statistical analyses}

At the start of the study, a sample size calculation was performed. Based on the number of determinants and the pragmatic rule of thumb to include ten cases for each determinant under study, at least 120 cases would be needed to obtain sufficient power (10x12 determinants=120). Since some loss-to-follow-up was expected, the total number needed was 150 subjects.

All data were collected. Missing values were not substituted and drop-outs were not replaced. All analyses were performed with SPSS version 23.[23] Means and standard deviations were calculated.

Univariate regression analysis was performed including WOMACF and all independent variables. Factors with a $p$-value $\leq 0.10$ were entered into the multivariate regression model, using the ENTER method according to Field.[23] Assumptions were checked by residual plots and statistics, and total WOMAC scores were not included as predictors because of possible collinearity. Two prediction models were constructed: one model to predict level of functioning as measured with the WOMACF at 3 months, and another for functioning at 12 months.

The following independent variables measured before surgery were used: (1) demographic variables (age, sex), (2) BMI, (3) PSFS, (4) SF12-Physical, (5) SF12Mental, (6) quadriceps strength, (7) hamstrings strength, (8) gait parameters, (9) ROM, (10) WOMAC at baseline. 


\section{RESULTS}

The pre-surgical values of all parameters are provided in Appendix 1, giving means and 95\% confidence intervals. The average overall improvement on the dependent variable of this study, the WOMACF, was 39.3\% after 3 months and $51.0 \%$ after 12 months (table 1).

The results of the univariate regression analysis including pre-surgical parameters and the WOMACF are presented in Appendix 2, which only shows the parameters that were significant and retained for multivariate analysis. As mentioned in the Methods section, only parameters with a significance level $\leq .10$ were included in the multivariate regression analysis. Since multiple parameters were significant for WOMACF at 3 and 12 months, several parameters were included in both models.

The final prediction model for level of functioning after 3 months, obtained from the multivariate regression analysis using the ENTER method, is presented in table 2. This model had an $\mathrm{R}^{2}$ of 0.228 .

\begin{tabular}{l|c|c|c|c|c}
\hline & B & Std. Error & p-value & $95 \%$ Cl LB & $95 \%$ Cl UB \\
\hline Constant & 143.40 & 58.10 & 0.01 & 28.52 & 258.28 \\
SF12P & 0.27 & 0.16 & 0.10 & -0.05 & 0.58 \\
SF12M & 0.27 & 0.10 & 0.01 & 0.08 & 0.47 \\
WOMACS & -1.16 & 0.65 & 0.08 & -2.44 & 0.13 \\
WOMACF & 0.44 & 0.11 & 0.00 & 0.22 & 0.66 \\
\hline
\end{tabular}

Table 2 Prediction model for level of functioning 3 months after TKA.

Std. Error; 95\% CI LB; 95\% confidence interval lower bound. 95\% CI UB; 95\% confidence interval upper bound.

\begin{tabular}{l|c|c|c|c|c}
\hline & B & Std. Error & p-value & $95 \%$ Cl LB & $95 \%$ CI UB \\
\hline (Constant) & 57.07 & 5.91 & 0.00 & 45.38 & 68.76 \\
WOMACF & 0.36 & 0.09 & 0.00 & 0.18 & 0.53 \\
KSSK & 0.12 & 0.07 & 0.09 & -0.02 & 0.25 \\
\hline
\end{tabular}

Table 3 Prediction model for level of functioning 12 months after TKA.

Std. Error; standard Error. 95\% CI LB; 95\% confidence interval lower bound. 95\% CI UB; 95\% confidence interval upper bound.

Table 3 shows the final prediction model for functioning level after 12 months, after multivariate regression analysis with significant parameters from the univariate analysis and this final model had an $\mathrm{R}^{2}$ of 0.163 . 


\section{DISCUSSION}

The most important finding of this study was that an extensive pre-surgical set of measurements including relevant parameters of the functions and disabilities domains of the ICF model only had a limited predictive value for the level of functioning 3 and 12 months after TKA. The prediction model, which included SF12Mental, SF12-Physical, WOMACS and WOMACF, explained $22.8 \%$ of the variance in the level of functioning at 3 months. This implies that the mental and physical status of the patients before surgery, combined with the degree of knee stiffness and the level of pre-surgical functioning predicted nearly a quarter of the level of functioning 3 months after surgery. This implies that better functioning before surgery, less knee stiffness and a better physical and mental health to some extent predict better functioning in the longer term.

The prediction model for 12 months after TKA surgery only included two predictors: WOMACF and KSSK, and explained $16.3 \%$ of the variance. In contrast to the model for 3 months, the patients' baseline mental status and overall physical status had no predictive value for the outcome after 12 months. Instead, only the presurgical level of functioning and the pre-surgical overall knee status predicted a mere sixth of the level of functioning one year after surgery. Both predictors are influenced by the timing of surgery; if the osteoarthritis worsens, the knee stiffens and muscle strength deteriorates, so the level of pre-surgical functioning is lower. After the TKA surgery there is then a higher risk that the level of functioning will still be lower after one year. Further research into the best timing for surgery would be helpful.

The constant factor in both our models was high, implying that the entire study sample showed good progress in terms of level of functioning. This supports the general concept of TKA as an effective procedure in osteoarthritis of the knee. The influence of the individual factors was small, as has also been reported by Jiang, Sanchez et al.[24] The small percentage of variance explained by both models is in line with what was reported in previous studies regarding the prediction of the level of functioning after a TKA using parameters measured before surgery. This means that a large part of the level of functioning could not be explained by physical predictors, neither in our study nor in those reported in the literature.[1, 6, 8, 24, 25] Therefore, the influence of other factors, not taken into account in this study, like surgical techniques, complications or comorbidities, could explain another part of the variance and should be investigated in future studies.[4]

In contrast with other reports $[25,26]$, age and BMI were not significant factors predicting the level of functioning after surgery in this study. However, previous studies used different time periods or different performance tests as dependent variables. Other studies $[7,9,10]$ have reported findings in line with those in this study.

Our finding that mental status can have an effect on pain and functional status has also been reported by others.[4, 5, 26] However, in our study the influence of the mental status was only evident in the short term, unlike what was found in other 
studies.[5, 26]

Several reports have described the influence of poor pre-surgical functioning on the level of functioning afterwards. $[1,2,4,6,10]$ It was only the importance of the predictors which differed between the various studies.

In contrast to what has been reported in the literature [2], and contrary to our expectations, our study was unable to find a predictive value for the gait parameters. A reason could be our choice of the WOMAC as a dependent variable, whereas Bade et al. [2] used gait-related outcomes as dependent variables. They concluded that the pre-surgical performances on the Timed-Up-and-Go (TUG) or the Stair Climbing Test $(\mathrm{SCT})$, or the distance walked in the 6-minute-walk test (6MWT) predicted the postsurgical scores for the TUG, SCT and 6MWT, respectively. It seems that pre-surgical tests are mainly good at predicting their own post-surgical values.

Overall, the results of this study confirm the results of previous studies, in that pre-surgical functional status and knee status are important factors to predict the level of functioning afterwards, both in the short and longer term. Therefore, further research should investigate if improving pre-surgical factors might contribute to better outcomes in the long term.

The findings can be useful to identify patients with a poor prognosis. These patients may benefit most from the surgery, but extra attention must be paid to their physical recovery. The focus of further research could be on the effect of more, and more intensive, physical therapy on the prognosis of functional recovery.

Finally, this study has added information on the effectiveness of a TKA for the level of functioning after surgery. It could be helpful in the process of informing patients during the pre-surgical process, to give them some idea of the prognostic consequences, which is important in patient-centred care [5] and could reduce dissatisfaction after surgery. In addition, health care providers can use these results in their day-to-day clinical work to inform and benchmark their patients about their post-surgical rehabilitation, and encourage them to improve their pre-surgical functional status.

One limitation of our study is the lack of information about the specific physical therapy programmes attended by the participants, in terms of specific treatment content, attendance rates, duration, frequency and reasons for ending the therapy.

This study focused on general factors and on factors which might be influenced by physical therapy and the overall mental status, which enabled part of the variance to be explained. However, the specific influence of individual components of the mental or social status was not taken into account. Investigating a combination of these factors could improve a prediction model for the level of functioning after a TKA. Therefore, further research could focus on a combination of these factors and the pre-surgical level of functioning. 


\section{Conclusions}

Overall, TKA is a successful form of surgery, in view of the considerable overall improvement in level of functioning. The predictive value of an extensive measurement set based on all important functions and disabilities of the ICF model proved to be limited. 


\section{REFERENCES}

1. Sharma L, Sinacore J, Daugherty C, Kuesis DT, Stulberg SD, Lewis M, Baumann G, Chang RW: Prognostic factors for functional outcome of total knee replacement: a prospective study. J Gerontol A Biol Sci Med Sci 1996, 51(4):M152-M157.

2. Bade MJ, Wolfe P, Zeni JA, Stevens-Lapsley JE, Snyder-Mackler L: Predicting poor physical performance after total knee arthroplasty. J Orthop Res 2012, 30(11):1805-1810.

3. Gandhi R, Dhotar H, Razak F, Tso P, Davey JR, Mahomed NN: Predicting the longer term outcomes of total knee arthroplasty. Knee 2010, 17(1):15-18.

4. Judge A, Arden NK, Cooper C, Javaid MK, Carr AJ, Field RE, Dieppe PA: Predictors of outcomes of total knee replacement surgery. Rheumatology 2012, 51(10):1804-1813.

5. Lingard EA, Katz JN, Wright EA, Sledge CB: Predicting the outcome of total knee arthroplasty. J Bone Joint Surg 2004, 86(10):2179-2186.

6. Jones CA, Voaklander DC, Suarez-Alma ME: Determinants of function after total knee arthroplasty. Phys Ther 2003, 83(8):696-706.

7. Papakostidou I, Dailiana ZH, Papapolychroniou T, Liaropoulos L, Zintzaras E, Karachalios TS, Malizos KN: Factors affecting the quality of life after total knee arthroplasties: a prospective study. BMC Musculoskelet Disord 2012, 13(1):116.

8. Fortin PR, Clarke AE, Joseph L, Liang MH, Tanzer M, Ferland D, Phillips C, Partridge AJ, Belisle P, Fossel AH: Outcomes of total hip and knee replacement: preoperative functional status predicts outcomes at six months after surgery. Arthritis Rheum 1999, 42(8):1722-1728.

9. Brown K, Kachelman J, Topp R, Quesada PM, Nyland J, Malkani A, Swank AM: Predictors of functional task performance among patients scheduled for total knee arthroplasty. J Strength Cond Res 2009, 23(2):436-443.

10. Harmelink KE, Zeegers AV, Hullegie W, Hoogeboom TJ, Nijhuis-van der Sanden MW, Staal JB: Are there prognostic factors for one-year outcome after total knee arthroplasty? A systematic review. J Arthroplasty 2017, 32(12):3840-3853.

11. Pua Y-H, Seah FJ-T, Clark RA, Poon CL-L, Tan JW-M, Chong H-C: Development of a Prediction Model to Estimate the Risk of Walking Limitations in Patients with Total Knee Arthroplasty. J Rheumatol 2016, 43(2):419-426.

12. Van Der Sluis G, Goldbohm R, Bimmel R, Galindo Garre F, Elings J, Hoogeboom $\mathrm{T}$, van Meeteren $\mathrm{N}$ : What augmented physical activity and empowerment can bring to patients receiving total knee replacement: content, implementation, and comparative effectiveness of a new function-tailored care pathway in a routine care setting. BioMed Res Int 2015, Article ID 745864.

13. Lützner J, Hartmann A, Lützner C, Kirschner S: Is range of motion after 
cruciate-retaining total knee arthroplasty influenced by prosthesis design? A prospective randomized trial. J Arthroplasty 2014, 29(5):961-965.

14. KNGF-richtlijn Artrose heup-knie [https://www.fysionet-evidencebased. nl/images/pdfs/richtlijnen/artrose_heup_knie_2018/artrose_heup-knie_ verantwoording_2018.pdf]

15. Stratford P: Assessing disability and change on individual patients: a report of a patient specific measure. Physiother Can 1995, 47(4):258-263.

16. Berghmans DD, Lenssen AF, van Rhijn LW, de Bie RA: Patient Specific Function Scale: Its Reliability and Responsiveness in Patients Undergoing a Total Knee Arthroplasty. J Orthop Sports Phys Ther 2015, 45(7):1-22.

17. Insall JN, Dorr LD, Scott RD, Scott WN: Rationale of the Knee Society clinical rating system. Clin Orthop Relat Res 1989, 248(248):13-14.

18. Lingard EA, Katz JN, Wright RJ, Wright EA, Sledge CB: Validity and responsiveness of the Knee Society Clinical Rating System in comparison with the SF-36 and WOMAC. J Bone Joint Surg Am 2001, 83-A(12):18561864.

19. Ware Jr JE, Kosinski M, Keller SD: A 12-Item Short-Form Health Survey: construction of scales and preliminary tests of reliability and validity. Med Care 1996, 34(3):220-233.

20. Drouin JM, Valovich-mcLeod TC, Shultz SJ, Gansneder BM, Perrin DH: Reliability and validity of the Biodex system 3 pro isokinetic dynamometer velocity, torque and position measurements. Eur J Appl Physiol 2004, 91(1):22-29.

21. Lenssen AF, van Dam EM, Crijns YH, Verhey M, Geesink RJ, van den Brandt PA, de Bie RA: Reproducibility of goniometric measurement of the knee in the in-hospital phase following total knee arthroplasty. BMC Musculoskelet Disord 2007, 8:83.

22. Webster KE, Wittwer JE, Feller JA: Validity of the GAITRite walkway system for the measurement of averaged and individual step parameters of gait. Gait Posture 2005, 22(4):317-321.

23. Field AP: Discovering statistics using SPSS: SAGE publications Ltd; 2009.

24. Jiang Y, Sanchez-Santos MT, Judge AD, Murray DW, Arden NK: Predictors of Patient-Reported Pain and Functional Outcomes Over 10 Years After Primary Total Knee Arthroplasty: A Prospective Cohort Study. J Arthroplasty 2016, 32(1):92-100.

25. Zeni JA, Jr., Snyder-Mackler L: Early postoperative measures predict 1- and 2-year outcomes after unilateral total knee arthroplasty: importance of contralateral limb strength. Phys Ther 2010, 90(1):43-54.

26. Sharma L, Cahue S, Song J, Hayes K, Pai YC, Dunlop D: Physical functioning over three years in knee osteoarthritis: role of psychosocial, local mechanical, and neuromuscular factors. Arthritis Care Rheum 2003, 48(12):3359-3370. 


\section{APPENDICES}

Appendix 1 Patient characteristics and baseline measurement. n; number. \%GC; percentage of gait cycle.

\begin{tabular}{|c|c|c|c|}
\hline & $\bar{n}$ & mean & $95 \% \mathrm{Cl}$ \\
\hline Age (years) & 150 & 64.7 & $63.4-66.0$ \\
\hline Weight (kg). Women & 79 & 84.6 & $81.2-88.0$ \\
\hline Weight (kg). Men & 71 & 95.7 & $92.5-98.9$ \\
\hline Height (m). Women & 79 & 1.66 & $1.65-1.67$ \\
\hline Height (m). Men & 71 & 1.75 & $1.74-1.77$ \\
\hline BMI. Women & 79 & 30.7 & $29.5-31.9$ \\
\hline BMI. Men & 71 & 31.2 & $30.2-32.2$ \\
\hline PSFS1 & 150 & 1.9 & $1.6-1.9$ \\
\hline PSFS2 & 149 & 2.2 & $1.9-2.6$ \\
\hline PSFS3 & 138 & 2.6 & $1.6-2.3$ \\
\hline KSS-Knee score & 150 & 52.5 & $49.8-55.1$ \\
\hline KSS-Function score & 150 & 57.2 & $55.1-59.4$ \\
\hline SF12-Physical & 146 & 33.5 & $32.2-34.8$ \\
\hline SF12-Mental & 146 & 44.7 & 42.9- 46.4 \\
\hline Quadriceps Isometric strength $60^{\circ}(\mathrm{Nm})$ & 147 & 79.6 & $73.2-86.0$ \\
\hline Quadriceps Isometric strength $30^{\circ}(\mathrm{Nm})$ & 132 & 40.1 & $36.3-43.8$ \\
\hline Quadriceps Isokinetic strength $60 \% / \mathrm{sec}(\mathrm{Nm})$ & 149 & 56.6 & $51.2-62.1$ \\
\hline Quadriceps Isokinetic strength $180^{\circ} / \mathrm{sec}(\mathrm{Nm})$ & 149 & 35.9 & $32.5-39.3$ \\
\hline Hamstrings Isometric strength $60^{\circ}(\mathrm{Nm})$ & 147 & 56.6 & $52.2-60.1$ \\
\hline Hamstrings Isometric strength $30^{\circ}(\mathrm{Nm})$ & 132 & 72.2 & $65.9-78.4$ \\
\hline Hamstrings Isokinetic strength $60 \% / \mathrm{sec}(\mathrm{Nm})$ & 149 & 40.3 & $36.6-43.9$ \\
\hline Hamstrings Isokinetic strength $180^{\circ} / \mathrm{sec}(\mathrm{Nm})$ & 149 & 30.8 & $28.0-33.6$ \\
\hline Flexion & 150 & 120.1 & $118.1-122.2$ \\
\hline Extension & 150 & -2.3 & $-3.2--1.4$ \\
\hline Walking Speed $(\mathrm{cm} / \mathrm{s})$ & 145 & 98.9 & $95.0-102.7$ \\
\hline Step Length Surgical leg $(\mathrm{cm})$ & 145 & 57.6 & $55.7-59.5$ \\
\hline Step Length Healthy leg (cm) & 145 & 58.0 & $56.4-59.7$ \\
\hline Stance Surgical leg (\%GC) & 145 & 67.3 & $66.5-68.2$ \\
\hline Stance Healthy leg (\%GC) & 145 & 65.8 & $65.0-66.7$ \\
\hline Swing Surgical leg (\%GC) & 145 & 33.1 & 32.3-33.9 \\
\hline Swing Healthy leg (\%GC) & 145 & 34.7 & $34.0-35.4$ \\
\hline Single Support Surgical leg (\%GC) & 145 & 34.5 & $34.0-35.0$ \\
\hline Single Support Healthy leg (\%GC) & 145 & 32.9 & $32.2-33.5$ \\
\hline Double Support Surgical leg (\%GC) & 145 & 33.0 & $31.9-34.1$ \\
\hline Double Support Healthy leg (\%GC) & 145 & 33.2 & $32.2-34.3$ \\
\hline
\end{tabular}


Appendix 2 Factors retained in multivariate regression analysis. r. correlation coefficient;ns. Non significant.

\begin{tabular}{l|l|l}
\hline & WOMAC3M & WOMAC12M \\
\hline WOMAC-Pain & 0.00 & 0.00 \\
WOMAC-Stiffness & 0.04 & 0.03 \\
WOMAC-Function & 0.00 & 0.00 \\
PSFS3 & 0.03 & 0.09 \\
KSS-Knee & ns & 0.00 \\
KSS-Function & ns & 0.06 \\
SF12-Physical & 0.00 & 0.00 \\
SF12-Mental & 0.01 & 0.09 \\
Quadriceps Isometric 60 & ns & 0.05 \\
Hamstrings Isokinetic 60 & ns & 0.01 \\
Walking Speed & ns & 0.02 \\
Step length Surgical & 0.07 & 0.00 \\
Step length Healthy & ns & 0.01 \\
Stance Surgical & ns & 0.08 \\
Stance Healthy & ns & 0.07 \\
Single support Surgical & 0.05 & 0.04 \\
Single Support Healthy & ns & 0.04 \\
Swing Surgical & ns & 0.03 \\
Swing Healthy & 0.06 & 0.03 \\
Double Support Surgical & ns & 0.09 \\
Double Support Healthy & ns & 0.06 \\
\hline
\end{tabular}





\title{
CHAPTER FOUR.
}

\author{
PATIENT SPECIFIC FUNCTION SCALE, \\ ITS RELIABILITY \& RESPONSIVENESS IN \\ PATIENTS UNDERGOING A TKA
}

Danielle D.P. Berghmans

Antoine F. Lenssen

Lodewijk W. van Rhijn

Rob A. de Bie

Published

BERGHMANS, Danielle DP, et al. The patient-Specific Functional Scale: Its reliability and responsiveness in patients undergoing a total knee arthroplasty. J Orthop Sport Phys, 2015, 45.7: 550-556. 


\section{ABSTRACT}

\section{Background}

Reliable and valid measurement instruments are important to measure functional status. The Patient Specific Functional Scale (PSFS) is frequently used in several patient populations, but its methodological characteristics in a population of patients with total knee arthroplasty (TKA) in the perioperative phase are unknown.

\section{Objectives}

To determine and compare the responsiveness and reliability of the PSFS in patients undergoing a TKA.

\section{Study design}

Prospective cohort study. Assessments take place before and three and 12 months after TKA.

\section{Methods}

PSFS, Western Ontario and McMaster Universities Osteoarthritis Index (WOMAC) and Global Perceived Effect (GPE) were taken at three time points in 150 patients undergoing a TKA. Correlations, effect sizes (ES) and standard response means (SRM) were calculated. The PSFS was administered twice to assess its reliability in terms of intra-class correlation coefficients (ICC) and limits of agreement (LOA).

\section{Results}

The correlation coefficient between PSFS and WOMAC was .41 at three months and .48 at one year, those between PSFS and GPE were -.37 and -.55. The ES of PSFS were 1.71 and 2.89 at three months and one year, respectively; those of WOMAC were 1.45 and 1.64. The SRMs of the PSFS were 0.96 and 1.48; those of WOMAC 1.28 and 1.37 , respectively.

The ICCs ranged between .73 and .86 . The systematic error was between .12 and 0.54 . The LoA ranged from \pm 2.17 to \pm 2.72 .

\section{Conclusion}

The reliability of the PSFS is good. Its responsiveness is high, especially in the long term. However, PSFS cannot be used interchangeably with WOMAC in the immediate post-operative period. 


\section{INTRODUCTION}

Measuring health status and treatment effects in patients has in recent years become more important in many patient populations.[1, 2] One of these populations is that of patients with osteoarthritis. Osteoarthritis is a major health problem, and a $40 \%$ increase in its prevalence is expected in the next 20 years.[3] Many patients with osteoarthritis are faced with pain, stiffness, and loss of function. To reduce loss of function, both conservative and surgical options are available.[4] Assessing treatment effects requires valid and reliable instruments measuring functional status.[5-8] The Dutch physical therapy guideline for knee and hip osteoarthritis recommends the use of patient-reported outcome measures (PROMs), like the Western Ontario and McMaster Universities Osteoarthritis Index (WOMAC), and the Patient Specific Functional Scale (PSFS), to assess functional status.[5]

The WOMAC is a condition-specific PROM, which contains predefined items. However, these predefined items mean that the WOMAC does not consider patient preferences or variability in functional status and the performance of activities. Since functional status is a patient-referenced concept and differs greatly between patients, questionnaires with predefined items may contain some items that are not relevant and valid for some patients, especially for patients with a high level of independence.[2, 9]

The PSFS, developed in 1995 by Stratford et al.,[1, 2] has no predefined items, and is adapted to the individual patient. On this scale, patient have to define important activities which they can only perform with difficulty, and rate the level of difficulty on an 11-point scale or a visual analogue scale (VAS). $[2,10,11]$ The main goal of the scale is to elicit, measure, and record patients' views regarding disabilities.[1] The PSFS is able to identify and evaluate relevant individual issues.[12, 13] It is also efficient and easy to use for different patient populations.[2] Worldwide interest in patient-specific outcomes has recently increased,[9] and this scale is now frequently used.[14]

The methodological aspects of the PSFS have been studied in different populations, mainly in patients with chronic low back pain. In this population the scale is rated as valid, reliable, and responsive for measuring change over time.[2, 7-9, 12, 14-17] One study [1] investigated its methodological quality in 38 patients with knee dysfunction (defined as any orthopedic condition of the knee that contributed to a decreased level of function as perceived by the patient). Overall, Chatman et al. (1997) concluded that the PSFS was reliable and responsive, but further research was recommended to assess the extent to which the PSFS can be used across a variety of patient populations and age groups.[1]

Stratford et al. (2014) investigated the responsiveness of the PSFS in 133 patients after a Total Knee Arthroplasty (TKA) as good. Patients enrolled in the study within 28 days after surgery, the follow up measurement was within 80 days after surgery.[13]

Responsiveness is an important characteristic of a measurement instrument when measuring treatment effects. It is defined as the ability of an instrument to detect clinically important changes in an outcome measure over time. $[2,7,8,12,15,16]$ 
However, it is not a fixed property, but should be considered with regard to context, patient population, time period, measurement properties, and the construct to be measured.[15, 18] Therefore, research is necessary in different patient populations and within different time intervals.

Another important concept is reliability. It is defined as the degree to which the measurement is free from measurement error. It is a characteristic of an instrument in a specific population.[18] The reliability of the PSFS in a population of patients with TKA is unknown. Because of the relation between the measurement error and patient's change over a time period measured, the measurement error is an important aspect in the evaluative using of the measurement instrument. Therefore, it is important to know the measurement error of the test to determine the true change or responsiveness in a patient.

In view of the absence of information about the methodological characteristics of the PSFS in a large patient population in the perioperative period of a TKA, the objective of this study was to determine and compare the responsiveness and reliability of the PSFS in patients in the perioperative period of a TKA.

\section{METHODS}

\section{Subjects}

Between March 1, 2011 and March 1, 2013, all consecutive patients with osteoarthritis of the knee who were about to undergo a TKA at the osteoarthritis clinic of the Maastricht University Medical Center (Artrose Kliniek Maastricht [AKM]) were informed about the study in writing and verbally at least one week before the planned surgery. The day before their surgery, all patients were contacted by the researcher and written informed consent was requested.

Inclusion criteria were: patients aged between 18 and 80 years at the time of surgery, diagnosed with osteoarthritis of the knee for which primary TKA was indicated, who were to be operated on at AKM and had sufficient command of Dutch. Patients were excluded if they underwent a unilateral knee arthroplasty (UKA), had a neurological problem influencing ambulation or had an immobile hip or ankle arthrodesis.

Patients who dropped out during the test period were not replaced.

The local medical research ethics committee of the Maastricht University Medical Center reviewed and approved the study procedures. The rights of subjects were protected. 


\section{STUDY DESIGN}

The study had a prospective design; all patients were assessed with a set of measurement instruments assessing their functional status, at three time points: preoperatively and three months and one year post-operatively. To measure reliability, a subpopulation was assessed twice, with a three-day interval, during their hospital stay for TKA.

\section{Measurements}

\section{Patient Specific Functional Scale (PSFS)}

The PSFS is a questionnaire aimed at recording patients' perceptions of their disabilities.[2, 19]

Patients define their main complaints (i.e. difficulties performing certain activities) and rate the difficulty of performance on an 11-point numerical rating scale (NRS) $(0=$ no problems; $10=$ impossible) or a visual analog scale (VAS).[2, 12] In view of its ability to detect small differences in the PSFS, the NRS is preferred over the VAS, and was therefore chosen in this study.[2, 8]

The three main complaints defined had to be as specific as possible, and had to cause difficulties related to the osteoarthritis of the knee. These main complaints were defined using a standardized procedure. Patients were not allowed to define problems that could be easily avoided, because of the risk of invalidating the evaluation during the follow-up.

Between September 2012 and March 2013, the PSFS was repeated two days after the surgery, in a subpopulation of 33 patients, to investigate its reliability. The activities defined the day before surgery, were rated independently, and no information was given about the previous rating. The patients were asked to indicate the difficulty in performing the activity the week before surgery both times.

Western Ontario and McMaster Universities Osteoarthritis Index (WOMAC)

The WOMAC is a self-administered health questionnaire designed to measure the functional status of the osteoarthritic hip and knee.[20] The WOMAC provides an aggregate score for each of 3 subscales: joint pain, joint stiffness, and physical function. The WOMAC is a responsive instrument that yields reliable and valid measurements and has been extensively used to evaluate this patient population.[14, 20-22]

The 5-point Likert version of this measure was used in our study. Each of the 3 subscale scores was calculated by transforming the range of the subscale score to a range from 0 to 100 points, with a score of 0 indicating no pain or dysfunction.

\section{Global perceived effect (GPE)}

The GPE of treatment was measured by self-assessment on a 7-point Likert scale $(6$ = greatly worsened, 1 = completely recovered). 


\section{Statistical analysis}

All analyses were performed with SPSS 20.[23] Means and standard deviations were calculated. All complaints defined for the PSFS were analyzed individually and a mean score was calculated and used in the analysis.[13] Results of the descriptive analyses are presented as means with standard deviations.

Responsiveness can be calculated by different methods.[8, 9] Recently, the COSMIN statement has extended the definition of responsiveness: the ability of an instrument to detect change over time in the construct to be measured.[24] Responsiveness is a part of validity, the difference being that responsiveness refers to the validity of a change score. The proposed calculation technique for measuring responsiveness is therefore identical to measuring construct validity, with the exception that in responsiveness assessment the hypotheses focus on the change score of an instrument.[24] Therefore, the correlation between the instrument of interest and an instrument known to measure the construct of interest, which in this study was the change in function, is measured. It is necessary to define the expected strength of the correlation beforehand.[24] Since we focused on the change score of two or more instruments, with their measurement error, we expected a correlation lower than validity studies, (a correlation smaller than .7).[18] In this study we chose to correlate the PSFS with the WOMAC and the GPE. We correlated with the WOMAC because this instrument is widely accepted as a useful and valid tool for measuring the functional status of a patient. The GPE measures the perceived effect of the treatment. In our opinion the construct of the PSFS overlaps with these two instruments.

Terwee et al. (2011) stated that the use of Effect Sizes (ES) is only allowed when one compares different instruments and when hypotheses are formulated beforehand.[18] Our hypotheses were:

1. The correlation between the WOMAC mean difference (MD) and the PSFS MD is between .3 and .5 .

2. The correlation between the GPE and the PSFS MD is between .3 and .5 .

3. The ES of the PSFS is higher than the ES of the WOMAC.

4. The Standard Response Mean (SRM) of the PSFS is higher than the SRM of the WOMAC.

We considered the responsiveness of the PSFS to be high when three or four hypotheses were verified, moderate when only one or two hypotheses were verified and poor when none of the hypotheses was verified. The responsiveness was calculated over three months and over one year. Separate conclusions are presented for both time periods.

Reliability was measured according to the COSMIN statement.[18] Reliability concerns the capacity to distinguish between categories of people, despite measurement error. It also reflects the ability of different observers to record the same value.[25-27] Reliability was calculated using the intraclass correlation coefficients (ICCS) of the two PSFS measurements, measured during the inhospital phase in a three day interval.[18] The ICCS were calculated using a random effects 
one-way analysis of variance.[25, 27] Before the start of the study, an ICC of .7 was specified as indicating satisfactory reliability.

The measurement error between two tests as examined using the BlandAltman method. Information on the agreement between the two tests was obtained by calculating the mean difference (MD) and the limits of agreement (LoA).[25, 27] The three patient-defined complaints were treated separately.

\section{RESULTS}

Between March 1, 2011 and March 1, 2013, 150 patients were recruited and assessed. The study population consisted of 79 (52.7\%) women and 71 (47.3\%) men. The mean age was $65( \pm 8.0)$ years.

Twelve patients were unable to define more than two complaints for the PSFS, and one patient was unable to define more than one. When patients were unable to formulate a second or third complaint, this was seen as a missing value in the analysis of that complaint, no substitution was made, therefore a lower number of patients participated in the analysis of the second and third compliant. Seven patients were unable to attend the follow-up measurement at three months and were regarded as missing values; three further patients had missing one-year data.

Examples of patient-defined complaints were: walking stairs (one level), walking (30 minutes), and cycling (5 kilometer). Especially the distance or duration differed highly between the patients.

The mean difficulty score for the three complaints on the PSFS was 7.8 points $( \pm 1.5)$ before surgery, 5.1 ( \pm 2.9$)$ three months after surgery and $3.3( \pm 2.9)$ one year after surgery. The mean total score on the WOMAC was 45.96 points ( \pm 16.9 ) before surgery, 24.7 ( \pm 18.6) three months after surgery and $18.3( \pm 19.1)$ one year after surgery. The change of the PFSF and the WOMAC between before surgery and three months after surgery were $2.6( \pm 2.8)$ and $24.5( \pm 19.1)$, respectively. The change of these two tests before surgery and one year after surgery were $4.5( \pm 3.0)$ and 27.8 ( \pm 20.3$)$, respectively (table 1$)$. 


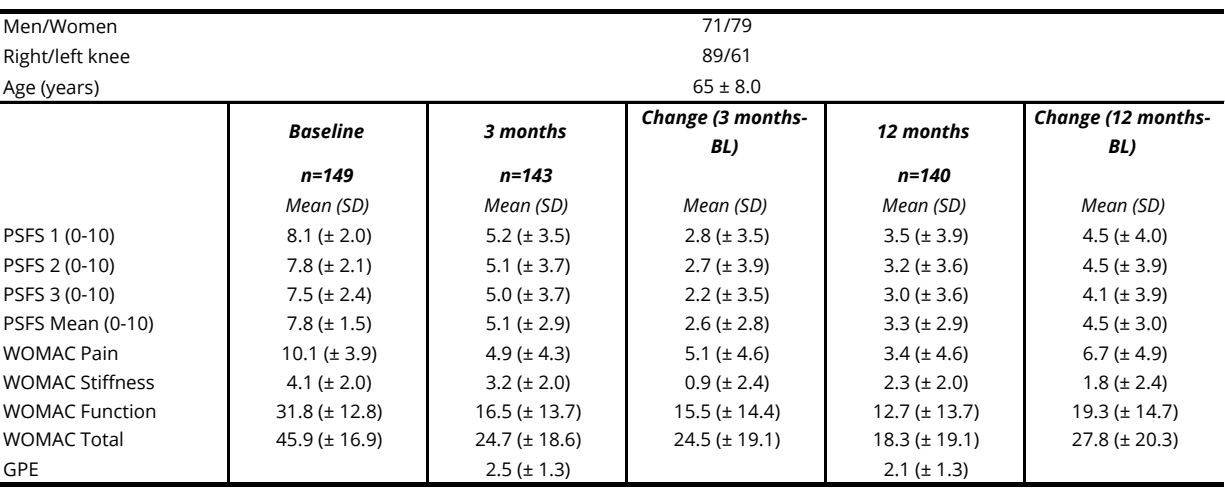

Table 1 Descriptives

PSFS, Patient Specific Function Scale. WOMAC, Western Ontario and McMaster Universities Osteoarthritis Index. GPE, global perceived effect. BL, baseline.

$\mathrm{SD}$, standard deviation.

\section{Responsiveness}

At three months, the correlation coefficient between the mean PSFS score and the total WOMAC score was .41, that between the PSFS and the GPE -.37, and that between the GPE and the WOMAC -.44. The ES of the WOMAC was 1.45, that of the mean PSFS 1.71. The SRMs were 1.28 and 0.96 , respectively (table 2).

\begin{tabular}{l|c|c|c|c|c}
\hline \multicolumn{1}{c|}{ 3 months } & ES & SRM & $\boldsymbol{r}$ with GPE & $\boldsymbol{r}$ with WOMAC Function & $\boldsymbol{r}$ with WOMAC Total \\
\hline PSFS 1 (0-10) & 1.40 & 0.80 & -.33 & .31 & .31 \\
PSFS 2 (0-10) & 1.24 & 0.68 & -.28 & .34 & .33 \\
PSFS 3 (0-10) & 0.91 & 0.62 & -.20 & .29 & .28 \\
PSFS Mean (0-10) & 1.71 & 0.96 & -.37 & .42 & .41 \\
WOMAC Function & 1.21 & 1.08 & -.42 & $*$ & $*$ \\
WOMAC Total & 1.45 & 1.28 & -.44 & $*$ & $*$
\end{tabular}

Table 2 Responsiveness of the PSFS and the WOMAC after three months

ES, effect size. SRM, standard response mean. $r$, correlation coefficient. GPE, global perceived effect. PSFS, Patient Specific Function Scale. WOMAC, Western Ontario and McMaster Universities Osteoarthritis Index.

At one year, the correlation between the mean PSFS score and the total WOMAC score was .48, that between the PSFS and the GPE -.55, and that between the GPE and the WOMAC -.46. The ES of the WOMAC was 1.64, that of the mean PSFS 2.89 . The SRMs were 1.37 and 1.48, respectively (table 3). 


\begin{tabular}{l|c|c|c|c|c}
\hline \multicolumn{1}{c|}{ 12 months } & ES & SRM & $\boldsymbol{r}$ with GPE & $\boldsymbol{r}$ with WOMAC Function & $\boldsymbol{r}$ with WOMAC Total \\
\hline PSFS 1 (0-10) & 2.20 & 1.12 & -.43 & .30 & .35 \\
PSFS 2 (0-10) & 2.11 & 1.16 & -.49 & .42 & .45 \\
PSFS 3 (0-10) & 1.70 & 1.05 & -.31 & .26 & .29 \\
PSFS Mean (0-10) & 2.89 & 1.48 & -.55 & .43 & .48 \\
WOMAC Function & 1.51 & 1.31 & -.43 & $*$ & $*$ \\
WOMAC Total & 1.64 & 1.37 & -.46 & $*$ & $*$ \\
\hline
\end{tabular}

Table 3 Responsiveness of the PSFS and the WOMAC after 12 months

ES, effect size. SRM, standard response mean. r, correlation coefficient. GPE, global perceived effect. PSFS, Patient Specific Function Scale. WOMAC, Western Ontario and McMaster Universities Osteoarthritis Index.

\section{Reliability}

All patients in the subpopulation used to test reliability were able to define three complaints. The ICC values for the three complaints ranged from .73 to .86 , the lowest correlation being within the first complaint, the highest within the third. The MD between two measurements, or the systematic error, was between 0.12 and 0.54 . Patients had lower scores during the second measurement. The LoA ranged from \pm 2.17 to \pm 2.72 (table 4).

\begin{tabular}{l|c|c|c}
\hline & $\begin{array}{c}\text { Complaint 1 } \\
n=33(C I)\end{array}$ & $\begin{array}{c}\text { Complaint 2 } \\
n=33(C I)\end{array}$ & $\begin{array}{c}\text { Complaint 3 } \\
n=33(C I)\end{array}$ \\
\hline ICC & $.73(.49-.86)$ & $.75(.56-.87)$ & $.86(.74-.93)$ \\
LOA & $0.54+/-2.4$ & $0.21+/-2.72$ & $0.12+/-2.17$ \\
\hline
\end{tabular}

Table 4 Reliability and measurement error of the PSFS in the perioperative period ICC, intraclass correlation coefficient. LoA, limits of agreement. CI, confidence interval. 


\section{DISCUSSION}

This study investigated the responsiveness of the PSFS, and found it to be high, both in the short and the longer term. Although the responsiveness of the PSFS over three months was comparable to that of the WOMAC, it was higher at 12 months, and may therefore be considered superior measuring functional status. However, the WOMAC also includes pain and stiffness, which is not included in the PSFS. We investigated the responsiveness using the four hypotheses stated in the methods.

\section{Responsiveness after three months}

Over a period of three months, the responsiveness was high: the first three hypotheses were verified. The higher ES of the PSFS compared to that of the WOMAC suggests a higher responsiveness. The correlation with the WOMAC and the GPE was good, suggesting that the PSFS, the WOMAC, and the GPE measure comparable constructs. However, the higher correlation between the WOMAC and the GPE indicates that their constructs are more comparable.

However, the WOMAC had a higher SRM compared to the PSFS, suggesting a higher responsiveness of the WOMAC. This was caused by a high standard deviation of the PSFS change; the self-defined complaints differed greatly as regards the activity and the degree of difficulty, and often worsened during the first three months after surgery, resulting in a larger standard deviation of the PSFS change. Before surgery, however, almost all patients gave their self-defined complaints the maximum score, resulting in a low standard deviation and a high ES. Rapid improvement is expected on the WOMAC, in view of the basic activities it evaluates, so the standard deviation of the WOMAC change is also low. A smaller SRM suggests a lower responsiveness of the PSFS compared to the WOMAC.

Taken together, these findings suggest that the WOMAC is a more responsive and more suitable instrument to measure the functioning and recovery of patients within three months after undergoing a TKA.

\section{Responsiveness after one year}

Over a one-year period, all hypotheses were verified. The SMR and the ES of the PSFS were high, and higher than those of the WOMAC. The correlation with the WOMAC was good, while the correlation with the GPE was higher than that with the WOMAC and even higher than expected. Taken together, this suggests that the PSFS has good responsiveness and is preferable to the WOMAC as regards measuring patients' functioning and recovery over one year.

One reason for this could be the goals; the self-defined complaints may well represent more long-term goals, whereas the WOMAC includes more basic daily activities that can be carried out by the majority of the population in the early postoperative period.

The responsiveness of the PSFS has also been investigated in other patient 
populations, and the results are in line with those of the present study. Beurskens et al. investigated the PSFS in 1996 [7] and 1999 [12] in a populations of patients with low back pain (consisting of 81 and 150 patients, respectively), and found ESs of between 1.63 (at five weeks) and 2.53 (at 12 weeks) for improvement and of between 0.73 (at five weeks)and 0.41 (at 12 weeks) and for deterioration. A review by Hall et al. (2011) used four studies, with a total of 831 patients with low back pain, to investigate the methodological qualities, and found an ES of 1.55-2.16 and an SRM of 1.11-1.12.[16] The correlation with the GPE found by Pengel et al. (2004) in a study of 155 patients with low back pain [8] was also comparable (.6) to that found in our study.

In the study of Stratford et al. (2014) the initial measurement, including defining complaints is within 28 days after surgery at the start of the therapy period.[13] In our study the individual complaints are defined before surgery. Therefore the focus and starting point of the defining complaints is different. Comparing the results, the SRM measured in our study is lower. An explanation is that the functional status before surgery is higher, than within four weeks after surgery (e.g walking with walking aid, not able to cycle after surgery). This is also visible in the baseline value of the PSFS in our study; the patients have overall less difficulty with the complaints. Further, the mean difference is smaller in our study; one possible explanation could be prior expectations. Before surgery and over a longer period the patients could have higher and possible unrealistic expectations, after surgery and expectations over a shorter period could be more adequate. At last our standard deviation is larger; one explanation could be again the time period and the moment in time. The largest recovery is within the first months after surgery [13], defining complaints and evaluating them in the same period will result in a higher change, than defining them before and evaluating them after this period.[13] Further, Stratford correlated the PSFS with the Lower Extremity Functional Scale (LEFS) and a pooled index; both correlations are lower compared with the correlation between the PSFS and the WOMAC in our study.[13] One possible explanation given by Stratford self: in their study patients defined complaints with relatively high difficulty, easily to improve, therefore a large improvement and resulting in a ceiling effect, the LEFS detected a larger spectrum. In our study, this was the opposite, the spectrum of the WOMAC is smaller and a ceiling effect is more likely to happen in this measurement instrument.[13, 28]

Our WOMAC results are also in line with previous research, which found ESs of 0.95-3.1 (3-12 months) and SRMs (3-12 months) of 0.63-2.02.[22]

\section{Reliability}

The reliability of the PSFS was good, with an ICC value above .7, although an ICC above .9 has been advised for use in individual patients.[11, 25] The LoAs in our study varied between -2.17 and +2.72 points on an 11-point scale. Our results are in line with those of previous studies [1, 2, 29, 30], which found an ICC for the PSFS of between .82 and .97. Only a study by Young et al. [31] reported an ICC of .19. LoAs were not reported in other studies. 
There was a difference between the three complaints, in that the first complaint had the lowest ICC and the highest MD and LoA suggesting the largest difference in rating between the two measurement points. However, in our opinion the first complaint is the most important one, which is most evaluated, and is the one that the therapy is based on. Therefore, this value should in our opinion have the lowest variance. One explanation for our findings could relate to intensity. The first and second complaints may be important and regard activities that patients still often engage in, like walking, whereas the third one may regard a less frequent activity and one that may be impossible due to the osteoarthritis, like cycling. If the patients did not engage in a particular activity, their recall could be more accurate than for an activity they still often engaged in.

Besides this difference between the complaints, another argument to use multiple complaints instead of one is that only total recovery is visible when several complaints are taken together.

\section{Limitations and strengths}

A limitation of this study is the short time available to the patients to define their complaints, despite the prior information they were given about the study, which means that some complaints may have been missed. A second limitation is the small subpopulation included in the reliability calculation.

One strength of this study is the small number of missing values, especially over the period of one year. A second strength is the completeness of the responsiveness analysis. These two advantages make the results more reliable.

Our study followed the guidelines for responsiveness en reliability measurement in the COSMIN statement. Formulating hypotheses is helpful for drawing conclusions afterwards, but in situations where no gold standard is available, selecting the most suitable instruments for the comparison is a challenge.

\section{Implications}

Over a period of one year, the PSFS is preferable as it has better responsiveness and is based on personalized therapy goals. On the other hand, the WOMAC has better responsiveness during the first three months. We therefore suggest using both instruments in the first months, and continuing to use the PSFS in later stages.

Further research is needed to investigate the minimally important change in a population of patient with TKA, and to confirm our reliability results. Further, research to investigate the responsiveness and reliability in other patient populations in is advisable. 


\section{Conclusion}

We can conclude that the responsiveness of the PSFS is high in patients after a TKA, especially in the longer term, one year post surgery. The reliability of the PSFS in patients after a TKA is good. Therefore, when interested in functional status we suggest using the PSFS, because of the higher responsiveness compared to the WOMAC one year post surgery. However, when interested in other domains covered by the WOMAC, we suggest using both instruments next to each other. 


\section{REFERENCES}

1. Chatman AB, Hyams SP, Neel JM, Binkley JM, Stratford PW, Schomberg A, Stabler M: The Patient-Specific Functional Scale: measurement properties in patients with knee dysfunction. Phys Ther 1997, 77(8):820-829.

2. Stratford P: Assessing disability and change on individual patients: a report of a patient specific measure. Physiother Can 1995, 47(4):258-263.

3. Schouten J, Poos M, Gijsen R: Neemt het aantal mensen met artrose toe of af. Volksgezondheid Toekomst Verkenning, Nationaal Kompas Volksgezondheid 2002.

4. Beers $\mathrm{MH}$, Berkow R: The merck manual. The merck manual 1999.

5. Peter WFH, Jansen MJ, Bloo H, Dekker-Bakker LMMCJ, Dilling RG, Hilberdink WKHA, Kersten-Smit C, Rooij M de, Veenhof C, Vermeulen HM et al: KNGFrichtlijn Artrose heup-knie. 2010.

6. Diagnostiek en behandeling van heup- en knieartrose [http://www.cbo.nl/ Downloads/363/rl_heup_knie_07.pdf]

7. Beurskens AJ, de Vet HC, Koke AJ: Responsiveness of functional status in low back pain: a comparison of different instruments. Pain 1996, 65(1):7176.

8. Pengel LH, Refshauge KM, Maher CG: Responsiveness of pain, disability, and physical impairment outcomes in patients with low back pain. Spine (Phila Pa 1976) 2004, 29(8):879-883.

9. Barten J, Pisters M, Huisman P, Takken T, Veenhof C: Measurement properties of patient-specific instruments measuring physical function. J Clin Epidemiol 2012, 65(6):590-601.

10. Sterling M, Brentnall D: Patient Specific Functional Scale. Aust J Physiother 2007, 53(1):65.

11. Ostelo RWJG, Verhagen AP, de Vet H: Onderwijs in wetenschap: lesbrieven voor paramedici: Bohn Stafleu Van Loghum; 2006.

12. Beurskens AJ, de Vet HC, Koke AJ, Lindeman E, van der Heijden GJ, Regtop W, Knipschild PG: A patient-specific approach for measuring functional status in low back pain. J manipulative Physiol Ther 1999, 22(3):144-148.

13. Stratford PW, Kennedy DM, Wainwright AV: Assessing the Patient-Specific Functional Scale's Ability to Detect Early Recovery Following Total Knee Arthroplasty. Phys Ther 2014, 94(6):838-844.

14. Gill SD, de Morton NA, Mc Burney $\mathrm{H}$ : An investigation of the validity of six measures of physical function in people awaiting joint replacement surgery of the hip or knee. Clin Rehabil 2012, 26(10):945-951.

15. McMillan CR, Binhammer PA: Which outcome measure is the best? Evaluating responsiveness of the Disabilities of the Arm, Shoulder, and Hand Questionnaire, the Michigan Hand Questionnaire and the PatientSpecific Functional Scale following hand and wrist surgery. Hand (N Y) 2009, 4(3):311-318. 
16. Hall AM, Maher CG, Latimer J, Ferreira ML, Costa LO: The patient-specific functional scale is more responsive than the Roland Morris disability questionnaire when activity limitation is low. Eur Spine J 2011, 20(1):79-86.

17. Horn KK, Jennings S, Richardson G, Vliet D, Hefford C, AbbottJH: The patientspecific functional scale: psychometrics, clinimetrics, and application as a clinical outcome measure. J Orthop Sports Phys Ther 2012, 42(1):30-42.

18. Terwee CB, Mokkink LB: Measurement in medicine: a practical guide: Cambridge University Press; 2011.

19. Gross DP, Battie MC, Asante AK: The Patient-Specific Functional Scale: validity in workers' compensation claimants. Arch Phys Med Rehabil 2008, 89(7):1294-1299.

20. Bellamy N, Buchanan WW, Goldsmith $\mathrm{CH}$, Campbell J, Stitt LW: Validation study of WOMAC: a health status instrument for measuring clinically important patient relevant outcomes to antirheumatic drug therapy in patients with osteoarthritis of the hip or knee. J Rheumatol 1988, 15(12):1833-1840.

21. Jones CA, Voaklander DC, Suarez-Alma ME: Determinants of function after total knee arthroplasty. Phys Ther 2003, 83(8):696-706.

22. Collins NJ, Misra D, Felson DT, Crossley KM, Roos EM: Measures of knee function: International Knee Documentation Committee (IKDC) Subjective Knee Evaluation Form, Knee Injury and Osteoarthritis Outcome Score (KOOS), Knee Injury and Osteoarthritis Outcome Score Physical Function Short Form (KOOS-PS), Knee Outcome Survey Activities of Daily Living Scale (KOS-ADL), Lysholm Knee Scoring Scale, Oxford Knee Score (OKS), Western Ontario and McMaster Universities Osteoarthritis Index (WOMAC), Activity Rating Scale (ARS), and Tegner Activity Score (TAS). Arthritis Care Res 2011, 63(S11):S208-S228.

23. Nie NH, Bent DH, Hull CH: SPSS: Statistical package for the social sciences, vol. 227: McGraw-Hill New York; 1975.

24. Mokkink LB, Terwee CB, Knol DL, Stratford PW, Alonso J, Patrick DL, Bouter LM, De Vet HC: The COSMIN checklist for evaluating the methodological quality of studies on measurement properties: a clarification of its content. BMC Med Res Methodol 2010, 10(1):22.

25. Beurskens S: Meten in de praktijk: stappenplan voor het gebruik van meetinstrumenten in de gezondheidszorg: Bohn Stafleu van Loghum; 2008.

26. Kottner J, Audige L, Brorson S, Donner A, Gajewski BJ, Hróbjartsson A, Roberts C, Shoukri M, Streiner DL: Guidelines for reporting reliability and agreement studies (GRRAS) were proposed. Int J Nurs Stud 2011, 48(6):661671.

27. Terwee CB, Bot SD, de Boer MR, van der Windt DA, Knol DL, Dekker J, Bouter LM, de Vet HC: Quality criteria were proposed for measurement properties 
of health status questionnaires. J Clin Epidemiol 2007, 60(1):34-42.

28. Field AP: Discovering statistics using SPSS: SAGE publications Ltd; 2009.

29. Westaway MD, Stratford PW, Binkley JM: The patient-specific functional scale: validation of its use in persons with neck dysfunction. J Orthop Sports Phys Ther 1998, 27(5):331-338.

30. Cleland JA, Fritz JM, Whitman JM, Palmer JA: The reliability and construct validity of the Neck Disability Index and patient specific functional scale in patients with cervical radiculopathy. Spine 2006, 31(5):598-602.

31. Young IA, Cleland JA, Michener LA, Brown C: Reliability, construct validity, and responsiveness of the neck disability index, patient-specific functional scale, and numeric pain rating scale in patients with cervical radiculopathy. Am J Phys Med Rehabil 2010, 89(10):831-839. 



\title{
CHAPTER FIVE.
}

\author{
ISOKINETIC QUADRICEPS \& HAMSTRING \\ STRENGTH IN THE FIRST YEAR AFTER A TKA
}

A SYSTEMATIC REVIEW

Danielle D.P. Berghmans

Anouk T.R. Weemaes

Antoine F. Lenssen

Pieter J. Emans

Rob A. de Bie

Submitted (October 2018)

Plos One 


\section{ABSTRACT}

\section{Objectives}

A total knee arthroplasty (TKA) is a pain-reducing, function-improving and costeffective solution in the treatment of knee osteoarthritis. However, quadriceps and hamstring strength mostly remains decreased after surgery. The purpose of this study is to provide a systematic review of the isokinetic quadriceps and hamstring strength development during the first year after total knee arthroplasty (TKA) surgery, and to obtain normative values for isokinetic quadriceps and hamstring strength during the first year after TKA surgery.

\section{Data sources}

We searched PUBMED, EMBASE, MEDLINE and COCHRANE databases for (combinations of) the following keywords: quadriceps, hamstring, TKA, total knee arthroplasty, total knee replacement, strength. Methodological quality was assessed by two reviewers.

\section{Data extraction}

Study characteristics, sample size, timing of follow-up measurements, participant characteristics, muscle strength assessment and muscle strength data were extracted from each individual study.

\section{Data synthesis}

Ten studies (455 patients, 303 women) were included. Isokinetic quadriceps and hamstring strength decreased immediately after surgery, but returned to presurgical values between 2 and 5 months after surgery, exceeding pre-surgical strength afterwards.

\section{Conclusions}

This systematic review reveals an initial post-surgical decrease, followed by strength increase between 2 and 5 months, exceeding pre-surgical strength afterwards. Rehabilitation could accelerate this process. However, existing data is too limited to generate precise norm values. This study therefore also emphasizes the need for more isokinetic strength data.

PROSPERA register number CRD42017072423. 


\section{INTRODUCTION}

Osteoarthritis (OA) is a global problem, since $10-15 \%$ of the population aged 60 or over have some degree of OA. Given the ageing population and a trend towards obesity, the prevalence of $\mathrm{OA}$ is expected to double in the coming years, the knee being one of the most affected joints.[1, 2] Pain is the most prominent complaint, which often results in functional limitations and muscle strength deficits.[3] In end stage OA of the knee, a total knee arthroplasty (TKA) is the treatment of first choice, aiming to relieve pain and enhance patient mobility.[4-6] However, activities demanding above average muscle strength, e.g. climbing stairs and walking a considerable distance, remain problematic for many patients after TKA.[6] Greene et al.[7] described quadriceps strength as a critical part of the success of a TKA, which can be affected by preoperative comorbidities, surgical techniques, prosthesis design, post-operative rehabilitation and patient-related factors.

Two previous systematic reviews on strength development after TKA have been published. In 2013, Schache et al. [8] described isometric and isokinetic strength values after a TKA (randomized clinical trials [RCT] and patient-control studies [PC], $\mathrm{n}=906$ ). They did not use restrictions on measurement method or follow-up time points, which resulted in large heterogeneity of studies and outcomes, reducing the quality of their meta-analysis. The review found a quadriceps strength deficit at each post-surgical time point (even years after TKA) and a hamstring strength deficit in the first year. The second review by Moon et al., [9] from 2016, focused on isokinetic strength pre-surgically and between 6 and 12 months after TKA surgery. They compared the strength of the surgical leg with that of the contralateral leg, in five studies $(n=274)$. The conclusion was that isokinetic strength decreased in the first months after surgery and returned to pre-surgical values by around 6 months after TKA surgery. However, the surgical leg had less strength than the contralateral leg at all time points. The greatest shortcoming of both reviews is that they did not analyze and describe sex-specific data, resulting in high variance in the absolute strength differences.

Recently, we published a large cohort study examining the functional status of 150 patients after a TKA surgery, which also included strength measurements.[10] We believe that adding these 150 patients to the existing dataset enhances the power of the available evidence on muscle strength deficits after TKA. Besides, in our opinion there was a gap in the existing evidence, since both of the previous reviews excluded all single-arm studies. We assume that this means that several studies were ignored which could help in calculating norm values for quadriceps and hamstring strength after TKA surgery. Therefore, the present systematic review focuses on the entire first year after surgery, and we did not impose any restrictions regarding study design or the use of a control group or contralateral measurement. In addition, we describe sex-specific results. To reduce the heterogeneity in study results, we decided to only include measurements made with fixed electronic strength measurement devices, since this is the gold standard for measuring strength. Finally, we focused on studies 
reporting isokinetic strength measurements. As described by Lauermann et al.,[11] the interchangeable use of isokinetic and isometric strength values is not advisable, since muscle strength deficit is larger when calculated with isometric measurements than with isokinetic measurements. Using isometric measurement could lead to an overestimation of the muscle strength deficit, so we followed Moon et al.,[9] who recommended using isokinetic strength measurement in studies.

\section{Objectives}

The first objective of the present review study was to provide an overview of the isokinetic quadriceps and hamstring strength development during the first year after TKA surgery, reporting sex-specific values if possible. Second, we want to build a database of norm values for isokinetic quadriceps and hamstring strength during the first year after TKA surgery.

\section{MATERIALS AND METHODS}

\section{Protocol and registration}

The research protocol has been registered in the PROSPERA register as CRD42017072423.

\section{Eligibility criteria of studies included}

We focused on studies reporting isokinetic quadriceps and/or hamstring strength (= outcome) in patients over the first year after a TKA (= patients and intervention). All study designs (with the exception of case reports and qualitative research) were eligible. The selection criteria for the studies were: an in vivo study published in English between 1990 and July 2018, assessing the volitional isokinetic quadriceps and/or hamstring strength with a fixed-unit electronic dynamometer in newton meter $(\mathrm{Nm})$ or foot pounds ( $\mathrm{ft} \mathrm{lbs}$ ) between the pre-surgical state and the situation one year after TKA, in patients (men and women) aged over 18 years. Excluded were studies with strength measurements only in the immediate post-surgical phase (up to one month after the TKA) since interference by wound pain and the fear of pain or damaging the prosthesis could influence the strength measurements.[12] In addition, we excluded studies focusing on the relation between specific comorbidities and $\mathrm{OA}$.

\section{Types of outcome measures}

The primary outcome measure was the maximal volitional isokinetic quadriceps and hamstring strength in the first year after a TKA, measured in Nm or ft lbs. All measurements in this time period were included in this review. 


\section{Information sources and search}

In July 2018, we searched the following databases: PUBMED, EMBASE, MEDLINE, COCHRANE. The search criteria were: quadriceps, hamstring, TKA, total knee arthroplasty, total knee replacement, strength.

\section{Selection of studies}

After deletion of duplicate articles, all articles were screened on the basis of title and abstract by two reviewers (DB and AW). Methods and results sections of the manuscripts were also screened for the measurement methods and absolute strength values, in case these were not provided in the abstract. Any discrepancies between the two reviewers were resolved by discussion or by consulting a third person (AL).

\section{Data collection process, extraction, analysis and management}

Study characteristics, sample size, timing of follow-up measurements, participant characteristics, muscle strength assessment and muscle strength data were extracted from each study. Data was searched for in the text, in tables and in figures (only data clearly visible in figures being included in the review). The present systematic review is reported according to the Preferred Reporting Items for Systematic reviews and Meta-Analysis (PRIMSA) guidelines.[13]

\section{Assessment of risk of bias in included studies}

To decrease the risk that bias in the individual studies influenced our conclusions, their methodological quality was checked by both examiners (DB and AW) using a modified checklist, based on the STROBE (Strengthening the Reporting of Observational Research in epidemiology) Statement [14] (Appendix 1). Once again, discrepancies were resolved by discussion or by consulting a third author (AL). The results are presented in table 2 .

\section{Summary Measure}

The summary measure is the absolute strength value with its standard deviation in Nm. Results initially presented in $\mathrm{ft}$ lbs were converted to $\mathrm{Nm}$.

\section{Secondary outcomes}

Factors possibly biasing the results, like sex, age and body mass index (BMI), were recorded and results were discussed with these in mind.

\section{Data synthesis/ Synthesis of results}

All study characteristics, numbers of patients, patient characteristics, and strength measurements are presented in table 1. Two other tables (tables 3 and 5) give an overview of all quadriceps and hamstring strength data. In addition, two figures 
(figures 1 and 2) depict the isokinetic strength development, at an angular speed of $60 \% \mathrm{sec}$, of the quadriceps and hamstring. Finally, tables 4 and 6 present the sexspecific isokinetic strength values.

\section{RESULTS}

\section{Study selection}

The initial search yielded 787 studies. After checking these studies against the eligibility criteria, 14 studies remained; 773 studies were excluded because they used in-vitro measurement, used different or inadequate strength measurements, had a different study sample, used too long follow-up periods or had missing data. Of the remaining 14 studies, another four were excluded. The studies by Topp et al. [15] and Lauermann et al.[16] used a different unit of strength measurement, with corrections for body weight $(\mathrm{Nm} / \mathrm{kg})$, which could not be converted to $\mathrm{Nm}$, since information on the raw strength or body weight data was lacking. The study by Umrani et al.[17] was eliminated since they used isokinetic power as the outcome in their study. Berman et al.[18] did not use fixed measurement moments but measured within a large range of 3 months, so we were unable to compare their results with those of the other studies. All ten remaining studies were used in this review and were checked for methodological quality (see Appendix 1). [14] See the flow chart in figure 1.
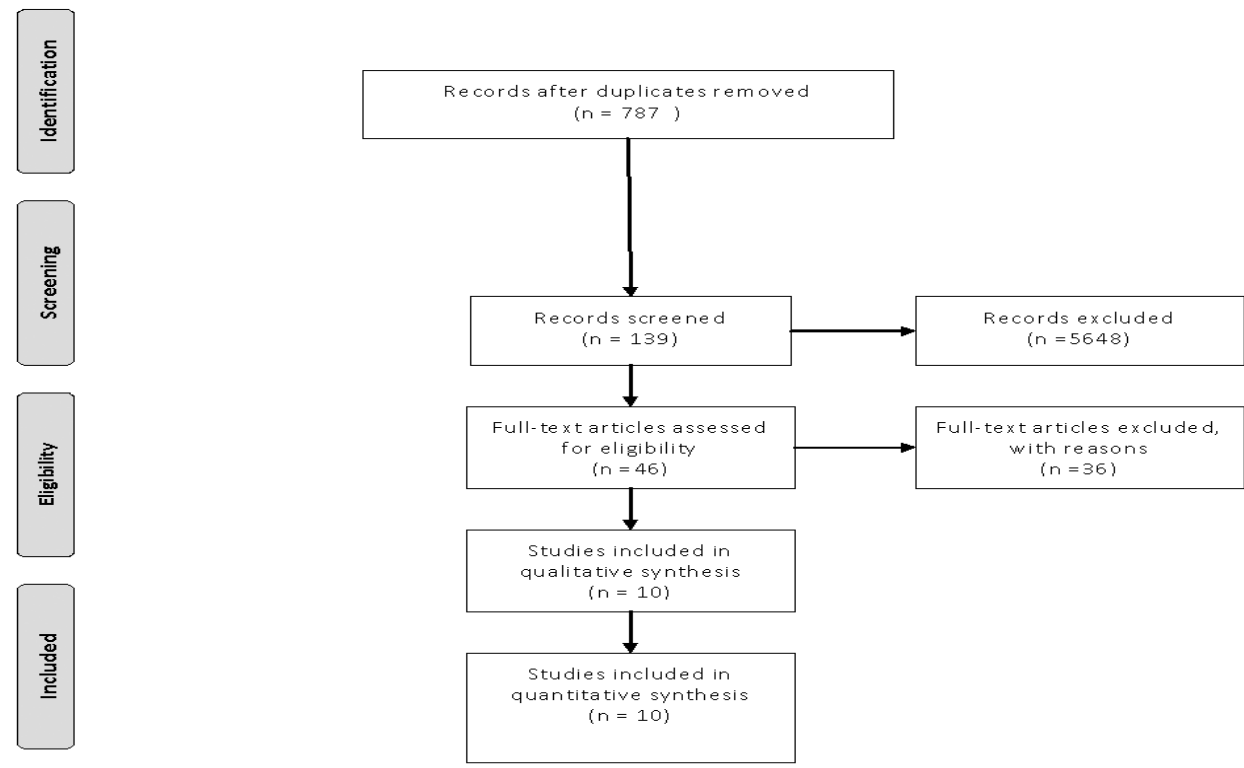

Figure 1 shows the flowchart of the selection of studies. 


\section{Study characteristics}

All ten studies were published between 2002 and 2018. In total, they included 455 patients (the largest study having 150 patients, the smallest 16), of whom 303 were female (67\%). The mean age ranged from 64.7 to 74 years, and the BMI from 25.4 to $33.2 \mathrm{~kg} / \mathrm{m}^{2}$. A summary of the study characteristics is presented in table 1.

\begin{tabular}{|c|c|c|c|c|c|c|c|c|c|c|}
\hline Author & Year & Design & $\mathbf{N}$ & F/M & Age(F/M) & BMI(F/M) & Unit & $\begin{array}{l}\text { Time- } \\
\text { points }\end{array}$ & Isokinetic & Instrument \\
\hline Berghmans.[10] & 2018 & Pros & 150 & $79 / 71$ & 64.7 & 30.9 & $\mathrm{Nm}$ & $\begin{array}{c}B \\
3 \mathrm{~m}\end{array}$ & $\begin{array}{r}60 \\
180\end{array}$ & Biodex \\
\hline Braito[19] & 2016 & $\begin{array}{l}\text { Pros } \\
\text { cohort }\end{array}$ & 17 & 43627,00 & 66.4 & 29.5 & $\mathrm{Nm}$ & $\begin{array}{c}13 \mathrm{~m} \\
\mathrm{~B} \\
8 \mathrm{w}\end{array}$ & 60 & Contrex \\
\hline Chang[20] & 2002 & Cohort & 28 & $28 / 0$ & 67.5 & 25.7 & $\mathrm{Nm}$ & $\begin{array}{c}6 \mathrm{~m} \\
12 \mathrm{~m}\end{array}$ & $\begin{array}{l}120 \\
180\end{array}$ & Cybex \\
\hline Lorentzen[21] & 2009 & Cohort & 30 & 43610,00 & 74 & 30 & $\mathrm{Nm}$ & $\begin{array}{c}B \\
3 \mathrm{~m}\end{array}$ & $\begin{array}{c}30 \\
120\end{array}$ & Cybex \\
\hline & & & & & & & & $\begin{array}{c}6 \mathrm{~m} \\
B\end{array}$ & & \\
\hline Chung[22] & 2013 & Cohort & 16 & 43567,00 & 65.7 & 25.4 & $\mathrm{Nm}$ & $\begin{array}{c}6 \mathrm{~m} \\
12 \mathrm{~m}\end{array}$ & 60 & Biodex \\
\hline Genet[23] & 2008 & $\begin{array}{l}\text { Pros } \\
\text { cohort }\end{array}$ & 45 & $28 / 17$ & 71.7 & 28.5 & $\mathrm{Nm}$ & $\begin{array}{l}1 \mathrm{~m}^{*} \\
6 \mathrm{~m}\end{array}$ & $\begin{array}{c}90 \\
180 \\
240\end{array}$ & Cybex \\
\hline $\operatorname{Kim}[24]$ & 2011 & RCT & 45 & $45 / 0$ & 67.5 & 27.8 & $\mathrm{Nm}$ & $\begin{array}{c}B \\
3 \mathrm{~m} \\
6 \mathrm{~m} \\
12 \mathrm{~m}\end{array}$ & 60 & Biodex \\
\hline Liebensteiner[25] & 2012 & $\begin{array}{l}\text { Pros } \\
\text { cohort }\end{array}$ & 36 & $21 / 17$ & 67.2 & 30.9 & $\mathrm{Nm}$ & $\begin{array}{c}B \\
8 w\end{array}$ & 60 & Contrex \\
\hline Rossi[26] & 2005 & $\begin{array}{l}\text { Pros } \\
\text { cohort }\end{array}$ & 38 & $19 / 19$ & 72.2 & 28.1 & $\mathrm{Nm}$ & $\begin{array}{c}B \\
1 \mathrm{~m}^{*} \\
2 \mathrm{~m}\end{array}$ & $\begin{array}{c}60 \\
180\end{array}$ & Cybex \\
\hline Schroer[27] & 2009 & $\begin{array}{l}\text { Pros } \\
\text { cohort }\end{array}$ & 50 & $35 / 15$ & 68.0 & 33.2 & Ft-lbs & $\begin{array}{c}6 \mathrm{w} \\
3 \mathrm{~m} \\
6 \mathrm{~m} \\
1 \mathrm{y}\end{array}$ & 60 & Primus \\
\hline
\end{tabular}

Table 1 shows the study characteristics of the included studies. N: number. BMI: body mass index measured in $\mathrm{kg} / \mathrm{m}^{2}$. Pros Cohort: prospective cohort study. RCT: randomized clinical trial. Nm: newton meter, Ft.lbs: foot pounds. B: baseline. m: months. w: weeks. y: years * Measurement not included in analysis.

\section{Risk of bias within studies}

The findings of our check on the risk of bias within the studies are presented in table 2.

All studies adequately described their study design, inclusion and exclusion criteria, measurement method used, and characteristics and follow-up of study participants. However, only five studies clearly described the setting in which they were performed, one study did not mention how patients were recruited, and only three studies described how missing values were handled. Seven studies reported the actual number of missing values. 


\begin{tabular}{|c|c|c|c|c|c|c|c|c|c|c|}
\hline & $\begin{array}{l}\text { ธ్ర్ } \\
\text { ปั }\end{array}$ & 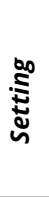 & & 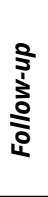 & 吝 & 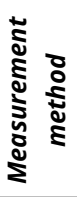 & 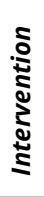 & 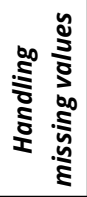 & 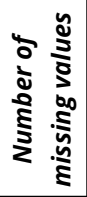 & 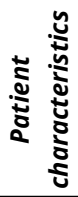 \\
\hline Berghmans [10] & $\mathrm{V}$ & $\mathrm{V}$ & $\mathrm{V}$ & $\mathrm{V}$ & $\mathrm{V}$ & V & $x$ & V & V & V \\
\hline Braito[19] & V & $x$ & V & V & V & V & V & $x$ & $x$ & V \\
\hline Chang [20] & V & $x$ & V & V & $\mathrm{V}$ & V & V & V & V & V \\
\hline Lorentzen[21] & V & $\mathrm{V}$ & V & V & V & V & $x$ & $x$ & $x$ & V \\
\hline Chung [22] & V & $x$ & V & V & V & V & V & $x$ & $x$ & V \\
\hline Genet [23] & V & $\mathrm{V}$ & V & V & V & V & $x$ & $x$ & V & V \\
\hline Kim [24] & V & V & V & V & V & V & V & $x$ & V & V \\
\hline Liebensteiner [25] & V & $x$ & V & V & V & V & V & V & V & V \\
\hline Rossi [26] & V & V & V & V & V & V & V & $x$ & $x$ & V \\
\hline Schroer[27] & V & $x$ & $x$ & V & $\mathrm{V}$ & V & $x$ & $x$ & $\mathrm{~V}$ & $\mathrm{~V}$ \\
\hline
\end{tabular}

Table 2 shows the risk of bias within the studies, based on a checklist (Appendix 1) which checks if the following conditions are adequately described. Design; Setting of patient inclusion and measurement; Recruitment of patients; Follow- up time points; inclusion and exclusion Criteria; Measurement method; Intervention applied in the study; method of Handling missing values; actual Number of missing values; Patient characteristics.

V: Available. X: Missing.

Six studies investigated the influence of different surgical interventions on the strength outcomes. Braito et al.[19] focused on unicondylar knee arthroplasty versus minimally invasive TKA. Chung et al.[22] compared bi-compartmental knee arthroplasty and TKA. Only the data of patients treated with TKA from these two studies were included in our review. Chang et al.[20] compared the effects of the subvastus and parapatellar surgical techniques. Liebensteiner et al.[25] and Kim et al.[24] investigated the differences between minimally invasive and standard surgical techniques on strength outcomes. Since we had not formulated any restrictions regarding surgical technique, all subgroups were included. Rossi et al.[26] investigated the strength response in a cohort during an 8-week resistive training after unilateral TKA. Since the details of the rehabilitation differed among the articles, and were not always specifically described, all patients of the study by Rossi et al.[26] were included.

The studies took place in the United States of America, [26, 27] Europe [10, 19, 21, 23, 25] and Asia. [20, 22, 24]

\section{Outcome measures}

\section{Quadriceps strength}

Quadriceps strength was described in all ten studies. As expected, an inverse relationship was found between speed and strength (table 3). Studies reporting assessments at 6 weeks and 2 months after surgery describe an initial dip in muscle strength post-surgery, followed by increasing strength. The results of studies having 


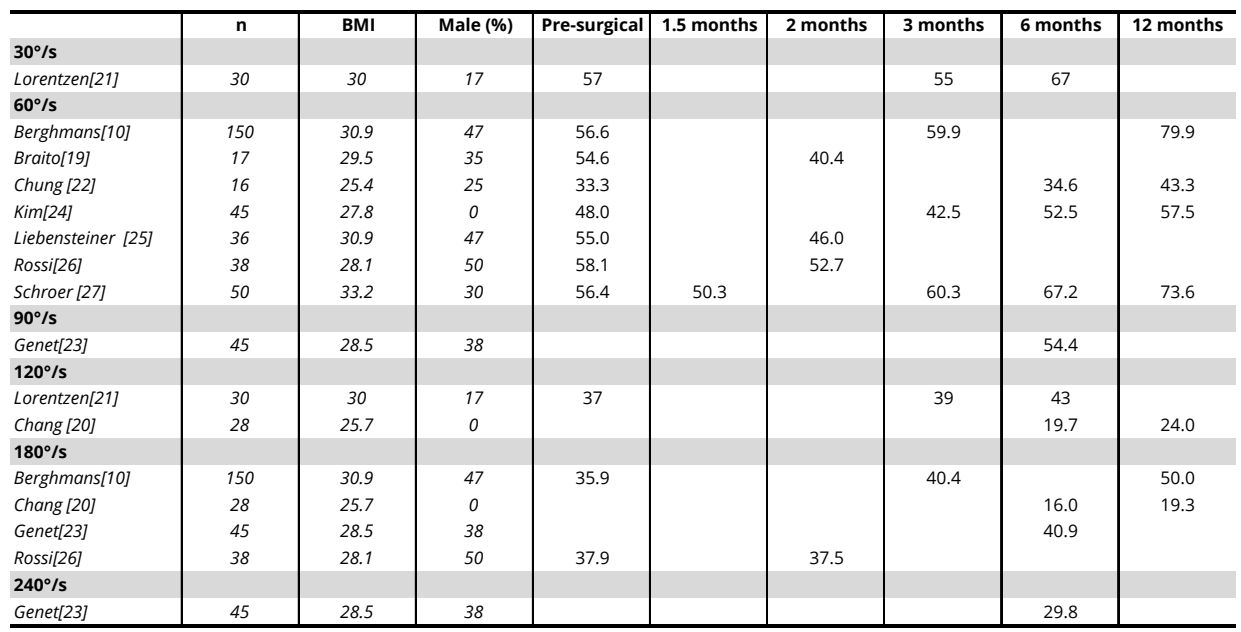

Table 3 shows the absolute isokinetic quadriceps strength values from each individual study at their specific measurement points. n: sample size. BMI: body mass index. Male: \% of men in the study sample. Nm: newton meter.

the first post-surgical measurement 3 months after surgery are inconsistent, with some already reporting strengths above pre-surgical values, while others report strengths below the baseline value.

The majority of the studies (seven out of ten) measured the isokinetic strength at a speed of $60 \% \mathrm{sec}$. All of these studies started with a baseline measurement. The timing of follow-up measurements after surgery varied. The data is presented in figure 2. This figure shows the same type of development as described above, with studies whose first post-surgical measurement took place after 6 weeks or 2 months

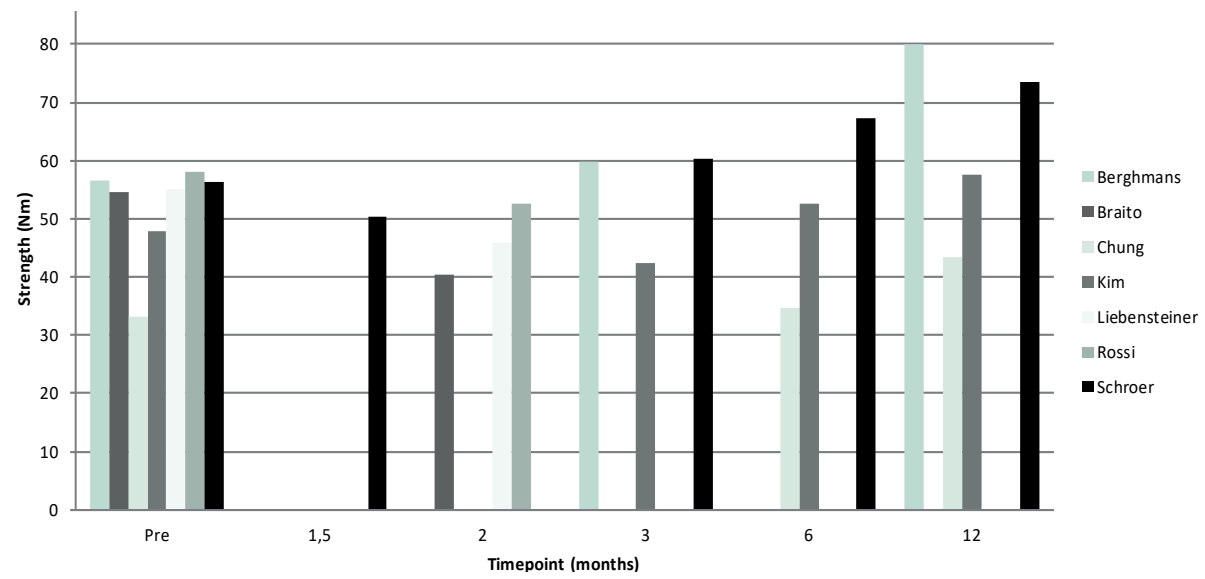

Figure 2 shows the development of $60 \% \mathrm{sec}$ isokinetic quadriceps strength in the first year as reported in the various studies. The exact values reported are given in table 3. 
reporting a post-surgical decrease, followed by an increase. One study whose first measurement took place 3 months after surgery described strengths above presurgical values, while another reported strengths below baseline values. Six months after surgery, all studies reported strengths above pre-surgical values.

\section{Men and women}

Since sex-specific results were presented only by Berghmans et al.[10] and Schroer et al.[27] (for their one-year measurement), table 4 shows sex-specific strength values for each time point from these two studies. Men had higher quadriceps strength than women at all time points and at both isokinetic angular speeds. However, the two studies differed greatly as regards sex-specific values. Schroer et al.[27] reported $12 \%$ higher values for men, while Berghmans et al.[10] reported men being $47 \%$ $(60 \% \mathrm{sec})$ and $62 \%(180 \% \mathrm{sec})$ stronger.

\section{Hamstring strength}

Hamstring strength was investigated in eight of the ten studies, resulting in the

\begin{tabular}{l|cc|cc|cc|cc}
\hline & \multicolumn{3}{|c|}{} & \multicolumn{2}{|c|}{ Pre-surgical } & \multicolumn{2}{c|}{ 3 months } & \multicolumn{2}{c}{ 12 months } \\
& $\mathbf{n}$ (\%male) & & Women & Men & Women & Men & Women & Men \\
\hline Berghmans et al. [10] & $150(47)$ & $60 \% \mathrm{sec}$ & 43.4 & 67.9 & 46.1 & 73.3 & 64.5 & 95.2 \\
& $150(47)$ & $180 \% \mathrm{sec}$ & 29.2 & 43.4 & 30.0 & 50.5 & 38.2 & 61.8 \\
\hline Schroer et al.[27] & $47(30)$ & $60 \% \mathrm{sec}$ & & & & & 70.6 & 79.3 \\
\hline
\end{tabular}

Table 4 shows the specific quadriceps strengths of men and women. Berghmans et al.[10] presented results for all time points, while Schroer et al.[27] only presented findings after one year. n: number of patients.

\begin{tabular}{|c|c|c|c|c|c|c|c|c|c|}
\hline Author & $\mathrm{n}$ & BMI & Male (\%) & \begin{tabular}{|l|} 
Pre-surgical \\
\end{tabular} & 1.5 months & 2 months & 3 months & 6 months & 12 months \\
\hline \multicolumn{10}{|l|}{$30 \% / \mathrm{s}$} \\
\hline Lorentzen[21] & 30 & 30 & 17 & 30 & & & 33 & 39 & \\
\hline \multicolumn{10}{|l|}{$60 \% / \mathrm{s}$} \\
\hline Berghmans[10] & 150 & 30.9 & 47 & 40.3 & & & 52.9 & & 63.9 \\
\hline Chung [22] & 16 & 25.4 & 25 & 15.9 & & & & 19.0 & 20.3 \\
\hline $\operatorname{Kim}[24]$ & 45 & 27.8 & 0 & 30.1 & & & 27.5 & 30.5 & 33.0 \\
\hline Liebensteiner [25] & 36 & 30.9 & 47 & 38.5 & & 31.0 & & & \\
\hline Schroer [27] & 50 & 33.2 & 30 & 42.3 & 40.8 & & 46.8 & 53.6 & 57.6 \\
\hline \multicolumn{10}{|l|}{$90 \% / \mathrm{s}$} \\
\hline Genet[23] & 45 & 28.5 & 38 & & & & & 37.6 & \\
\hline \multicolumn{10}{|l|}{$120 \% / \mathrm{s}$} \\
\hline Lorentzen[21] & 30 & 30 & 17 & 17 & & & 21 & 26 & \\
\hline Chang [20] & 28 & 25.7 & 0 & & & & & 14.9 & 37.6 \\
\hline \multicolumn{10}{|l|}{$180 \% / \mathrm{s}$} \\
\hline Berghmans[10] & 150 & 30.9 & 47 & 30.8 & & & 37.2 & & 43.8 \\
\hline Chang [20] & 28 & 25.7 & 0 & & & & & 12.6 & 15.4 \\
\hline Genet[23] & 45 & 28.5 & 38 & & & & & 27.8 & \\
\hline \multicolumn{10}{|l|}{$240 \% / \mathrm{s}$} \\
\hline Genet[23] & 45 & 28.5 & 38 & & & & & 18.4 & \\
\hline
\end{tabular}

Table 5 shows the absolute isokinetic hamstring strength values from each individual study at their specific measurement points. $\mathrm{n}$ : sample size. BMI: body mass index. Male: \% of men in the study sample. Nm: newton meter. 
same inverse relationship between isokinetic speed and strength. The same strength development is seen, with studies having their first post-surgical measurement after 6 weeks or 2 months reporting a decrease in hamstring strength. All but one of the studies having the first post-surgical measurement after 3 months reported hamstring strength above pre-surgical values (table 5).

Like the quadriceps assessments, most studies performed the hamstring measurements at an isokinetic speed of $60 \% \mathrm{sec}$. Five studies started the hamstring strength assessment with a baseline measurement and measured it again postsurgically. The variance in follow-up points is shown in table 5. Figure 3 presents the data in visual form. Just as with quadriceps strength, hamstring strength decreases after TKA surgery, as was seen in the two studies presenting measurements 6 weeks or 2 months after surgery. The study by Berghmans et al.,[10] with its first measurement 3 months after surgery, also reported hamstring strengths above baseline values, while the study by Kim et al.[24] reported hamstring strengths below pre-surgical values. After 6 months, all studies reported values above pre-surgical measurements.

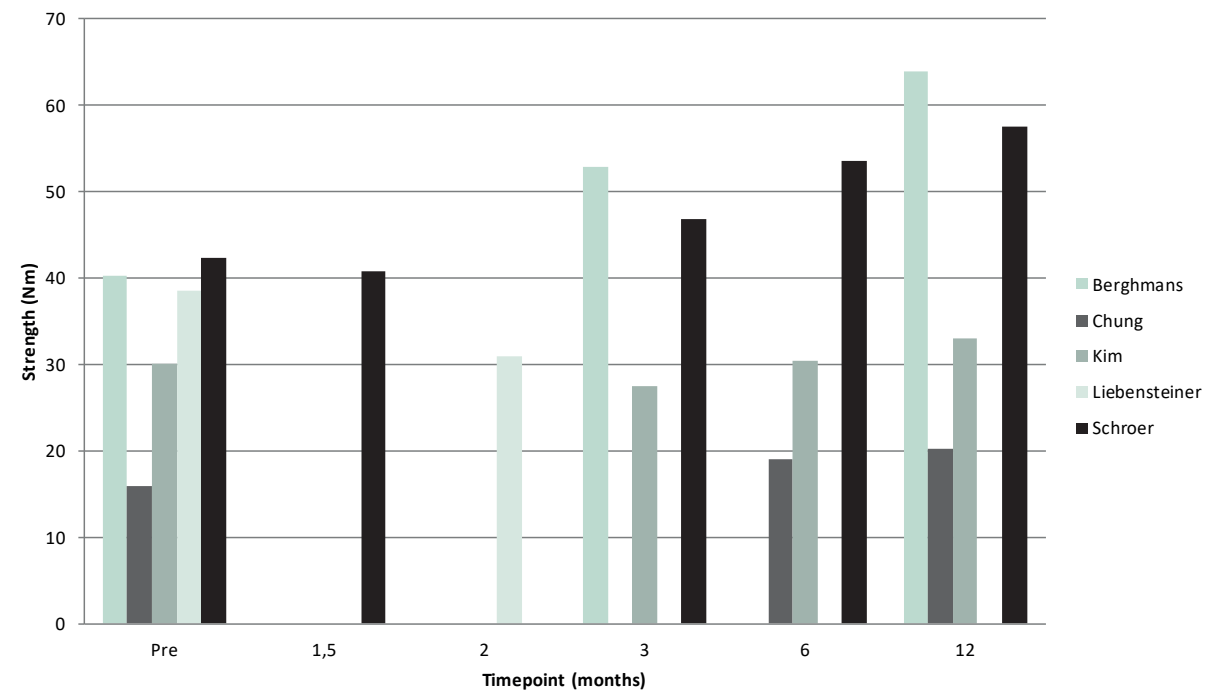

Figure 3 shows the development of $60 \% \mathrm{sec}$ isokinetic hamstring strength in the first year as reported in the various studies. The exact values are given in table 5. 


\section{Men and women}

Only Berghmans et al.[10] presented sex-specific isokinetic hamstring results. Table 6 shows the difference in strength between the two sexes, with men having higher values at all time points at two isokinetic angular speeds. At one year after surgery, the men were $53 \%(60 \% \mathrm{sec})$ and $63 \%(180 \% \mathrm{sec})$ stronger than the women.

\begin{tabular}{|c|c|c|c|c|c|c|c|c|}
\hline \multirow{4}{*}{ Berghmans et al.[10] } & \multirow[b]{2}{*}{ n (\%male) } & \multirow[b]{3}{*}{$60 \% \mathrm{sec}$} & \multicolumn{2}{|c|}{ Pre-surgical } & \multicolumn{2}{|c|}{3 months } & \multicolumn{2}{|c|}{12 months } \\
\hline & & & Women & Men & Women & Men & Women & Men \\
\hline & $150(47)$ & & 33.3 & 48.0 & 39.8 & 65.6 & 50.7 & 77.2 \\
\hline & $150(47)$ & $180^{\circ} / \mathrm{sec}$ & 24.4 & 37.8 & 27.1 & 47.1 & 33.3 & 54.4 \\
\hline
\end{tabular}

Table 6 shows the specific hamstring strength of men and women. n: number of patients.

\section{DISCUSSION}

\section{Summary of main results}

The first objective of this review was to give an overview of isokinetic quadriceps and hamstring strength development during the first year after a TKA. We selected ten studies, all of which measured isokinetic strength at some rotational speed and at some time point during the first year after TKA surgery. Studies with a measurement 6 weeks or 2 months after TKA surgery reported decreased values of both quadriceps and hamstring strength. Studies with their (first) measurement 3 months after surgery reported a variety of values relative to pre-surgical measurements. Six months after TKA surgery, all studies found strengths above pre-surgical values. One possible cause of the variance in findings after 3 months could be the study samples, since Lorentzen et al.[21] included 83\% women and Kim et al.[24] even 100\% women, whereas Berghmans et al.[10] used a more balanced sample. Greene et al. described that women typically undergo TKA at a more advanced OA stage, have reduced muscle activation, are more adversely affected by the effects of OA and suffer more severe weakness after an immobilization period.[7] A second cause could be a difference in rehabilitation protocols. Rossi et al.[26] described post-surgical therapy, and in the study by Berghmans et al.[10] almost all patients received standard physical therapy after TKA surgery, since this is usual care in the Netherlands.[28] Both studies reported high post-surgical values: Rossi et al.[26] reported nearly pre-surgical values after 2 months and Berghmans et al.[10] found strengths above baseline values after 3 months.

Our results are in line with those reported in previous reviews. The main difference with the review by Schache et al.[8] is that they used a wider time frame, but less isokinetic data for the period up to one year $(n=45)$. Also, the amount of data on which our review was based was much larger, since the total included sample in our study was 455 patients for the first year, with multiple measurements at different 
time points. The review by Moon et al.[9] also included fewer patients ( $n=274)$. The findings of their review showed that it took patients 6 months to exceed pre-surgical values, and no significant strength change was seen in the first year after TKA surgery. The difference with the findings of our present review could have been caused by differences between the included studies in rehabilitation protocols or usual care regarding physical therapy.

Despite the fact that the included studies reported the same type of isokinetic strength development during the first year after TKA surgery, the absolute values they present varied substantially. In view of this high variance in absolute values, which was due to the heterogeneity of the studies, as well as the large difference in number and the chosen follow-up points, we could not justify pooling the data and calculating norm values. Thus, we were not able to meet our second objective, to present norm values. The first problem, and biggest drawback, is that most of the studies described the mean strength values based on the total sample, and did not present sex-specific results. Only the results of our own cohort study[10] and the one-year results reported by Schroer et al.[29] were presented for men and women separately. The studies by Kim et al.[24] and Chung et al.[22] included only women. As expected, and as shown by our sex-specific findings, women's strength is lower at all time points and at all isokinetic angular speeds; this explains the lower values reported in both studies [22, 24] (see tables 3 and 5, figures 2 and 3). However, the exact difference between both the two sexes is unknown, as is shown by the large difference between the study by Schroer et al.,[29] who reported a 12\% difference between men and women, and that by Berghmans et al.,[10] who reported a difference of almost 50\% at the same angular speed one year after TKA. Therefore, presenting results of both sexes together increases the variance in the results.

The second source of variance could be the differences in rehabilitation protocols and usual care between the different settings and countries. In the study by Berghmans et al.,[10] which was performed in the Netherlands, all patients received standardized protocol-based physical therapy after TKA surgery, if necessary for up to one year after surgery.[28] Of the others, only Rossi et al.[26] described their rehabilitation protocol in detail. Together, these two studies concerned $41 \%$ of the total study sample in the present review, and both of these studies reported higher post-surgical values than the other eight studies. It is important to notice that the presurgical values are more comparable between all studies, which clearly suggests the effect of post-surgical physical therapy on the increase in muscle strength.

Another reason for the impossibility to generate norm values is the limited number of studies. Several reasons for this can be postulated. Firstly, reporting the current status of the muscle strength of TKA patients is often not the main aim of studies. Even in the literature which we included, isokinetic strength measurements were often a secondary outcome measure. Secondly, there is a lack of uniformity with regard to strength measurements: studies use a variety of methods, varying from a measurement scale (0-5) to hand-held devices or fixed electronic isometric 
measurements. Comparing strength values collected with different methods would give biased results. Uniformity in strength measurement would be valuable in the muscle strength research, but isokinetic strength measurement instruments like the Biodex are expensive and therefore very difficult to apply in everyday practice. Nevertheless, since strength is seen as an important factor in the contemporary literature, [6-9, 28, 30, 31] and we believe that more knowledge about the development of strength in the first year after a TKA would be helpful, more studies investigating isokinetic strength after TKA are needed.

\section{Limitations}

The first limitation of this review is selection bias, since we only selected studies using the gold standard for measuring isokinetic strength (a fixed electronic dynamometer).

Secondly, the large degree of heterogeneity of the included studies did not allow us to pool the data and to generate norm values.

What we were able to do, however, is to reveal knowledge gaps in the available literature, which provides direction for further research. Firstly, only a small number of studies have investigated isokinetic strength. Secondly, the large majority of patients in the combined study sample in this review were women, and since women's strength is generally lower than men's, we assume that the values in our tables are an underestimation compared to a more balanced population sample, so future studies should include a more gender-balanced sample. In addition, more studies are needed providing serial investigations of isokinetic strength after TKA surgery, to improve our knowledge and to generate norm values for isokinetic strength.

\section{Conclusions}

Despite the importance of strength in the daily lives of TKA patients, we noted a gap in the findings of existing studies regarding isokinetic quadriceps and hamstring strength. We can conclude from the existing literature that after an initial decrease in quadriceps and hamstring strength immediately after surgery, strength values increase and come to exceed pre-surgical values 2 to 5 months after surgery. This moment could perhaps be influenced by the amount and content of therapy. In the later stages of recovery, strength increases further, with the greater overall improvement in quadriceps strength than in hamstring strength. Most striking is the large differences between the studies regarding the absolute values they report, which at this moment makes it impossible to pool the data and generate norm values. 


\section{REFERENCES}

1. Priority Medicines for Europe and the World 2013 Update [http://www. who.int/medicines/areas/priority_medicines/Ch6_12Osteo.pdf]

2. Welke aandoeningen hebben we in de toekomst? [https://www.vtv2018. nl/aandoeningen]

3. Chronic rheumatic conditions [http://www.who.int/chp/topics/rheumatic/ en/]

4. Beers MH, Berkow R: The Merck Manual, vol. 2: Bohn Stafleu Van Loghum; 2003.

5. Kennedy DM, Stratford PW, Riddle DL, Hanna SE, Gollish JD: Assessing recovery and establishing prognosis following total knee arthroplasty. Phys Ther 2008, 88(1):22-32.

6. Meier W, Mizner R, Marcus R, Dibble L, Peters C, Lastayo PC: Total knee arthroplasty: muscle impairments, functional limitations, and recommended rehabilitation approaches. J Orthop Sports Phys Ther 2008, 38(5):246-256.

7. Greene KA, Schurman JR, 2nd: Quadriceps muscle function in primary total knee arthroplasty. J Arthroplasty 2008, 23(7 Suppl):15-19.

8. Schache MB, McClelland JA, Webster KE: Lower limb strength following total knee arthroplasty: a systematic review. Knee 2014, 21(1):12-20.

9. Moon Y-W, Kim H-J, Ahn H-S, Lee D-H: Serial changes of quadriceps and hamstring muscle strength following total knee arthroplasty: a metaanalysis. PloS one 2016, 11(2):e0148193.

10. Berghmans DD, Lenssen AF, Emans PJ, De Bie RA: Functions, disabilities and perceived health in the first year after total knee arthroplasty; a prospective cohort study. BMC Musculoskelet Disord 2018, 19(250).

11. Lauermann SP, Lienhard K, Item-Glatthorn JF, Casartelli NC, Maffiuletti NA: Assessment of quadriceps muscle weakness in patients after total knee arthroplasty and total hip arthroplasty: methodological issues. J Electromyogr Kinesiol 2014, 24(2):285-291.

12. Van Egmond JC, Verburg H, Mathijssen NM: The first 6 weeks of recovery after total knee arthroplasty with fast track: A diary study of 30 patients. Acta orthop 2015, 86(6):708-713.

13. Moher D, Liberati A, Tetzlaff J, Altman DG, Group P: Preferred reporting items for systematic reviews and meta-analyses: the PRISMA statement. PLoS Med 2009, 6(7):e1000097.

14. Von Elm E, Altman DG, Egger M, Pocock SJ, Gøtzsche PC, Vandenbroucke $J P$, Initiative S: The Strengthening the Reporting of Observational Studies in Epidemiology (STROBE) Statement: guidelines for reporting observational studies. Int J Surg 2014, 12(12):1495-1499.

15. Topp R, Swank AM, Quesada PM, Nyland J, Malkani A: The effect of prehabilitation exercise on strength and functioning after total knee 
arthroplasty. PM R 2009, 1(8):729-735.

16. Lauermann SP, Lienhard K, Item-Glatthorn J, Casartelli NC, Maffiuletti NA: Assessment of quadriceps muscle weakness in patients after total knee arthroplasty and total hip arthroplasty: methodological issues. J Electromyogr Kinesiol 2014, 24(2):285-291.

17. Umrani SP, Cho K-Y, Kim K-I: Patellar eversion does not adversely affect quadriceps recovery following total knee arthroplasty. J Arthroplasty 2013, 28(4):591-594.

18. Berman AT, Bosacco SJ, Israelite C: Evaluation of total knee arthroplasty using isokinetic testing. Clin Orthop Relat Res 1991(271):106-113.

19. Braito M, Giesinger JM, Fischler S, Koller A, Niederseer D, Liebensteiner MC: Knee Extensor Strength and Gait Characteristics After Minimally Invasive Unicondylar Knee Arthroplasty vs Minimally Invasive Total Knee Arthroplasty: A Nonrandomized Controlled Trial. J Arthroplasty 2016, 31(8):1711-1716.

20. Chang $\mathrm{CH}$, Chen $\mathrm{KH}$, Yang RS, Liu TK: Muscle torques in total knee arthroplasty with subvastus and parapatellar approaches. Clin Orthop Relat Res 2002(398):189-195.

21. Lorentzen JS, Petersen MM, Brot C, Madsen OR: Early changes in muscle strength after total knee arthroplasty: a 6-month follow-up of 30 knees. Acta Orthop Scand 1999, 70(2):176-179.

22. Chung JY, Min BH: Is bicompartmental knee arthroplasty more favourable to knee muscle strength and physical performance compared to total knee arthroplasty? Knee Surg Sports Traumatol Arthrosc 2013, 21(11):25322541.

23. Genet F, Schnitzler A, Lapeyre E, Roche N, Autret K, Fermanian C, Poiraudeau S: Change of impairment, disability and patient satisfaction after total knee arthroplasty in secondary care practice. Ann Readapt Med Phys 2008, 51(8):671-676, 676-682.

24. Kim JG, Lee SW, Ha JK, Choi HJ, Yang SJ, Lee MY: The effectiveness of minimally invasive total knee arthroplasty to preserve quadriceps strength: a randomized controlled trial. Knee 2011, 18(6):443-447.

25. Liebensteiner MC, Krismer M, Koller A, Semenitz B, Mayr E: Does minimally invasive total knee arthroplasty improve isokinetic torque? Clin Orthop Relat Res 2012, 470(11):3233-3239.

26. Rossi MD, Brown LE, Whitehurst M: Early strength response of the knee extensors during eight weeks of resistive training after unilateral total knee arthroplasty. J Strength Cond Res 2005, 19(4):944-949.

27. Schroer WC, Diesfeld PJ, Reedy ME, LeMarr AR: Isokinetic strength testing of minimally invasive total knee arthroplasty recovery. J Arthroplasty 2010, 25(2):274-279.

28. KNGF-richtlijn Artrose heup-knie [https://www.fysionet-evidencebased. 
nl/images/pdfs/richtlijnen/artrose_heup_knie_2018/artrose_heup-knie_ verantwoording_2018.pdf]

29. Schroer WC, Diesfeld PJ, Reedy ME, LeMarr AR: Isokinetic strength testing of minimally invasive total knee arthroplasty recovery. J Arthroplasty 2009, 25(2):274-279.

30. Mistry JB, Elmallah RD, Bhave A, Chughtai M, Cherian JJ, McGinn T, Harwin SF, Mont MA: Rehabilitative guidelines after total knee arthroplasty: a review. J Knee Surg 2016, 29(03):201-217.

31. Pozzi F, Snyder-Mackler L, Zeni J: Physical exercise after knee arthroplasty: a systematic review of controlled trials. Eur J Phys Rehabil Med 2013, 49(6):877. 


\section{APPENDIX}

Appendix 1. Quality criteria based on STROBE Statement.

1. Is the study design described? What is the design?

2. Is the setting described? What is the setting?

3. Is the period of recruitment described? How did they recruite patients?

4. Is the follow-up described? How long was the follow-up period?

5. Are the inclusion and exclusion criteria clearly described? What are the criteria?

6. Is the measurement method clearly described? How did they measure the primary outcome?

7. Was there an intervention? What was the intervention?

8. Did they describe how they handled missing values? How did they handle missing values?

9. Are missing values described? What is the percentage missing values?

10. Did they describe patient characteristics? What were the patient characteristics? 



\title{
CHAPTER SIX.
}

\author{
A PROGRESSIVE STRENGTH TRAINING \\ PROGRAM STARTING 3 MONTHS POST TKA \\ SURGERY IMPROVES STRENGTH BUT NOT \\ FUNCTIONAL OUTCOME
}

Danielle D.P. Berghmans

Antoine F. Lenssen

Pieter J. Emans

Rob A. de Bie

\section{Published}

BERGHMANS, D. D. P., et al. A Progressive Strength Training Program Starting 3 Months Post Total Knee Arthroplasty Surgery Improves Strength but Not Functional Outcome. J Orthop Ther: JORT-1118. DOI, 2018, 10: 2575- 


\section{ABSTRACT}

\section{Background}

Decreased quadriceps and hamstring strength is common even one year after a total knee arthroplasty. Hence, patients with persistent functional complaints treated at the Maastricht University Medical Centre (MUMC+) received a progressive strength training program.

\section{Objectives}

The aim of this study was to investigate the impact of the progressive strength training program on quadriceps and hamstring strength.

\section{Methods}

Patients were referred to the outpatient physical therapy department of MUMC+ and received a 6-week progressive strength training program. Their isokinetic quadriceps and hamstring strength and functional ability were assessed before and after the program.

\section{Results}

Men significantly improved in terms of all strength parameters assessed at an angular velocity of $60 \% \mathrm{sec}$ and $180 \% \mathrm{sec}$. Women only improved their quadriceps strength at $180^{\circ} / \mathrm{sec}$. No significant improvement at functional level was seen.

\section{Conclusion}

A 6-week progressive strength training program has a positive impact on the isokinetic quadriceps and hamstring strength in both men and women, but not on functional ability. 


\section{INTRODUCTION}

A total knee arthroplasty (TKA) generally reduces pain and restores range of motion in patients with end-stage osteoarthritis (OA) of the knee. This is important as an increase in the incidence of knee $\mathrm{OA}$ is expected in the next years due to an ageing population and a trend toward obesity.[1, 2] Notwithstanding these generally positive results, however, quadriceps and hamstring strengths remain lower than those of healthy controls, even one year after TKA.[3-8] Decreased quadriceps and hamstring strength negatively influences knee stability, increasing the risk of falls and generating a feeling of uncertainty in patients.[9] Additionally, activities like rising from a chair, standing, walking and climbing stairs become more difficult, which leads to a loss of independency.[9-15]

A number of explanations can be given for this decreased strength. Firstly, pain-induced disuse in the pre-surgical phase changes activity patterns and reduces strength.[16] Secondly, the bio-kinematics change due to the surgical procedure, the possible resurfacing of the patella and the removal of the cruciate ligaments. $[6,7,14]$ Thirdly, proprioception is changed as a result of the surgery as such (removal of the tibia and femur ends, removal of the cruciate ligament, cleaving of the joint capsule, and the ingrowth of scar tissue).[6, 7, 14] And finally, it can result from possibly inadequate post-surgical therapy. Comparison and investigation of the therapeutic validity of the post-surgical therapy after TKA is difficult because of the considerable diversity in the amount and intensity of therapy applied worldwide, as well as because of the lack of accurate descriptions of the therapy provided.[17,18] Two systematic reviews, by Pozzi et al.(2013)[19] and Skoffer et al.(2015)[16], were unable to draw unambiguous conclusions on the effect of progressive strength training on the muscle strength of patients after TKA, based on the results of three (methodologically low-rated) randomized clinical trials (RCTs). However, the studies by Petterson et al.(2009)[20], Petterson et al.(2011) [21] and Johnson et al.(2010)[22] all showed a significant improvement in isometric quadriceps strength.

In addition to the two reviews based on RCTs, there have been three pilot studies in recent years. A pilot study by Jakobsen et al.[23] in 2012 found an improvement in isometric quadriceps strength after a two-week, thrice a week, progressive strength training program in 14 patients. They started within 2 days after surgery with leg press and knee-extension exercises at a training intensity of around $80 \%$ of one repetition maximum ( $1 \mathrm{RM}$ ) and performed $2 * 10$ repetitions. Combined with gait training, range of motion exercises, functional activities, balance training and stretching, one session lasted 60 minutes. However, an RCT by Jakobsen et al.[24] in 2014 did not find a significant difference in quadriceps strength 8 weeks after TKA, compared with presurgical values after a 7-week, twice a week, progressive strength training program, and compared with a therapy without strength training. They started between days 6 and 8 after surgery and performed $2 * 12$ repetitions; the exact intensity was not reported, although the authors stated that they had adjusted the load in accordance with the repetitions at each session. Each session lasted 60 minutes, but the strengthening 
part was only 15 minutes. Husby et al.[9] performed an RCT in which they compared a maximal strength training program with standard rehabilitation. Their program had a higher intensity (80-90\% of 1RM) and fewer repetitions (4-5 repetitions). They were able to find a significant improvement in quadriceps strength after an 8-week, thrice a week program, starting on day 8 after surgery. The total duration of a session was 30 minutes. Both Petterson et al.[20] and Johnson et al.[22] found an improvement in functional ability after a strength training program, after 12 months and 4 weeks, respectively. This is in contrast with Husby et al.,[9] who found no improvement in functional ability after their strength training program.

The main differences with the program offered in our study is that we started between 3 and 18 months after surgery, in those patients who had remained significantly hampered by a strength deficit. Therapy was initiated when they expressed complaints at a follow-up visit to their orthopaedic surgeon. A second difference is the strength measurement, as we tested isokinetic strength. According to Lauermann et al.,[25] isokinetic and isometric strength improvements should not be mixed, as percentages of muscle weakness based on these measurements differ between the two methods, when compared with controls. Presenting baseline and change values in isokinetic strength after TKA and after a progressive strength training program is therefore useful to understand isokinetic strength development and to enable comparison of therapies. In addition, greater insight into the impact of a progressive strength training program on the quadriceps and hamstring strength is useful in the investigation of the therapeutic validity of post-TKA therapy. $[2,16,26]$ This was also noted by Bandholm et al.,[27] who stated that the 'pill' of physical therapy may not contain the right stimulus or may not be given at the right moment. Hence, the main aim of our study was to examine the impact of 6-week progressive strength training program, described in detail and starting at least 3 months after TKA surgery as part of usual care in the MUMC+, on quadriceps and hamstring muscle strength and functional ability of patients after a TKA.

\section{METHODS}

\section{Design}

Patients with complaints after receiving a TKA at MUMC+, who were not receiving physical therapy at that moment, were referred to the hospital's outpatient department for physical therapy. They were offered a 6-week progressive strength training program.

\section{Population}

Patients were enrolled during regular follow-up appointments with their orthopaedic surgeon at the knee outpatient clinic at the MUMC+ Department of Orthopaedic Surgery. 
Patients were eligible to participate if they met the following inclusion criteria: having undergone primary TKA at the MUMC+ at least 3 months ago, age $<80$ years, subjectively reported complaints regarding physical functioning, and no simultaneous outpatient physical therapy. Patients with a limited cognitive function or with limited command of Dutch which interfered with filling out questionnaires, or who were unable to follow instructions, were excluded.

Patients eligible for training were referred to the MUMC+ outpatient physical therapy department by their attending surgeon. The baseline maximal isokinetic quadriceps and hamstring strengths of their affected leg were measured with a Biodex System Pro 3 dynamometer (Biodex Medical Systems, Shirley, NY, USA), by an experienced physical therapist. Values were compared with normative values from healthy controls $(n=295)$. The normative values were calculated using equations obtained in a previous study.[8] The normative values are given in table 1. Patients with inadequate strength were informed about the MUMC+ physical therapy program, a 6-week progressive strength training program.

This retrospective study investigated the data of twelve patients who attended the therapy at MUMC+ after a TKA, and was approved by the regional ethics committee (METC 2018-0519). It was performed in accordance with the Declaration of Helsinki. Since patients were treated with usual care, no written informed consent was obtained, but all patients were able to object to the use of their data in scientific publications. None of these twelve patients did. All patients agreed with physical therapy at MUMC+ and were able to withdraw from physical therapy treatment at any moment.

\section{Surgery}

Surgeries were performed by two orthopedic surgeons, both with extensive experience with the prosthesis. All patients received a cemented Scorpio NRG® prosthesis (Stryker, Kalamazoo, Michigan, USA) or an Attune ${ }^{\circledR}$ Knee System (DePuy Synthes, Raynham, Massachusetts, USA). After a medial parapatellar approach, the surgeons used a bony referenced, tibia first technique. A cemented patella component was used in all patients, and a tourniquet was only used during the cementation period of the prosthesis.

\section{Demographics}

Relevant demographic characteristics, including age (years), sex (M/F), height (m), weight $(\mathrm{kg})$, body mass index (BMI) in $\mathrm{kg} / \mathrm{m}^{2}$, side of TKA $(\mathrm{R} / \mathrm{L})$ and time since TKA surgery (months) were obtained during the baseline measurement.

\section{Measurements}

Muscle strength and functional ability were both assessed before and after the 6-week progressive strength training program, by an experienced physical therapist. 


\section{Muscle strength}

The maximal isokinetic quadriceps and hamstrings strength, in Newton meter $(\mathrm{Nm})$, was measured with the Biodex System Pro 3 dynamometer (Biodex Medical Systems, Shirley, NY, USA) at angular velocities of $60 \% / \mathrm{sec}$ (5 repetitions) and $180 \% \mathrm{sec}$ (10 repetitions). The Biodex is a reliable and valid measurement instrument and is the gold standard for measuring maximal isokinetic strength up to angular velocities of $300 \% \mathrm{sec}$.[28] Measuring isokinetic strength was preferred to isometric strength measurements: Lauermann et al.[25]. reported that since the percentage of patients diagnosed with muscle weakness was higher when calculated on the basis of isometric muscle strength measurements than with isokinetic strength measurements, the isometric strength difference could be an overestimation of the muscle weakness and could underestimate the effect of an intervention.[29]

\section{Functional ability}

Functional ability was assessed with the Western Ontario and McMaster Universities Osteoarthritis Index (WOMAC). This self-administered disease-specific health questionnaire has been designed to measure the functional ability of the osteoarthritic knee before and after TKA surgery.[30, 31] The WOMAC provides aggregate scores for each of 3 subscales: joint pain, joint stiffness and functional ability. Together, they yield the WOMAC sum score. The 5-point Likert version of the WOMAC was used in our study, with a scale ranging from 0 to 96 points ( 0 indicating no pain or dysfunction). Afterwards the scores were standardized to a 0-100 scale, with 100 indicating no pain or dysfunction. The WOMAC is a responsive instrument that yields reliable and valid measurements in a population of patients with knee OA and after a TKA, and has been used extensively to evaluate this patient population.[30-34]

\section{Physical training program}

During the 6-week strength training program, patients had two sessions a week (total of 12 session), with at least 48 hours between two individual training sessions. Each session lasted 45 minutes and started with a warm-up cycle ergometer session (5 minutes, at a self-chosen comfortable wattage) and cool-down walking on a treadmill (5-10 minutes, at a self-chosen comfortable speed). Before the start of the strength training program, an X-Repetition Maximum (XRM) assessment of all individual exercises was performed to test individual strength. Thereafter, the Oddvar Holten diagram [35] was used to calculate the 1RM from the XRM [36]. The XRM is a frequently used alternative to calculate the $1 \mathrm{RM}$, because the $1 \mathrm{RM}$ is often not feasible [37]. The resulting 1RM was used to design an individual progressive strength training program, according to the American College of Sports Medicine guidelines, starting at $60 \%$ of the 1 RM. $[16,38]$

All patients received an individual training protocol, with prescriptions for resistance, as well as the number of repetitions (8-15) and sets (3-4). The patients were instructed to take a pause of 60 seconds between sets. The total workload was 
adjusted at each session, by raising the resistance and the number of repetitions or sets according to the personal rating on the Borg Rating of Perceived Exertion Score (Scale 0-10).[39] If patients rated their exertion as 'tolerable' (Borg 0-4), weight was increased (one step being $10 \mathrm{~kg}$ for the leg press, $2.5 \mathrm{~kg}$ for the leg extension and 2 $\mathrm{kg}$ for the leg curl), and the number of repetitions was reduced to the starting value of 8. If patients rated their exertions as 'heavy' (Borg 5-10), the number of repetitions was first increased (from 8 to 10 or in a subsequent session from 10 to 12 repetitions). When patients had reached 3 sets of 12 repetitions, the weight was increased by one step in the next session, and the repetitions were reduced to the starting point of 8 . If at that moment an increase in weight was not possible, an extra set was added (4 sets instead of 3). The original weight and repetitions were retained, and in the subsequent session the weight was once again increased and the number of repetitions again reduced (as described above).

Patients were tested and trained on three different stationary resistance training stations (Leg Press, Leg Curl and Leg Extension). To prevent a dominant role of the non-surgical leg in the training, we decided to test and train both legs unilaterally, to achieve sufficient training stimulus for each leg.[16]

\section{Data Analysis}

Data were analyzed with SPSS, version 22.0 for Windows (IBM $®$ SPSS $®$ Statistics version 22.0). Descriptive statistics were used for sex, age, height, weight, TKA side and time since TKA surgery. The data for the two sexes are presented separately below.

Normality was tested with the Shapiro-Wilk test. In case data were normally distributed, data is presented as means \pm standard deviation (SD) and, where appropriate, in absolute numbers and percentages. Otherwise, medians and percentiles are used.

Paired sample t-tests were used to test mean differences in continuous data between baseline and follow-up measurements. A cut-off value for significance of 0.05 was used.

Values were also compared with normative values calculated using formulas for normative values of healthy controls which we have published earlier [8].(table 1) 


\begin{tabular}{l|cc|cc}
\hline & \multicolumn{2}{|c|}{ Men $(\mathbf{n}=\mathbf{1 2 9})$} & \multicolumn{2}{c}{ Women $(\mathbf{n}=166)$} \\
& Mean & SD & Mean & SD \\
Q60 & 129 & 17 & 79 & 9 \\
H60 & 78 & 12 & 49 & 6 \\
Q180 & 84 & 10 & 46 & 6 \\
H180 & 59 & 9 & 35 & 5 \\
\hline
\end{tabular}

Table 1 shows the normative values calculated using equations including age and sex.[8] Nm: Newton meter. SD: standard deviation. Q60: isokinetic quadriceps strength $60 \% \mathrm{sec}$. Q180: isokinetic quadriceps strength $180 \%$ sec. H60: isokinetic hamstring strength $60 \%$ sec. $\mathrm{H} 180$ : isokinetic hamstring strength $180 \%$ sec.

\section{RESULTS}

Thirteen patients were referred to the physical therapy department. One patients had strength values comparable with the normative values for healthy persons and was therefore excluded from this progressive strength training program. The other twelve were included between March 2016 and January 2018. They were seven men (age 66.0 [6.3] years, BMI 28.9 [4.9] kg/m²) and five women (age 67.4 [7.3] years, BMI 32.5 [9.4] kg/m²) (table 2). Patients were referred between 3 and 18 months after TKA surgery. Adherence to therapy was good; all patients completed the program and attended 12 sessions. No adverse events were seen during this period. One patient had a delay of 10 days between the 11 th and 12th sessions, due to illness (influenza).

Five patients received a Scorpio NRG® knee system (Stryker, Michigan, USA) and seven patients an Attune ${ }^{\circledR}$ knee system (Depuy Synthesis Companies, Massachusetts, USA).

\begin{tabular}{l|cc|cc}
\hline & \multicolumn{2}{|c|}{ Men $(\mathbf{n = 7})$} & \multicolumn{2}{c}{ Women $(\mathbf{n = 5})$} \\
& Mean & SD & Mean & SD \\
Age (years) & 66.0 & 6.3 & 67.4 & 7.3 \\
Height (m) & 1.75 & 0.07 & 1.59 & 0.04 \\
Weight (kg) & 88.2 & 13.2 & 81.9 & 22.4 \\
BMI (kg/m $\left.{ }^{2}\right)$ & 28.9 & 4.9 & 32.5 & 9.4 \\
\hline
\end{tabular}

Table 2 shows the patients characteristics. BMI: Body Mass Index, SD: standard deviation. 


\section{Quadriceps and hamstring strength}

All men improved in terms of quadriceps (figure 1) and hamstring strength. One woman's hamstring strength decreased, as did another woman's quadriceps strength. Overall, a favorable change of $45-81 \%$ was seen: the men had a significant improvement on all isokinetic strength parameters $(p=0.00-0.01)$ (figure 2$)$. The overall change for the women was $12-37 \%$, and only the isokinetic quadriceps $180^{\circ} / \mathrm{sec}$ strength showed significant improvement $(p=0.02)$. (figure 3 )

Comparison with normative values showed that the men scored $35-46 \%$ of these values at baseline. After the 6-week progressive strength training program, this was $59-71 \%$ (figure 2). As regards the percentage of the normative value for women, this was $55-79 \%$ before the start of the program and $73-94 \%$ afterwards (figure 3).

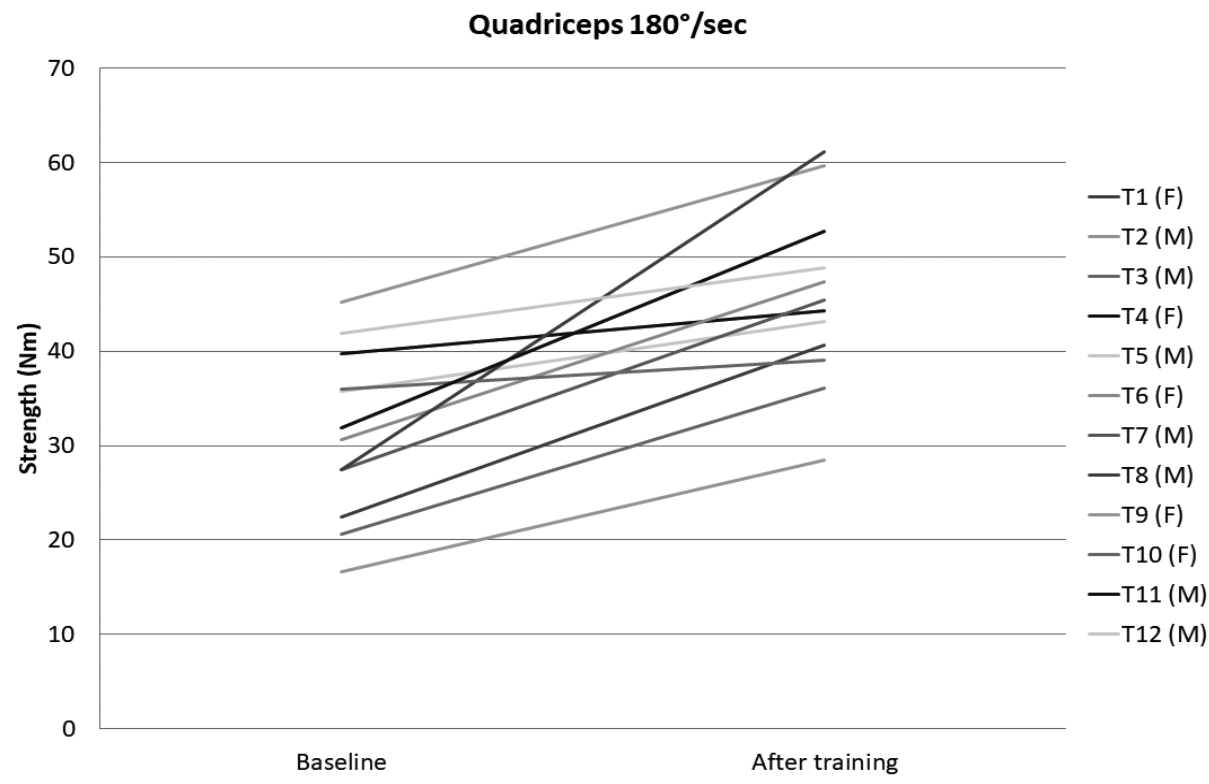

Figure 1 shows the change in quadriceps strength of all individual patients before and after training, in $\mathrm{Nm}$. Each line represents an individual patient. Their sex is given to the right of the diagram (F[Female] and $\mathrm{M}[\mathrm{male}])$. 


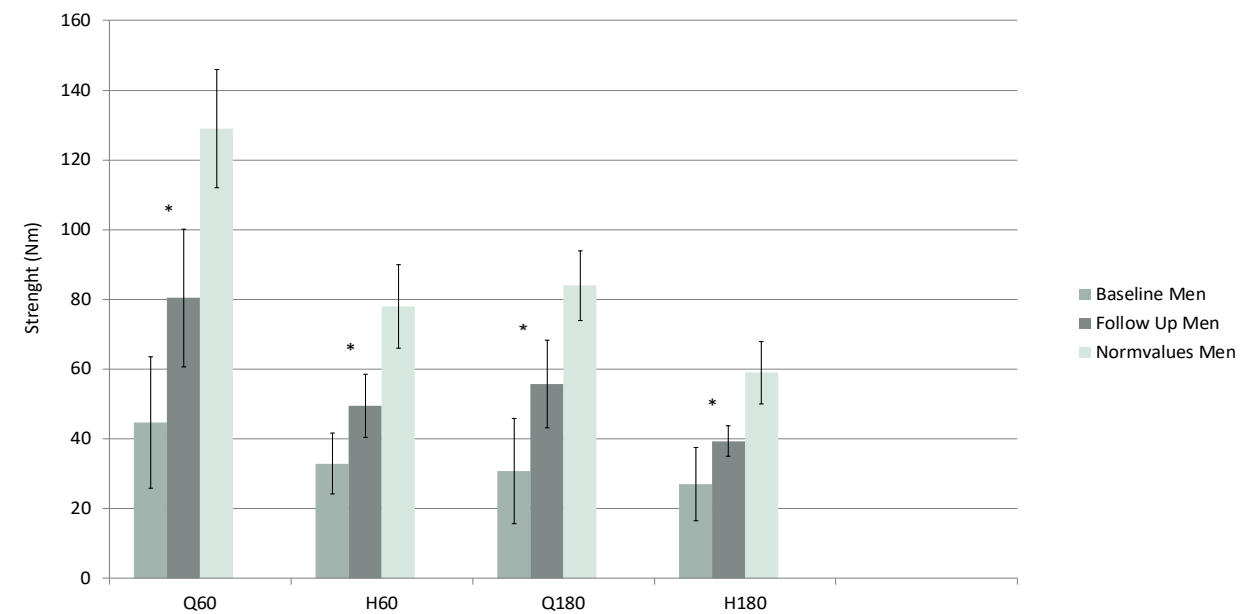

Figure 2 shows the mean quadriceps and hamstrings strengths in men, at baseline and after the training program, in $\mathrm{Nm}$ with standard deviations Q60: isokinetic quadriceps strength $60 \% \mathrm{sec}$. Q180: isokinetic quadriceps strength $180 \% \mathrm{sec}$. $\mathrm{H} 60$ : isokinetic hamstring strength $60 \% \mathrm{sec}$. $\mathrm{H} 180$ : isokinetic hamstring strength $180 \%$ sec. Normative values are the means of the individual normative values based on sex and age.

* Significant improvement between baseline and post-training assessments $(p<0.05)$.

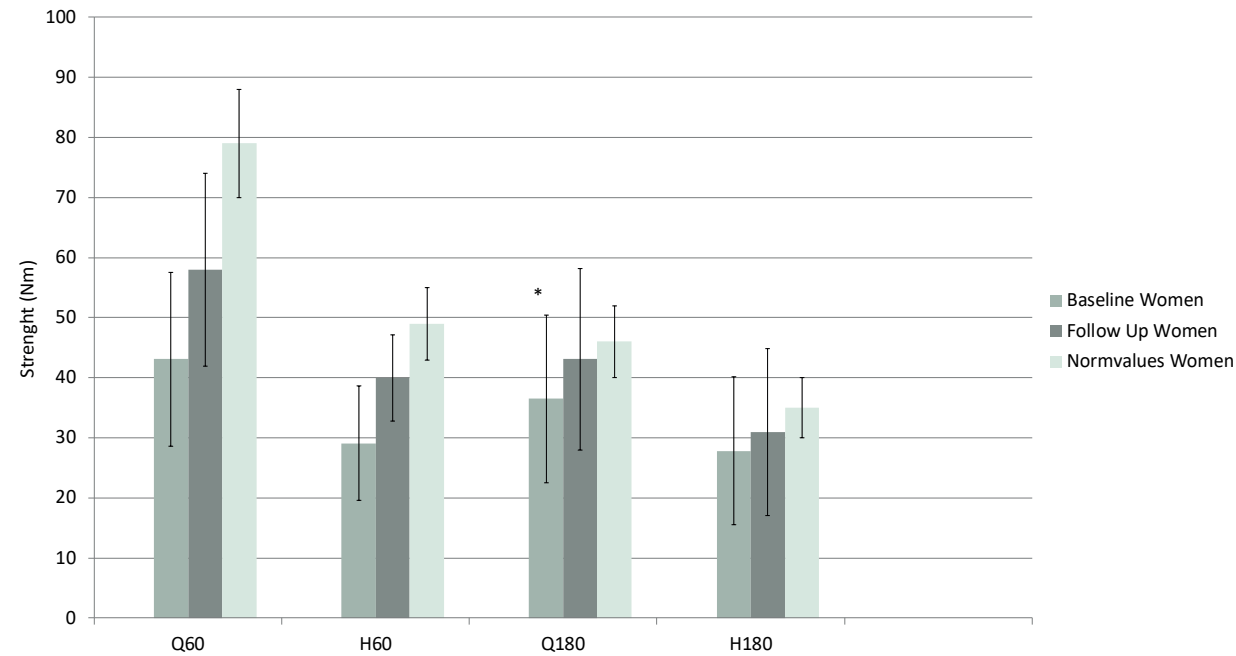

Figure 3 shows the mean quadriceps and hamstrings strengths in women, at baseline and after the training program, in $\mathrm{Nm}$ with standard deviations Q60: isokinetic quadriceps strength $60^{\circ} / \mathrm{sec}$. Q180: isokinetic quadriceps strength $180 \%$ sec. $\mathrm{H} 60$ : isokinetic hamstring strength $60 \%$ sec. $\mathrm{H} 180$ : isokinetic hamstring strength $180 \%$ sec. Normative values are the means of the individual norm values based on sex and age.

* Significant improvement between baseline and post-training assessments $(p<0.05)$. 


\section{Functional ability}

The variance in the change in functional ability was high, with five patients improving their WOMAC function score, four patients deteriorating and three not showing any change (change $<5$ standardized points). The individual change is shown in figure 4.

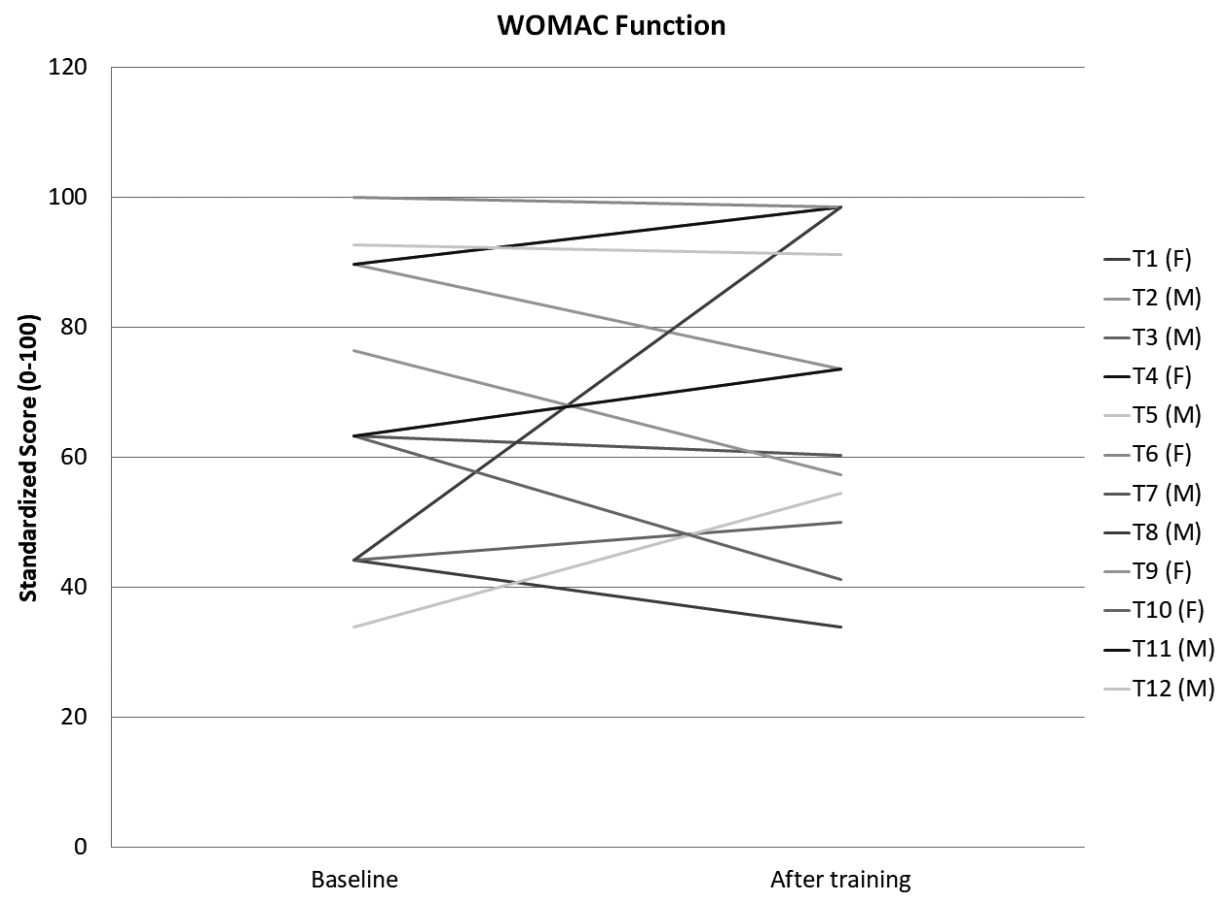

Figure 4 shows the change in WOMAC Function score of each individual patient before and after training. Each line represents an individual patient. The sex is given to the right of the diagram (F[Female] and M[male]). 


\section{DISCUSSION}

This study examined the impact of a 6-week progressive strength training program, started at least 3 months after TKA surgery, on the change in isokinetic quadriceps and hamstring strength and the functional ability of patients who had undergone a TKA. The results show a significant improvement in all strength parameters for men and for one quadriceps strength measurement in women. No significant improvement in functional ability was seen, since the change in functional ability was highly variable.

Our results are in agreement with those of several previous studies.[9, 20-23] Although all of these studies started the training program earlier after surgery than ours, it is useful to know that progressive strength training which starts at a later moment after surgery still has a positive impact on muscle strength. It is important to notice that direct comparison with our results is impossible, since these other studies used isometric instead of isokinetic strength measurements, and did not present their results for men and women separately, or failed to describe their interventions in detail. Although the sample size in our study was small, the fact that two women showed a decrease in one of the two hamstrings or quadriceps strength measures suggests that women only improved significantly regarding quadriceps strength at an angular speed of $180^{\circ} / \mathrm{sec}$. It is important to note that the two women whose hamstrings or quadriceps strength deteriorated both reported mild influenza complaints.

No adverse events were reported during the therapy sessions in our study. In general, patient compliance was high and most of the patients continued their exercise training after our program, since the training and the strength measurement results encouraged them to maintain training. In addition, they experienced a positive change in their daily life and became enthusiastic about the training sessions. Our findings confirm that progressive resistance training is possible and safe in patients after a TKA.

Although our patients improved their muscle strength, there was high variance in the change on the WOMAC function score. Due to this high variance and the small sample, no conclusions can be drawn regarding functional change. This corresponds to what has been reported in the literature,[9] although Johnson et al.[22] found an improvement on the Timed Up and Go test after their 4-week program. An explanation for this difference may lie in the fact that performance-based tests are driven by muscle strength while self-reported questionnaires are driven by pain, as mentioned by Pozzi et al.[19] Possible reasons for the high variance we found could be the short duration of our program, as 6 weeks may have been too short to see an improvement in functional ability, since patients were adjusting their daily life routine to this therapy. In addition, the statistical power of our study may have been too low to detect a significant change in functional ability. Finally, the patients expanded their activities, which might mean they experienced their limitations more clearly, giving them a better insight into their individual functional abilities and problems, which 
could result in greater acceptance of their position in the rehabilitation process.

\section{Study limitations}

Our study had some limitations. Firstly, given the small sample size, the power was too small to draw conclusions regarding the change in functional ability. Secondly, the fact that we did not find a significant difference in functional ability might have been influenced by the fact that we chose a patient-reported outcome measure; a performance test might be more directly related to muscle strength. Thirdly, our pre-post study design had some limitations as regards studying the effectiveness of a progressive strength training. Therefore, the results have to be interpreted with caution. Nevertheless, this study has yielded important evidence and starting points for future studies to evaluate the addition of progressive strength training to the standard physical therapy program after TKA.[40]

\section{Future research}

Although the results of this study are promising in terms of improving the quadriceps and hamstring strengths of patients after a TKA, further studies are required to compare our progressive strength training with the functional training often given in outpatient physical therapy departments and to investigate the effect of progressive strength training on the change in functional ability in a larger population. Additionally, the long-term effects of a progressive strength training program on strength remain unknown, as do the optimal and ultimate moments for starting strength training. Finally, the optimal duration of the program should also be studied.

\section{Conclusion}

In conclusion, a 6-week progressive strength training program starting at least 3 months after TKA surgery had a positive impact on isokinetic quadriceps and hamstring strengths in men and women, though no significant improvement in functional ability was detectable.

\section{Key points}

A 6-week strength training program, starting at least 3 months after TKA surgery, has a favorable effect on quadriceps and hamstring strength, though not on functional ability. Caution is necessary in interpreting our findings, since we only included a small population and we did not compare with other therapies. Therefore, further research to investigate the long-term impact of a strength training program, comparing our program with other therapies, would be useful, and impact on functional ability should also be investigated in a larger population. 


\section{REFERENCES}

1. Nelissen R, Rozing P: Goede 10-jaarresultaten na gecementeerde totale knieartroplastiek. Ned Tijdschr Geneeskd 1992, 136:1206-1210.

2. Schache $M B$, McClelland JA, Webster KE: Lower limb strength following total knee arthroplasty: a systematic review. Knee 2014, 21(1):12-20.

3. Huang $\mathrm{CH}$, Cheng CK, Lee YT, Lee KS: Muscle strength after successful total knee replacement: a 6- to 13-year followup. Clin Orthop 1996(328):147154.

4. Ritter M, Thong A, Davis K, Berend M, Meding J, Faris P: Long-term deterioration of joint evaluation scores. Bone Joint J 2004, 86(3):438-442.

5. Walsh M, Woodhouse LJ, Thomas SG, Finch E: Physical impairments and functional limitations: a comparison of individuals 1 year after total knee arthroplasty with control subjects. Phys Ther 1998, 78(3):248-258.

6. Silva M, Shepherd EF, Jackson WO, Pratt JA, McClung CD, Schmalzried TP: Knee strength after total knee arthroplasty. J Arthroplasty 2003, 18(5):605611.

7. Stevens-Lapsley JE, Balter JE, Kohrt WM, Eckhoff DG: Quadriceps and Hamstrings Muscle Dysfunction after Total Knee Arthroplasty. Clin Orthop 2010.

8. Berghmans DD, Lenssen AF, Emans PJ, De Bie RA: Functions, disabilities and perceived health in the first year after total knee arthroplasty; a prospective cohort study. BMC Musculoskelet Disord 2018, 19(250).

9. Husby V, Foss O, Husby O, Winther S: Randomized controlled trial of maximal strength training vs standard rehabilitation following total knee arthroplasty. Eur J Phys Rehabil Med 2017.

10. Greene KA, Schurman JR, 2nd: Quadriceps muscle function in primary total knee arthroplasty. J Arthroplasty 2008, 23(7 Suppl):15-19.

11. Stevens-Lapsley JE, Balter JE, Wolfe P, Eckhoff DG, Kohrt WM: Early neuromuscular electrical stimulation to improve quadriceps muscle strength after total knee arthroplasty: a randomized controlled trial. Phys Ther 2012, 92(2):210.

12. Valtonen A, Pöyhönen T, Heinonen A, Sipilä S: Muscle deficits persist after unilateral knee replacement and have implications for rehabilitation. Phys Ther 2009, 89(10):1072.

13. Rossi MD, Hasson S: Lower-limb force production in individuals after unilateral total knee arthroplasty. Arch Phys Med Rehabil 2004, 85(8):12791284.

14. Mizner RL, Petterson SC, StevensJE, Vandenborne K, Snyder-Mackler L: Early quadriceps strength loss after total knee arthroplasty. The contributions of muscle atrophy and failure of voluntary muscle activation. J Bone Joint Surg 2005, 87(5):1047-1053.

15. Yoshida Y, Mizner RL, Ramsey DK, Snyder-Mackler L: Examining outcomes 
from total knee arthroplasty and the relationship between quadriceps strength and knee function over time. Clin Biomech 2008, 23(3):320-328.

16. Skoffer B, Dalgas U, Mechlenburg I: Progressive resistance training before and after total hip and knee arthroplasty: a systematic review. Clin Rehabil 2015, 29(1):14-29.

17. Westby $\mathrm{MD}$, Backman $\mathrm{CL}$ : Patient and health professional views on rehabilitation practices and outcomes following total hip and knee arthroplasty for osteoarthritis: a focus group study. BMC Health Serv Res 2010, 10(1):119.

18. Bade MJ, Kohrt WM, Stevens-Lapsley JE: Outcomes before and after total knee arthroplasty compared to healthy adults. J Orthop Sports Phys Ther 2010, 40(9):559-567.

19. Pozzi F, Snyder-Mackler L, Zeni J: Physical exercise after knee arthroplasty: a systematic review of controlled trials. Eur J Phys Rehabil Med 2013, 49(6):877.

20. Petterson SC, Mizner RL, Stevens JE, Raisis L, Bodenstab A, Newcomb W, Snyder-Mackler L: Improved function from progressive strengthening interventions after total knee arthroplasty: a randomized clinical trial with an imbedded prospective cohort. Arthritis Care Res 2009, 61(2):174-183.

21. Petterson SC, Barrance P, Marmon AR, Handling T, Buchanan TS, SnyderMackler L: Time course of quad strength, area and activation after knee arthroplasty and strength training. Med Sci Sports Exerc 2011, 43(2):225.

22. Johnson AW, Myrer JW, Hunter I, Feland JB, Hopkins JT, Draper DO, Eggett D: Whole-body vibration strengthening compared to traditional strengthening during physical therapy in individuals with total knee arthroplasty. Physiother Theory Pract 2010, 26(4):215-225.

23. Jakobsen $T L$, Husted $H$, Kehlet $H$, Bandholm $T$ : Progressive strength training (10 RM) commenced immediately after fast-track total knee arthroplasty; is it feasible? Disabil Rehabil 2012, 34(12):1034-1040.

24. Jakobsen TL, Kehlet H, Husted H, Petersen J, Bandholm T: Early Progressive Strength Training to Enhance Recovery After Fast-Track Total Knee Arthroplasty: A Randomized Controlled Trial. Arthritis Care Res 2014, 66(12):1856-1866.

25. Lauermann SP, Lienhard K, Item-Glatthorn J, Casartelli NC, Maffiuletti NA: Assessment of quadriceps muscle weakness in patients after total knee arthroplasty and total hip arthroplasty: methodological issues. J Electromyogr Kinesiol 2014, 24(2):285-291.

26. Zech A, Hendrich S, Pfeifer K: Association between exercise therapy dose and functional improvements in the early postoperative phase after hip and knee arthroplasty: an observational study. Am J Phys Med Rehabil 2015, 7(10):1064-1072.

27. Bandholm T, Kehlet $\mathrm{H}$ : Physiotherapy exercise after fast-track total hip and 
knee arthroplasty: time for reconsideration? Arch Phys Med Rehabil 2012, 93(7):1292-1294.

28. Drouin JM, Valovich-mcLeod TC, Shultz SJ, Gansneder BM, Perrin DH: Reliability and validity of the Biodex system 3 pro isokinetic dynamometer velocity, torque and position measurements. Eur J Appl Physiol 2004, 91(1):22-29.

29. Moon Y-W, Kim H-J, Ahn H-S, Lee D-H: Serial changes of quadriceps and hamstring muscle strength following total knee arthroplasty: a metaanalysis. PloS one 2016, 11(2):e0148193.

30. Bellamy N, Buchanan WW, Goldsmith CH, Campbell J, Stitt LW: Validation study of WOMAC: a health status instrument for measuring clinically important patient relevant outcomes to antirheumatic drug therapy in patients with osteoarthritis of the hip or knee. J Rheumatol 1988, 15(12):1833-1840.

31. McConnell S, Kolopack P, Davis AM: The Western Ontario and McMaster Universities Osteoarthritis Index (WOMAC): a review of its utility and measurement properties. Arthritis Care Res 2001, 45(5):453-461.

32. Jones CA, Voaklander DC, Suarez-Alma ME: Determinants of function after total knee arthroplasty. Phys Ther 2003, 83(8):696-706.

33. Collins NJ, Misra D, Felson DT, Crossley KM, Roos EM: Measures of knee function: International Knee Documentation Committee (IKDC) Subjective Knee Evaluation Form, Knee Injury and Osteoarthritis Outcome Score (KOOS), Knee Injury and Osteoarthritis Outcome Score Physical Function Short Form (KOOS-PS), Knee Outcome Survey Activities of Daily Living Scale (KOS-ADL), Lysholm Knee Scoring Scale, Oxford Knee Score (OKS), Western Ontario and McMaster Universities Osteoarthritis Index (WOMAC), Activity Rating Scale (ARS), and Tegner Activity Score (TAS). Arthritis Care Res 2011, 63(S11):S208-S228.

34. Gill SD, de Morton NA, Mc Burney H: An investigation of the validity of six measures of physical function in people awaiting joint replacement surgery of the hip or knee. Clin Rehabil 2012, 26(10):945-951.

35. One-Repeated Maximum (1RM) [https://meetinstrumentenzorg.blob.core. windows.net/test-documents/Instrument262/382_1_N.pdf]

36. Jacobsen F, Holten O, Faugli H, Leirvik R: Medical exercise therapy. J Phys Ther Sci 1992, 3:2-11.

37. Morree dJ, Jongert M, Van der Poel G: Inspanningsfysiologie oefentherapie en training. In.: Houten: Bohn Stafleu van Loghum; 2011.

38. ACSM information on Resistance Training for Health and Fitness [https:// www.prescriptiontogetactive.com/app/uploads/resistance-training-ACSM. pdf]

39. Borg GA: Psychophysical bases of perceived exertion. Med Sci Sports Exerc 1982, 14(5):377-381. 
40. Marcellis R, van der Veeke M, Mesters I, Drent M, de Bie R, de Vries G, Lenssen A: Does physical training reduce fatigue in sarcoidosis? Sarcoidosis Vasc Diffuse Lung Dis 2015, 32(1):53-62. 



\section{CHAPTER SEVEN.}

GENERAL DISCUSSION 
This dissertation reports on research performed among patients in the perioperative phase up to one year after total knee arthroplasty (TKA) surgery. In this last chapter, our main findings are critically reviewed, methodological considerations are discussed and suggestions on implications for clinical practice and for future research are made.

\section{SUMMARY AND DISCUSSION OF MAIN FINDINGS}

One of the most important findings of our research is that patients in our cohort study (Chapter 2) were doing well after TKA surgery, implying that TKA can really be regarded as an effective solution for patients with end stage OA. All functional parameters improved significantly over time. Some residual complaints remained, however, as the patient-reported outcome measures (PROMs) we used did not reach maximal values, as was also found in other studies.[1-8] However, the most striking finding was the quadriceps and hamstring muscle strength deficit after TKA surgery. This has been recognized and described in the literature before (Chapter 5), although scientific research into these deficits is scarce. In addition, published studies have often lacked objective measurement of strength. A possible cause of the strength deficit could be that the main focus in Dutch physical therapy guidelines for rehabilitation after TKA surgery is on the level of activity and participation, with less attention towards basic motor skills such as mobility and strength.[9] As described in Chapter 5, there are several possible causes that could underlie this muscle strength deficit, such as pre-surgical pain-induced changes in activity patterns, bio-kinematic and proprioceptive changes due to the surgical procedure, or inadequate postsurgical therapy. The last of these potential causes is what we would like to address here, as rehabilitation protocols could influence the observed muscle strength deficit. In the Netherlands, patients after TKA are in a unique position: they receive physical therapy over a prolonged period, as Dutch health insurance covers physical therapy for one year. In other countries, patients often receive physical therapy for a short period or a specific number of sessions,[7, 10-12] after which they have to exercise by themselves, and the literature describes poor adherence to prescribed unsupervised therapy. According to a study by Campbell et al.[13], all patients reported full or partial compliance with therapy during a supervised period, but after the supervision ended, the compliance rate fell to $25 \%$. Since Dutch patients receive a larger number of therapy sessions, we were surprised to find quadriceps and hamstring muscle strength deficits in our study (Chapter 2). Nevertheless, our systematic review (Chapter 5) showed that our patients' results were actually better than those reported in studies performed in other countries: although the pre-surgical values in most studies were more or less comparable to ours, the increase in strength in our study appear to be faster and larger. This difference can possibly be explained by the amount of postsurgical therapy.

Gait parameters and satisfaction rates (Chapter 2) were also better in our study than in those reported in the literature.[4, 7, 14-18] Goldsmith et al.[19] performed a 
study of the patient perspective in TKA and the level of dissatisfaction after surgery in Canada. They described physical therapists as key players in helping patients regain mobility and resume their regular activities, and as necessary partners in rehabilitation. The physical therapists in their study [19] provided tailored programs, used an individual approach and had sufficient time for their patients. Besides, patients often met fellow TKA patients during the sessions, with whom they could share information and benchmark their progress.[19] The Dutch situation differs from that in Canada, with an even larger role for the physical therapists, as described in the general introduction to this dissertation (Chapter 1). This might explain the superior values we found regarding functional performance and satisfaction.

Given the muscle strength deficit observed in our cohort study, we wanted to investigate the trainability of muscle strength in TKA patients. Chapter 6 reports on a study of the impact of a progressive strength training program on isokinetic muscle strength and functional ability, as assessed 3 to 18 months after TKA surgery in a small group of patients who reported persistent limitations in both strength and functional ability at follow-up consultations with the surgeon. We found a significant improvement, which contributes to the idea that patients receiving a TKA are trainable, even after a long period (a mean of 6 months) after TKA surgery. This was also observed after an initial period of standard physical therapy (Chapter 6). These findings suggest that the current rehabilitation programs may be suboptimal, since patients report functional limitations, and specific basic motor skills like strength are not trained as fully as they could be. It is important to note that none of our patients experienced adverse events, and that all of the participating patients said they would recommend this training program, to their fellow patients. The strength training and strength assessment improved patients' insight into their own muscle recovery compared to others, both TKA patients and healthy persons, and after the training program patients often restarted supervised physical training or performed exercises on their own. Overall, we think that extra emphasis on muscle strength during therapy sessions could improve the rehabilitation process and may lead to a reduction in residual complaints. However, in view of the high variance in change scores on functional ability in our study, further research is needed to confirm this.

Another factor which could determine post-surgical satisfaction is that of presurgical expectations. The literature shows that in $37 \%$ of all cases, patients have higher expectations than their surgeon, and this increases the risk of dissatisfaction after surgery.[15] We expect that improved techniques and shortening of the hospitalization period may cause patients to underestimate the impact of TKA surgery. Besides, $60 \%$ of all patients expect to be 'their old self' again after surgery and want to return to their daily activities and work as soon as possible, $[14,20]$ which may also indicate unrealistic expectations. Matching patients' and surgeons' expectations before the decision to perform surgery seems an important step in managing satisfaction.[15, 21]

As regards satisfaction, it is worth noting that in our study (Chapter 4) of the 
methodological characteristics of the patient specific function scale (PSFS), as well as in the literature [14], a response shift is sometimes reported for the most important complaints. In these cases patients seem to pursue different goals before and after surgery. This makes it difficult to set individual goals before the surgery, which implies that a certain percentage of patients may always be dissatisfied.

Since pre-surgical functional ability plays a minor role in post-operative functioning (Chapter 3), questions arise regarding the right moment for TKA surgery. In the Netherlands, OA is treated according to the Stepped Care principle [22], meaning that treatment is adapted to patients' needs and they only receive complex therapies when simple remedies are no longer effective. This means that several steps are followed when a patient is diagnosed with OA. It is only when complaints persist and functional ability is decreased that a TKA is offered. However, the optimal moment for this surgery is unclear. The information from our prediction study suggests that waiting too long could influence functional ability afterwards (Chapter 3). Determining the optimal time-window is necessary to optimize post-surgical functional ability. Further research could include psycho-social factors in addition to the baseline level of functioning, and could focus on generating cut-off points.

\section{METHODOLOGICAL CONSIDERATIONS}

During the design and implementation of our study choices had to be made which influenced the study results. While most of the methodological issues have been discussed in the individual chapters, some general remarks are discussed below.

\section{Outcome measures and measurement time points}

During the design phase of our cohort study, our objective was to generate as complete as possible a picture of the physical condition of patients with end-stage osteoarthritis, both at intake and during the first year after a TKA. To this end, we included a wide range of questionnaires and performance measurements, which were all well established, valid and reliable. Total assessment time was 45 minutes, which made it time-consuming for both patient and therapist. Therefore, we decided to keep the number and the frequency of follow-up measurements to a minimum, and linked these to the follow-up consultations with the doctor. We think this was one of the reasons for our low drop-out rate. In view of the time-consuming measurements, and our main focus on physical status, we also decided to exclude potential predictors such as psychosocial functioning. In an ideal situation, we would have liked to have multiple follow-up measurements and to include psychosocial questionnaires to obtain a more complete picture of each patient and the development of physical parameters, for example the muscle strength development in the first months after surgery.

As a secondary outcome measure, we chose the WOMAC to assess physical ability in our studies, since this instrument is reliable for our study population and has frequently been used in other studies and in daily practice. However, the WOMAC is 
a PROM which assesses a patient's perception of function, and it shows a steep initial recovery after surgery. By contrast, performance-based outcome measures (PBOMs) assess the actual level of physical functioning, and these show an early postsurgical decline followed by an increase.[23] This could have influenced the results of our prediction models (Chapter 3 ) and our strength study (Chapter 5), and could explain the differences between our findings and those reported in the literature.

\section{Study population and external generalizability}

We were able to recruit our entire study sample within the predetermined inclusion time. We informed and invited all eligible patients consecutively. In view of our large study sample and the small number of patients who were unwilling to participate, we believe the findings in our study sample have a good external generalizability toward the Dutch population. To our knowledge, no other study has investigated isokinetic quadriceps and hamstring strength in such a large group of TKA patients.

Although the sample in our progressive strength study was small, this was justified because this was a pilot study, since we merely wanted to get an idea whether a progressive strength training program provided several months after TKA surgery in patients with residual complaints would impact on muscle strength and functional ability. The small sample size was also caused by the fact that most of the patients with complaints were still receiving physical therapy and were therefore not able to participate in our study. In an ideal situation, we would like to perform a randomized controlled trial to investigate the effect of progressive strength training, added to or instead of, regular physical therapy after TKA surgery. The compliance in our small study sample was high, we had no drop outs, and although patients missed some sessions, they had good reasons for this, including illness, and made up for the missed sessions afterwards.

Since rehabilitation after TKA surgery differs in various countries of the world, the external generalizability of our findings is a matter for consideration. As described above, rehabilitation in the Netherlands is different than in other countries, so our study results have to be interpreted with this in mind. The overall functional status of patients at one year after TKA is influenced by the amount of therapy. Since we did not take the content and amount of physical therapy of individual patients into consideration, we cannot compare therapies, nor draw any conclusions regarding the impact of physical therapy. Future studies should focus on the optimal content and amount of physical therapy, investigate the effectiveness of a therapeutically valid rehabilitation program, and result in recommendations regarding post-surgical therapy that could be used worldwide.[24] Nevertheless, ours was the first study, as far as we know, to use an intensive measurement kit for basic motor skills and functions in a large sample. Therefore, our findings do provide some insights into the physical status of TKA patients, and this could be a starting point for other studies, or for comparing individual values with the reference values we established. 


\section{IMPLICATIONS FOR CLINICAL PRACTICE}

The studies reported on in this dissertation revealed that TKA patients in the Netherlands have a satisfactory functional status. With the exception of the quadriceps and hamstring strength, patients showed near healthy values, and the overall satisfaction rate was high. This information can be used by several target groups. Firstly, health care providers can use it in multiple ways, such as comparing their patients' results with ours, or informing patients about the rehabilitation process. Secondly, policy makers and health care insurers could use our results to make adjustments to guidelines, since designing a cost-effective peri-surgical knee osteoarthritis and TKA program remains important, especially given the high prevalence of osteoarthritis. Minor adjustments to increase patients' functional abilities could lead to fewer disabilities and higher social and work-related participation, and thereby reduce the social and financial burden. This may involve prolonged supervision of the rehabilitation process to improve patients' adherence to exercise programs, or improve the mutual communication among healthcare providers and between such providers and their patients.

\section{SUGGESTIONS FOR FUTURE RESEARCH}

Multiple aspects could be investigated on the basis of the results reported in this dissertation. Firstly, it would be useful to conduct studies into the effect of pre-surgical training on the pre-surgical and the short- and long-term post-surgical functional status, since information regarding the effectiveness of this procedure could help to improve their effectiveness and offer insights into the course of recovery, and may thereby enhance patients' awareness and influence their satisfaction. Furthermore, additional knowledge may also reduce general health care costs. Secondly, the precise content of physical therapy after surgery needs further attention, since we found a positive impact of strength training on the quadriceps and hamstring muscle strength. Research into the added value of progressive strength training compared with usual care, combined with patients' satisfaction and their functional ability (measured with a PBOM) would give guidance for further imbedding of strength training in clinical practice. Thirdly, studies could try to identify patients to improve a patient-tailored approach in the pre- and post-surgical rehabilitation process.

\section{GENERAL CONCLUSIONS}

We can conclude that patients after TKA generally show great improvements on all functions and functional ability, and are highly satisfied after surgery. Residual complaints regarding functional ability and walking speed remain, the most striking ones being the quadriceps and hamstrings muscle strength deficits, even one year after surgery. Although these deficits have been confirmed in the literature, the high variance in absolute values preclude direct comparisons and pooling of the data from 
multiple studies. It is noteworthy that the results of our cohort study are among the best post-surgical TKA results reported in the literature. This may be the consequence of the large amount of physical therapy provided for these patients in the Netherlands, especially since we found a positive impact of progressive strength training on muscle strength. The findings reported in this dissertation indicate opportunities for improvements in clinical practice and offer starting points for future research to verify our results and to investigate other aspects. 


\section{REFERENCES}

1. Kennedy DM, Stratford PW, Riddle DL, Hanna SE, Gollish JD: Assessing recovery and establishing prognosis following total knee arthroplasty. Phys Ther 2008, 88(1):22-32.

2. Beers MH, Berkow R: The Merck Manual, vol. 2: Bohn Stafleu Van Loghum; 2003.

3. Zeni JA, Jr., Snyder-Mackler L: Early postoperative measures predict 1- and 2-year outcomes after unilateral total knee arthroplasty: importance of contralateral limb strength. Phys Ther 2010, 90(1):43-54.

4. Mizner RL, Petterson SC, Stevens JE, Axe MJ, Snyder-Mackler L: Preoperative quadriceps strength predicts functional ability one year after total knee arthroplasty. J Rheumatol 2005, 32(8):1533-1539.

5. Jones CA, Voaklander DC, Suarez-Alma ME: Determinants of function after total knee arthroplasty. Phys Ther 2003, 83(8):696-706.

6. Bourne RB, Chesworth BM, Davis AM, Mahomed NN, Charron KD: Patient satisfaction after total knee arthroplasty: who is satisfied and who is not? Clin Orthop Relat Res 2010, 468(1):57-63.

7. Bade MJ, Kohrt WM, Stevens-Lapsley JE: Outcomes before and after total knee arthroplasty compared to healthy adults. J Orthop Sports Phys Ther 2010, 40(9):559-567.

8. Yoshida Y, Mizner RL, Ramsey DK, Snyder-Mackler L: Examining outcomes from total knee arthroplasty and the relationship between quadriceps strength and knee function over time. Clin Biomech 2008, 23(3):320-328.

9. KNGF-richtlijn Artrose heup-knie [https://www.fysionet-evidencebased. nl/images/pdfs/richtlijnen/artrose_heup_knie_2018/artrose_heup-knie_ verantwoording_2018.pdf]]

10. Westby MD, Backman CL: Patient and health professional views on rehabilitation practices and outcomes following total hip and knee arthroplasty for osteoarthritis: a focus group study. BMC Health Serv Res 2010, 10(1):119.

11. Lingard EA, Berven S, Katz JN: Management and care of patients undergoing total knee arthroplasty: variations across different health care settings. Arthritis Care Res 2000, 13(3):129-136.

12. Benz T, Angst F, Oesch P, Hilfiker R, Lehmann S, Mebes CM, Kramer E, Verra $\mathrm{M}$ : Comparison of patients in three different rehabilitation settings after knee or hip arthroplasty: a natural observational, prospective study. BMC Musculoskeletal Disord 2015, 16(1):317.

13. Campbell R, Evans M, Tucker M, Quilty B, Dieppe P, Donovan J: Why don't patients do their exercises? Understanding non-compliance with physiotherapy in patients with osteoarthritis of the knee. J Epidemiol Community Health 2001, 55(2):132-138.

14. Tilbury C, Haanstra TM, Leichtenberg CS, Verdegaal SH, Ostelo RW, de Vet 
HC, Nelissen RG, Vlieland TPV: Unfulfilled expectations after total hip and knee arthroplasty surgery: there is a need for better preoperative patient information and education. J Arthroplasty 2016, 31(10):2139-2145.

15. Ghomrawi HM, Mancuso CA, Westrich GH, Marx RG, Mushlin Al, Group EDS: Discordance in TKA expectations between patients and surgeons. Clin Orthop Relat Res 2013, 471(1):175-180.

16. Neuprez A, Delcour J-P, Fatemi F, Gillet $P$, Crielaard J-M, Bruyère $O$, Reginster J-Y: Patients' Expectations Impact Their Satisfaction following Total Hip or Knee Arthroplasty. PloS one 2016, 11(12):e0167911.

17. Bolink S, Grimm B, Heyligers I: Patient-reported outcome measures versus inertial performance-based outcome measures: A prospective study in patients undergoing primary total knee arthroplasty. Knee 2015, 22(6):618623.

18. Walsh M, Woodhouse LJ, Thomas SG, Finch E: Physical impairments and functional limitations: a comparison of individuals 1 year after total knee arthroplasty with control subjects. Phys Ther 1998, 78(3):248-258.

19. Goldsmith LJ, Suryaprakash N, Randall E, Shum J, MacDonald V, Sawatzky R, Hejazi S, Davis JC, McAllister P, Bryan S: The importance of informational, clinical and personal support in patient experience with total knee replacement: a qualitative investigation. BMC Musculoskelet Disord 2017, 18(1):127.

20. Fransen BL, Hoozemans MJ, Argelo KD, Keijser LC, Burger BJ: Fast-track total knee arthroplasty improved clinical and functional outcome in the first 7 days after surgery: a randomized controlled pilot study with 5-year follow-up. Arch Orthop Trauma Surg 2018:1-12.

21. Tolk JJ, Janssen RP, Haanstra TM, Bierma-Zeinstra SM, Reijman M: The EKSPECT study: the influence of Expectation modification in Knee arthroplasty on Satisfaction of PatiEnts: study protocol for a randomized Controlled Trial. Trials 2018, 19(1):437.

22. Smink AJ, van den Ende CHM, Vliet Vlieland TPM, Swierstra BA, Kortland JH, Bijlsma JWJ, Voorn TB, Schers HJ, Bierma-Zeinstra SMA, Dekker J: “Beating osteoARThritis": Development of a stepped care strategy to optimize utilization and timing of non-surgical treatment modalities for patients with hip or knee osteoarthritis. Clin Rheumatol 2011, 30(12):1623-1629.

23. Luna I, Kehlet H, Peterson B, Wede HR, Hoevsgaard S, Aasvang E: Early patient-reported outcomes versus objective function after total hip and knee arthroplasty: a prospective cohort study. Bone Joint J 2017, 99(9):1167-1175.

24. Hoogeboom TJ, Oosting E, Vriezekolk JE, Veenhof C, Siemonsma PC, De Bie RA, Van den Ende $\mathrm{CH}$, Van Meeteren NL: Therapeutic validity and effectiveness of preoperative exercise on functional recovery after joint replacement: a systematic review and meta-analysis. Plos one 2012, 7(5):e38031. 

VALORISATION
ADDENDUM. 
Knee osteoarthritis $(O A)$ is a globally occurring health problem, which leads to complaints like pain and joint stiffness that influence all daily activities. As a consequence, participation in sports, work and social activities decreases. When conservative treatment options, such as life style advice, exercise and medication are no longer effective, a surgical approach (total knee arthroplasty [TKA]) is necessary.[1-4] The increase in life expectancy and relevant comorbidities such as obesity, next to a widening of surgical criteria and improved safety lead to an increase in the number of TKA surgeries.[5-7] Consequently, an increase in the social and financial burden on the whole community is to be expected. Interventions to minimize this burden of TKA surgery on individuals and society should be investigated. Next to this, it is necessary to translate research outcomes from these interventions into practice to improve the availability of evidence to health care providers and patients. This translation is known as knowledge valorisation and refers to the "process of creating value from knowledge, by making knowledge suitable and/or available for social (and/ or economic) use, and by making knowledge suitable for translation into competitive products, services, processes and new commercial activities" (adapted definition based on the National Valorisation Committee 2011:8).

In this chapter we translate the results of this dissertation to the relevance for society and the individual patient.

\section{RESULTS AND RELEVANCE}

This dissertation reports on the functioning of patients in the Netherlands after a TKA surgery. Although, some residual complaints remain on functioning level, patients improve on all 'International Classification of Function, Disability and Health' (ICF) domains and differences in relevant outcome domains with healthy persons become smaller. Remarkable outcomes are the remaining muscle strength deficits after TKA surgery, which could cause or be intermediate factors for problems at activity level. Therefore, in our pilot training study we investigated the impact of progressive strength training on the quadriceps and hamstring muscle strength and in functioning level. We were only able to find an impact on the muscle strength.

Next to the performance of patients after a TKA-surgery, we found a high reproducibility and responsiveness of the patient specific function scale in this patient population. Therefore, this is an ideal too in individual tailored treatment to define personal goals. Ideally, important activities which are difficult to perform are defined pre-surgically, health care providers get insight in patient's expectations of TKA surgery and could advise and educate them appropriately if necessary. After surgery, individual-tailored post-surgical rehabilitation should focus on these important activities, next to training of basic motor skills. In our opinion this process will improve the satisfaction of the patients. 


\section{TARGET GROUPS}

\section{Patients with knee OA or a TKA}

Patients with knee OA or a TKA are the main target populations of this dissertation. In our opinion they may profit most of this knowledge, since information regarding results of TKA surgery, satisfaction rates and the post surgical functional ability are very important in the information gathering process before surgery. Further, this information could be used to adapt patients' expectations and reach agreement with the surgeon's expectations. When using measurement instruments like the Patient Specific Functional Scale (PSFS), unrealistic expectations may be discussed and adapted if needed. Next, it addresses the importance of adherence to (supervised) exercise therapy to optimize their individual rehabilitation process, based on their predefined goals and expectations. In our opinion this information may be already provided to the patients during pre-surgical group-information sessions or individual consultations.

\section{Physical therapists}

Therapists can use the information provided in this dissertation in multiple ways. First, by using our data as a benchmark with the data of their patients. Second, by using the data for personalized goal setting and evaluation of progression. Third, they can use the overall results to inform their patients about potential health improvements after TKA surgery. Fourth, this dissertation emphasizes the need for more attention towards measurement in a broader sense.

\section{Medical doctors, including orthopedic surgeons}

The results of this dissertation can be of use to family physicians as well as orthopedic surgeons, since with the knowledge obtained from this dissertation, they could better inform patients regarding the course and results on functioning level. Besides, they can benchmark their patients' rehabilitation progression towards this Dutch population.

\section{Researchers}

This dissertation describes the functional status of a TKA patients in the Netherlands. This could stimulate researchers worldwide to compare their own populations and outcomes with the results provided in this thesis. Besides, the fact that the quadriceps and hamstring muscle strength remains inferior compared to healthy individuals' strength, it could enhance other researchers to investigate interventions to improve strength. Further, the effect of a progressive strength training program should be confirmed in a larger trial. At last, the impact of physical therapy could be investigated specifically, since post surgical rehabilitation is different in the Netherlands compared with other countries. 


\section{Health policy makers and health care insurers}

Health policy makers and health care insurers are the last target group of this dissertation since designing cost-effective knee osteoarthritis and TKA perisurgical programs is of ongoing importance, especially given the high prevalence of osteoarthritis. Small adjustments in the peri-surgical process to increase functional abilities could therefore lead to less disabilities and higher social and work related participation and therewith lower the social and financial burden.

Other innovations like an online platform with information for patients and healthcare professionals may further enhance the independency of patients. In a secure online environment patients, therapists and surgeon could inform each other, which may contribute to consistent and clear information and communication. Possibly, group therapy could be valuable, because patients can share complaints and questions, this makes them less dependent on health care providers or the internet. $[8,9]$ Next to the focus on functional training, optimal training of basic motor skills should not be forgotten during therapy sessions or independent training. Together, we think this could further increase muscle strength, reduce residual complaints and improve overall satisfaction rate.

Lastly, the information of this dissertation can be used as benchmark data for both, single health care practices and in general. 


\section{REFERENCES}

1. KNGF-richtlijn Artrose heup-knie [https://www.fysionet-evidencebased. nl/images/pdfs/richtlijnen/artrose_heup_knie_2018/artrose_heup-knie_ verantwoording_2018.pdf]

2. Welke aandoeningen hebben we in de toekomst? [https://www.vtv2018. nl/aandoeningen]

3. Artrose, Cijfers en Context [https://www.volksgezondheidenzorg.info/ onderwerp/artrose/cijfers-context/huidige-situatie\#node-prevalentie-enaantal-nieuwe-gevallen-van-artrose]

4. Priority Medicines for Europe and the World 2013 Update [http://www. who.int/medicines/areas/priority_medicines/Ch6_120steo.pdf]

5. Bourne RB, Chesworth BM, Davis AM, Mahomed NN, Charron KD: Patient satisfaction after total knee arthroplasty: who is satisfied and who is not? Clin Orthop Relat Res 2010, 468(1):57-63.

6. Pozzi F, Snyder-Mackler L, Zeni J: Physical exercise after knee arthroplasty: a systematic review of controlled trials. Eur J Phys Rehabil Med 2013, 49(6):877.

7. Ghomrawi HM, Mancuso CA, Westrich GH, Marx RG, Mushlin Al, Group EDS: Discordance in TKA expectations between patients and surgeons. Clin Orthop Relat Res 2013, 471(1):175-180.

8. Goldsmith LJ, Suryaprakash N, Randall E, Shum J, MacDonald V, Sawatzky R, Hejazi S, Davis JC, McAllister P, Bryan S: The importance of informational, clinical and personal support in patient experience with total knee replacement: a qualitative investigation. BMC Musculoskelet Disord 2017, 18(1):127.

9. Marks R: Knee osteoarthritis and exercise adherence: a review. Current aging science 2012, 5(1):72-83. 

SUMMARY. 


\section{SUMMARY}

Knee osteoarthritis (OA) is a highly prevalent disease in which patients complain of pain, knee stiffness and disabilities experienced in daily life. When conservative treatments are no longer effective in reducing pain and retaining functional abilities, patients qualify for a total knee arthroplasty (TKA) surgery. This is seen as a costeffective treatment in reducing pain and improving daily functioning. However, an overview of the rehabilitation course after a TKA surgery on several levels of the International Classification of Functioning, Disability and Health (ICF) model is nonexistent. This was our rationale for this dissertation.

Chapter 1 describes the disease process of knee OA and the implications of this disease on different aspects of the ICF model. For more clarification, the ICF is shown, combined with a patient case participating in one of our studies. Besides, it provides an overview of the therapeutic options of knee OA and the rehabilitation process after TKA surgery in the Netherlands. TKA patients in the Netherlands have an especially unique position as these patients have the possibility to receive physical therapy treatment for the duration of one year. Lastly, it presents the outline of the dissertation.

Chapter 2 reports the functional status of a patient with end stage knee OA and during the first year after a TKA surgery. Patients perform well after TKA surgery in the Netherlands, which is evident by high satisfaction rates and significant improvement on patient reported outcomes, like functional ability and quality of life, and on objective measurements such as muscle strength and gait parameters. Compared to the literature, satisfaction rates are even higher in our study. Despite the significant improvements, the persisting quadriceps and hamstring muscle strength deficit after TKA surgery is striking.

In Chapter 3 two prediction models are presented which predict the functional ability 3 and 12 months after TKA surgery with pre-surgical measured baseline characteristics and physical parameters. Factors included were pre-surgical physical health, mental health, functional ability and knee stiffness to predict functional ability after 3 months. For the model to predict functioning after 12 months the pre-surgical measured parameters knee function and functional ability were significant predictors. In contrast with other studies we were not able to find a significant influence of age and body composition on the level of functioning after TKA surgery. The explained variance of both models is low, which means that other factors not included in this study have an influence on the functional ability after TKA surgery.

Chapter 4 discusses the methodological characteristics, reproducibility and responsiveness of the patient specific functioning scale (PSFS). We reported on a good reproducibility and high responsiveness (especially on the long term) which supports 
the use of this measurement instrument in this population. Next to this, the PSFS can be used to define therapy goals or expectations. It is worth noting that because of different underlying concepts the PSFS can not substitute the often used Western Ontario and McMaster Universities Osteoarthritis Index (WOMAC). Therefore, our recommendation is to use both instruments next to each other, in which the WOMAC is better suitable and more responsive on the short term and the PSFS on the long term.

The systematic review described in Chapter 5 negotiates the isokinetic quadriceps and hamstring muscle strength in the first year after TKA surgery. We presented absolute strength values of ten studies who measured isokinetic muscle strength at some point in time within the first year after surgery. Our intention was to present sex-specific values, however, this was not possible since most studies only presented overall results. Besides, we wanted to generate norm values for isokinetic strength at several time points in the first year after TKA. Unfortunately, it was not justified to pool the data because of a high variance in the absolute values, next to a high fluctuation in follow-up appointments and follow-up duration. Nonetheless, this review adds to the information that isokinetic quadriceps and hamstring muscle strength deficits are globally present, are often recognized but are minimally investigated. Further, it encouraged our idea of a positive influence of prolonged training after TKA surgery.

Because of the quadriceps and hamstring muscle strength deficit, we performed a pilot-study after the impact of a progressive strength training program. The results of this study are presented in Chapter $\mathbf{6}$. The study population consisted of a small group of 12 patients who had TKA surgery several months before (range 3-18 months, mean 6 months, without physical therapy, but who still had some residual complaints). After a training period of 6 weeks (twice a week for 45 minutes) we were able to find a significant improvement on the isokinetic quadriceps and hamstring strength. This means that the muscle strength can be further trained during the rehabilitation process. Unfortunately, we were unable to find an impact of the strength training on the functional ability, probably due to high variance in the WOMAC change value. The first possible reason for this high variance could be that the power of our study population was too low to detect a difference in functional ability. Secondly, the use of a patient's reported outcome (like the WOMAC) could have had an influence because a long period of time had lapsed after surgery and the patient was already able to perform daily activities with or without little complaints.

In the last chapter, Chapter 7, I discussed the results of the different studies and described the methodological considerations. We were only able to select a few follow-up time points, we combined these with consultations at the doctor's office, to reduce drop out rates. This was successful, however, for some parameters it 
would be interesting to have multiple follow-up points, for example to improve the understanding of the development of muscle strength in the early months after TKA surgery. We also discussed the use of the WOMAC as a (secondary) outcome measure in both our prediction and progression strength training program. We believe that the choice for this instrument could partially explain the results. The results of this dissertation can be used by several target groups, mainly patients, healthcare providers, health care policymakers and health care insurers. Furthermore, this dissertation gives starting points for future research, like investigating the impact of the amount of physical therapy, the influence of improving the pre-surgical status on the pre and post-surgical functional status. The chapter ends with the general conclusion, that patients in the Netherlands are performing well after TKA surgery. They improve significantly in the first year after TKA surgery, but residual complaints remain. One reason for this could be the muscle strength deficit which was seen in our studies and in the literature. This could be a starting point for further studies. 

SAMEN VATTING. 


\section{SAMENVATTING}

Knie artrose is een veelvoorkomend aandoening waarbij patiënten klachten als pijn en kniestijfheid aangeven. Daarnaast ervaren ze moeilijkheden bij het uitvoeren van dagelijkse activiteiten. Wanneer conservatieve behandelingen niet langer effectief zijn in het verminderen van de pijnklachten, of het behouden van de functionele activiteiten, komen patiënten in aanmerking voor een totale knie prothese (TKP). Deze operatie wordt gezien als een kosteneffectieve behandeling in het verminderen van pijn en het verbeteren van het dagelijks functioneren. Aangezien een overzicht van het fysieke beloop na een TKP operatie op verschillende facetten van het International Classification of Functioning, Disability and Health (ICF) model ontbreekt, was dit het overkoepelende doel van deze thesis.

Hoofdstuk 1 bespreekt het ziekteproces en de consequenties van de ziekte op verschillende onderdelen van het ICF model. Ter verduidelijking is het ICF model weergegeven, waarbij gebruik gemaakt is van een patiënten casus uit een van onze studies. Daarnaast geeft dit hoofdstuk een overzicht van het revalidatieproces van een patiënt die een TKP operatie heeft ondergaan in Nederland. Dit proces is uniek in de wereld, aangezien op dit moment in Nederland mensen na een operatie gedurende één jaar lang begeleid mogen worden door een fysiotherapeut. Het hoofdstuk eindigt met het beschrijven van de opzet van de thesis.

Hoofdstuk 2 beschrijft de functionele status van een patiënt met ernstige knie artrose en tijdens het eerste jaar na een TKP operatie. Hieruit blijkt dat patiënten in Nederland het goed doen. Dit is te zien aan hoge tevredenheidsscores en significante verbeteringen op vragenlijsten betreffende het fysiek functioneren en de kwaliteit van leven, evenals op fysieke testen, die bijvoorbeeld de spierkracht of gangparameters meten. Echter, ondanks de goede vooruitgang is er ook een jaar na de operatie nog sprake van een isokinetisch spierkracht tekort vergeleken met gezonden mensen in de quadriceps en hamstring spieren.

In Hoofdstuk 3 worden twee predictie modellen gepresenteerd, die trachten het fysiek functioneren 3 en 12 maanden na een TKP operatie te voorspellen met preoperatief gemeten baseline karakteristieken en fysieke parameters. Om het fysiek functioneren 3 maanden na een operatie te voorspellen zijn de preoperatieve lichamelijke en psychische kwaliteit van leven, het fysiek functioneren en de knie stijfheid meegenomen. In het voorspellend model voor het fysiek functioneren na 12 maanden zijn de parameters knie functie en preoperatief fysiek functioneren significant. In tegenstelling tot andere studies hebben wij geen voorspellende waarde voor leeftijd of lichaamssamenstelling gevonden voor het fysiek functioneren na een TKP operatie. Echter, de verklaarde variantie van beide modellen is laag, dit betekent dat andere factoren, die wij niet meegenomen hebben in het model, het fysiek functioneren na een TKA operatie beïnvloeden. 
De methodologische eigenschappen reproduceerbaarheid en responsiviteit van de patiënt specifieke klacht (PSK) zijn bediscussieerd in Hoofdstuk 4. We kunnen stellen dat de reproduceerbaarheid goed is en de responsiviteit, zeker op de lange termijn, hoog is. Dit draagt bij aan de hypothese dat de PSK een geschikt meetinstrument is om in deze populatie te gebruiken. Daarnaast kan de PSK ook ingezet worden om therapiedoelen en verwachtingen te definiëren. Het is echter goed om op te merken dat door een verschil in onderliggende concepten de PSK de veel gebruikte Western Ontario and McMaster Universities Osteoarthritis Index (WOMAC) niet kan vervangen. Daarom is het advies om beide instrumenten naast elkaar te gebruiken, waarbij de WOMAC meer geschikt is voor gebruik in de direct postoperatieve fase en de PSK meer op de langere termijn ingezet kan worden.

Het systematische review in Hoofdstuk $\mathbf{5}$ behandeld de isokinetische quadriceps en hamstring kracht in het eerste jaar na een TKA operatie. We presenteren de absolute krachtwaarden uit tien studies die op enig moment in het eerste jaar na een TKP operatie de isokinetische spierkracht meten. Onze intentie was om de getallen sekse specifiek te beschrijven, dit was niet mogelijk, omdat het merendeel van de studies alleen overall waarden weergaven. Daarnaast wilden we norm waardes creëren voor isokinetische kracht op verschillende momenten in het eerste jaar na een TKP operatie. Door een grote verscheidenheid aan meetmomenten en duur van de follow-up evenals een grote diversiteit aan absolute waarden, was het onmogelijk om op een juiste manier de data te poolen. De toegevoegde waarde van dit review is het overzichtelijk presenteren van verlies van quadriceps en hamstringkracht na een TKP operatie wereldwijd. Dit wordt vaak wel herkend, maar is nog weinig onderzocht. Daarnaast voedt het ons idee dat er meer aandacht mag zijn voor post operatief trainen.

Gezien de beperkte quadriceps en hamstrings kracht, is er een pilot studie naar de impact van een kracht trainingsprogramma opgezet, deze resultaten beschrijven we in Hoofdstuk 6. Deze pilot studie is uitgevoerd in een kleine populatie van 12 personen die enkele maanden ervoor een TKP operatie gehad hebben (range 3-18 maanden, gemiddelde is 6 maanden. Momenteel zonder fysiotherapie, maar wel nog fysieke klachten). Na een trainingsperiode van 6 weken (twee maal per week voor 45 minuten) was er een significante vooruitgang op de isokinetische quadriceps en hamstrings kracht zichtbaar. Dit betekent dat de spierkracht na een totale knieoperatie (ook na enkele maanden) nog verder getraind kan worden. Het was niet mogelijk om ook een verschil te bemerken in het fysiek functioneren, gemeten met de WOMAC, waarschijnlijk door een te grote variatie in de verschilwaarde van de WOMAC. Dit kan veroorzaakt worden doordat de power van onze studie te klein was om een verschil te meten in deze secondaire uitkomstsmaat. Daarnaast zou het gebruik van de WOMAC zelf ook van invloed kunnen zijn, aangezien patiënten reeds een langere tijd na de operatie zijn en weinig klachten ervaren in de dagelijkse bezigheden. 
In het laatste hoofdstuk, Hoofdstuk 7, bediscussieer ik de resultaten van de verschillende studies. Daarnaast worden enkele methodologische overwegingen besproken. Een van deze beperkingen is dat we maar enkele follow-up momenten gecreëerd hebben, we combineerden de afspraken met controle afspraken bij de orthopedisch chirurg, met de gedachte om de drop-out waarde zo laag mogelijk te houden. Dit heeft gewerkt, alleen zou het voor bepaalde waarden, zoals bijvoorbeeld de spierkracht, interessant zijn om meerdere follow-up momenten te hebben, om meer inzicht te krijgen in de ontwikkeling in de eerste maanden na de operatie. Een ander punt van aandacht dat beschreven wordt is het gebruik van de WOMAC als (secundaire) uitkomstmaat in onze predictie- en trainingsstudie, waarvan wij denken dat de resultaten mede hierdoor bepaald zijn.

De resultaten van deze thesis kunnen gebruikt worden door verschillende groepen, hierbij moet gedacht worden aan (para) medische hulpverleners, patiënten, beleidsmakers en verzekeraars. Daarnaast geeft deze thesis aangrijpingspunten voor nieuwe studies, zoals het onderzoeken van het effect van de hoeveelheid van fysiotherapie, evenals de invloed van het verbeteren van de preoperatieve status op het fysiek functioneren pre- en post operatief.

Het hoofdstuk eindigt met de algemene conclusie dat patiënten in Nederland goed functioneren na een TKP operatie. Ze verbeteren significant gedurende het eerste jaar na een operatie, maar restklachten blijven aanwezig. Een reden hiervoor zou het spierkrachttekort kunnen zijn dat beschreven staat in onze studie, maar ook in de literatuur. Dit kan een aanleiding zijn voor verder onderzoek. 


\section{ABOUT THE AUTHOR}

On May 5th, 1984 Danielle (Dorothea Petra) Berghmans was born in Maastricht, the Netherlands. In 2002, she completed her secondary education at the Atheneum of the Trichter College in Maastricht. The same year she started Health Sciences at Maastricht University. In her second year she specialized in Movement sciences and combined this with the Physical therapy program at Zuyd Hogeschool, Heerlen. In December 2006 she graduated in physical therapy and in March 2007 the obtained her Bachelors degree in Movement Science.

She started working at the department of physical therapy in the Maastricht University Medical Center (MUMC+) in February 2007 as a physical therapist. During the following years she worked with several patient groups. Next to her work she started the Masters Health Science program Epidemiology at Maastricht University in 2008. In 2010 she graduated and obtained her Masters degree.

Her PhD trajectory started in 2011 as part of her job description at the Department of Physical Therapy in the MUMC+ in collaboration with research school CAPRHI at Maastricht University. Her supervision team consisted of Prof. dr. Rob de Bie, Prof.dr. Ton Lenssen and dr. Pieter Emans.

Currently, she continued her work for the department of physical therapy at the MUMC+. She lives with her husband François Peeters and their three children in Maastricht. 


\section{DANKWOORD}

Voor ik startte aan deze uitdaging had ik nooit kunnen denken dat ik nu dit stukje tekst zou schrijven. Tijdens mijn studie had ik niet direct tot doel om een PhD traject in te gaan. Maar toen dit eenmaal op mijn pad kwam, ging ik ervoor en dacht ik "het wel af te kunnen ronden binnen enkele jaren". Uiteindelijk heeft het allemaal wat langer geduurd; een beperkt aantal uren in de week gecombineerd met het krijgen van drie kinderen hielp niet mee in de voortgang van het proces. Toch heeft het de pret niet mogen drukken, en ben ik des te blijer dat ik dit stukje nu kan schrijven. In de acht jaar dat ik bezig ben geweest met dit onderzoek en het behalen van mijn PhD heb ik hulp en ondersteuning gekregen van vele verschillende mensen en op allerlei gebieden, dank! Het reikt te ver om alle mensen te bedanken die een rol gespeeld hebben, maar met het gevaar dat ik iemand vergeet, wil ik hier toch enkele personen specifiek benoemen.

Als eerste dank voor alle patiënten die hebben deelgenomen in één van de studies. Zonder jullie was er geen data geweest om over te schrijven. Ook de opkomst bij de vervolgmetingen en het enthousiasme bij de trainingen, waren een goede stimulans tijdens het gehele traject.

Dan een woord van dank voor de beoordelingscommissie en de overige leden van de corona. Dank voor de tijd en aandacht bij het lezen en beoordelen van dit proefschrift. En voor de tijd die jullie hebben vrijgemaakt voor de voorbereiding en het bijwonen van mijn verdediging.

Dan wil ik graag mijn dank uitspreken voor mijn promotieteam. Rob, al tijdens de opleidingen aan de universiteit wist jij de methodologie van wetenschappelijk onderzoek op een boeiende manier over te brengen op studenten en dat heb ik ook terug gezien tijdens onze gesprekken. Hartelijk dank voor alle begeleiding en je kritische blik de afgelopen jaren. Lodewijk, ook jij hoort hier in het rijtje thuis. Je was betrokken in de eerste jaren van mijn promotie en als hoofd van de afdeling orthopedie natuurlijk indirect betrokken tijdens het gehele traject. Hartelijk dank voor je bijdrage! Pieter, jij was pas later betrokken bij mijn promotietraject, maar een zeer waardevolle toevoeging. Als orthopedisch chirurg wist je het team te versterken met kennis omtrent de operatie of het proces na de operatie. Dit zorgde voor een betere fundering van mijn artikelen. Ook jouw blik, als niet fysiotherapeut, zorgde voor een verbetering van de opzet van de stukken. Ook jou wil ik hartelijk bedanken voor je bijdrage de afgelopen tijd. Als laatste en belangrijkste factor in mijn team: Ton. Jij was het die ervoor zorgde dat ik werd aangenomen als fysiotherapeut jaren geleden en diegene die het promotieballetje aan rollen heeft gebracht. Zelf een expert op TKP gebied, stond jij als denkvader aan de start van dit onderzoek. Daardoor was je ook nauw betrokken bij het onderzoek. Als ik er niet was dan nam je de metingen over, maar je was ook een goede gesprekspartner en expert om te raadplegen. 
Waarschijnlijk heb je je de afgelopen jaren wel eens achter je oren gekrabd en je afgevraagd of en wanneer ik mijn proefschrift af zou ronden, maar dit heeft je enthousiasme nooit kunnen temperen. Typerend hiervoor was je reactie toen ik (voor de derde keer tijdens mijn promotie) vertelde dat ik zwanger was. Je "Gossigefeliciteerd" zal ik niet snel vergeten. Samen maakten we een plan om toch vooral te zorgen om het proefschrift af te ronden voor mijn verlof. Jouw ondersteuning en begeleiding hierin heeft zeker geholpen om dit voor elkaar te krijgen. Alle dank voor je begeleiding, je enthousiasme en alle tijd de afgelopen jaren!

Dan, al mijn collega's van de afdeling fysiotherapie, jullie hebben het mede mogelijk gemaakt dat ik hier uiteindelijk sta. Begonnen in een tijd dat academiseren nog geen algemeen goed van de afdeling was, was het zeker met een toenemende werkdruk regelmatig lastig voor mij om onderzoekstijd te 'claimen'. Frustatie hieromtrent lieten jullie niet merken, zonder jullie inzet en steun was dit boekje er niet geweest, dank! Daarnaast een speciaal woord van dank voor de dames en heer van het secretariaat: voor het extra werk dat ik jullie bezorgd heb en jullie luisterend oor.

Mandy, Roy, Aniek, Dennis en Yvonne (Crijns), jullie ondersteunden me in de praktische uitvoering van de onderzoeken. Dat zorgde ervoor dat er in korte tijd meerdere patiënten gemeten konden worden en de tijd zo efficiënt mogelijk benut werd. Ook op de momenten dat ik er niet was, was het goed te weten dat de data goed verzameld werd door jullie. Zonder jullie had ik zeker meer tijd nodig gehad. Thanks voor de hulp en het mede mogelijk maken van mijn leven naast een PhD :).

Daarnaast ook alle stagiaires die geholpen hebben bij de directe uitvoering van de studie. Honderdvijftig patiënten driemaal meten, telkens 45-60 minuten was voor mij alleen een onbegonnen zaak zijn geweest. De inclusie, maar ook het gehele traject zouden vele malen langer geduurd hebben. Nu konden we een mooi carrouselletje vormen en hadden we drie patiënten gemeten binnen een uur! Ook de stagiaires die geholpen hebben bij de trainingen hebben ervoor gezorgd dat ik effectief data heb kunnen verzamelen in een beperkte tijd. Toppie!

Conny, dank voor de hulp, het plannen van alle afspraken van mijn promotieteam en het regelen van alle randzaken. Ik wil niet weten hoeveel tijd me dit heeft gescheeld!

Dan alle dank voor de medewerkers van de (poli)kliniek orthopedie voor het verstrekken van gegevens aan de patienten over de studies en vervolgens het opvangen en verwijzen van de patiënten. Kortom, dank voor de samenwerking!

Jona, Julia en Yvonne jullie horen gewoon in één adem genoemd en bedankt te worden! Dank voor het feit dat wij elkaar zo'n 12 jaar geleden leerden kennen als 
fysiotherapiecollega's in het MUMC+. Heel langzaam groeide we van collega's naar vriendinnen. Kwamen er naast de avondjes kletsen en dansen met wijn, middagjes met thee en kinderen. We misten de vierde tafelpoot toen jij naar China vertrok, Yvonne! Maar, ieder nadeel heeft zijn voordeel, hierdoor maakte je wel de weg voor mijn promotie vrij :). Dames, al die jaren hebben jullie me ondersteund in al ups en downs van de onderzoekswereld. Heerlijk was het om met jullie die er zo dicht-maartoch-niet-helemaal- bij staan, van gedachten te wisselen. Daarnaast weet ik zeker dat zonder jullie mijn werk in het MUMC+ nooit zo leuk zou zijn!

George, jij hebt het mogelijk gemaakt dat ik kon starten met dit traject. In het begin nog niet geheel vol vertrouwen om er zo definitief een naam aan te geven, omdat ik nog geen artikel gepubliceerd had. Maar je zag wel in dat we het traject zo vanaf het begin goed vorm konden geven. De visie op onderzoek binnen de afdeling fysiotherapie is ontzettend veranderd in de jaren dat ik hier werk en daar heb jij een grote rol in gehad. Dankjewel voor de fijne samenwerking, je steun en je vertrouwen in mij!

Rob, als nieuw hoofd van de afdeling kwam je in mijn promotie op een moment dat ik al een heel eind gevorderd was. Jij zette door wat opgestart was: het verdubbelen en bundelen van mijn onderzoeksuren. Toen ik aangaf graag voor mijn verlof mijn proefschrift af te ronden, stond je klaar om meer toezeggingen te doen. Die waren niet nodig, maar dit gaf wel blijk van jouw medewerking. Hartelijk dank voor je ondersteuning.

Rik, de eerste jaren was je nauw betrokken. Als klein groepjes onderzoekers en als enige twee promovendi van de afdeling fysiotherapie zaten we samen met aan de tafel bij Ton op de kamer. Met ook al onze onderzoekspullen en gegevens daar, was het een krappe bedoeling. Hierdoor was het makkelijk om vragen te bespreken en om samen te brainstormen. Uiteindelijk ben je járen eerder dan mij gepromoveerd, maar heb ik de laatste tijd toch nog jouw kennis mogen gebruiken in de laatste fase van mijn promotie. Dankjewel!

Anouk, wat heb ik genoten van onze tijd samen op een kamer. Eerst in het provisorium waar jij nog niet zeker wist of je mocht beginnen aan een PhDtraject en je mij hielp bij het review. Daarna op de Uni. We zaten allebei op een heel verschillend punt in ons traject, maar wel op één lijn qua werken, denken en muzieksmaak. Dank voor je hulp in de afgelopen jaren, zeer zeker bij het review en bij het meten en trainen van de patiënten. Maar ook voor je luisterend oor en voor de leuke dagen. Ik wens je veel succes toe tijdens de komende jaren van je promotie en help je graag waar mogelijk. 
Lieve medepromovendi, mede door jullie komst werden we echt een clubje onderzoekers. Een clubje waar we elkaar met vragen kunnen bestoken, maar ook alle strubbelingen kunnen ventileren. De 15.00 uur koffiemomentjes waren leerzaam, gezellig en vaak ook lekker. Evenals onze dinertjes. Het motiveerde mij ontzettend om de laatste jaren van mijn promotie met jullie te delen en hoop dan toch nog eens uitgenodigd te worden voor een promovendi-etentje.

Beste familie en vrienden, voor velen van jullie was het in het begin waarschijnlijk nog niet eens duidelijk dat ik naast mijn werk als fysiotherapeut nog iets anders deed. Zeker met eenzelfde werkgever, zelfde werkplek en zelfde werkuren! Daarnaast was het ook niet heel vaak onderwerp van gesprek. Met de start en afronding van meerdere PhD trajecten in de omgeving veranderde dit. Vaak was de vraag: 'Ben je nog bezig? En wanneer denk je klaar te zijn?' Het heeft even geduurd, maar het is zover! Al deze tijd heb ik genoten van alle afleiding die jullie me boden, waardoor ik met nieuwe energie weer aan een volgende stuk, maar met name aan revisies begon!

Pap en mam, nooit hebben jullie me gepusht om iets te doen, wel hebben jullie het mogelijk gemaakt dat ik kon gaan studeren. En de ruimte gegeven om zelf te kiezen wat ik wilde. Promoveren is voor jullie geen dagelijkse kost, en vaak was het dan ook lastig te begrijpen wat ik dan zoal deed. Ik hoop dat deze dag en dit boek jullie een en ander duidelijk maken. Bedankt voor alle mogelijkheden die jullie me gegeven hebben!

François, wat hielp jij me relativeren! Telkens als een artikel weer terugkwam en ik de moed dreigde te verliezen, wist jij met je nuchtere kijk me binnen de kortste keren weer rustig en gemotiveerd te krijgen. Jij stond er onbevangen in, zorgde voor de kaders en leerde me kleine stapjes te nemen. En niet te vergeten: je hebt prachtig werk geleverd! 'Daanke' voor jouw inzet én vertrouwen in mij!

Lieve spookjes, jullie waren er nog niet toen mama begon aan dit traject en hebben ook geen idee waar ik mee bezig ben geweest. Volgens jullie heb ik het beste werk ooit: de hele dag 'op knupkes duie'! Zonder jullie had ik hier waarschijnlijk veel eerder gestaan, maar was het leven niet zo waardevol en mooi geweest. Jullie laten me zien waar het in het leven om draait en zetten me met beide benen op de grond. Hoe vaak vergat ik niet het meegenomen werk als ik de lach op jullie gezichtjes zag... Houd die lach op jullie snoetjes lieverds, bedankt voor wie jullie zijn! 


\section{LIST OF PUBLICATIONS}

Lenssen, A. F., Wijnen, L. C., Vankan, D. G., Eck, B. H. V., Berghmans, D. P., \& Roox, G. M. (2010). Six-minute walking test done in a hallway or on a treadmill: how close do the two methods agree? European Journal of Cardiovascular Prevention \& Rehabilitation, 17(6), 713-717.

Berghmans, D. D., Lenssen, A. F., Bastiaenen, C. H., Ilhan, M., Lencer, N. H., \& Roox, G. M. (2013). Reliability, agreement, and responsiveness of a 6-minute walk/run test in patients with heart disease. European Journal of Preventive Cardiology, 20(1), 135-141.

Berghmans, D. D., Lenssen, A. F., Van Rhijn, L. W., \& De Bie, R. A. (2015). The Patient-Specific Functional Scale: Its reliability and responsiveness in patients undergoing a total knee arthroplasty. Journal of Orthopaedic \& Sports Physical Therapy, 45(7), 550-556.

Berghmans, D. D., Lenssen, A. F., Emans, P. J., \& de Bie, R. A. (2018). Functions, disabilities and perceived health in the first year after total knee arthroplasty; a prospective cohort study. BMC Musculoskeletal Disorders, 19(1), 250.

Berghmans, D. D., Lenssen, A. F., Emans, P. J., \& de Bie, R. A. (2018). A Progressive Strength Training Program Starting 3 Months Post Total Knee Arthroplasty Surgery Improves Strength but Not Functional Outcome. Journal of Orthopedic research and Therapy, 10, 2575-8241.

Berghmans, D. D., Lenssen, A. F., Emans, P. J., van Rhijn, L. W., \& de Bie, R. A. (2018). Limited predictive value of pre-surgical level of functioning for functioning at 3 and 12 months after TKA. Knee Surgery, Sports Traumatology, Arthroscopy, 1-7. 
NOTES 